\title{
The functional response of the Antarctic bivalve Laternula elliptica to ocean warming and acidification
}

Sonja Marama Everett Hempel

\author{
A thesis \\ submitted to Victoria University of Wellington \\ in partial fulfilment of the requirements \\ for the degree of \\ Master of Science in Marine Biology
}

Victoria University of Wellington

Te Whare Wānanga o te Ūpoko o te Ika a Māui 



\section{Acknowledgements}

First and foremost, I would like to thank Ken Ryan and Vonda Cummings for their support and guidance throughout every stage of this thesis. You have both been amazing supervisors, and I have hugely valued your wisdom and advice. Ken, you have been there whenever I needed you, which has meant so much to me. Vonda, thank you for your expertise and the opportunity to undertake research in this fascinating area. Thank you both for the gift of Antarctica. Those weeks on the ice were truly unforgettable.

Huge thanks go to Chazz and the NIWA dive team for collecting my animals. Graeme and especially Neill have been integral, at both Mahanga Bay and Greta Point, for constructing and maintaining the facilities I was lucky enough to be able to use for my experiment. Thank you both for your support, and for many excellent games of table tennis to get the circulation back in our hands as the cicadas sang outside.

Many thanks to Sarah Hailes (NIWA Hamilton) who dry-ashed my L. elliptica samples, and to Kim Currie (NIWA/University of Otago Research Centre for Oceanography) who analysed my water samples and calculated the raw seawater chemistry data. Many thanks also go to Dr Darren Day for the use of his laboratory for the HSP70 analyses, and to Bridget, Jen, Varun and Darren (VUW) for their advice in conducting these analyses. Tracey also has my gratitude for her advice on the respiration setup. All of you have helped so much, and I've learned a lot. Thank you.

Christine, you have obviously been a huge part of my postgraduate study. Thanks for making all that time in the OA room surprisingly enjoyable. To James, Mark, and the lab group: You guys are the best. Also, shout out to the good folk of KK702 for some epic yarns.

And, of course, thank you to my family, especially Mum and Dad, and my friends, particularly Cobi and Rosie, for your unending patience, understanding, and humour as I crafted The Bivalve Monologues. I couldn't have done this without you. 


\section{Abstract}

"It is a curious situation that the sea, from which life first arose, should now be threatened by the activities of one form of that life. But the sea, though changed in a sinister way, will continue to exist; the threat is rather to life itself."

- Rachel Carson

Marine life is currently under threat from large-scale, long-term changes to the marine environment. Anthropogenic emissions of greenhouse gases, particularly carbon dioxide $\left(\mathrm{CO}_{2}\right)$, are causing ongoing change to global marine systems, particularly through ocean warming and acidification. Greenhouse gases in the atmosphere are trapping radiation and heating the entire Earth surface, including the ocean. At the same time, oceanic uptake of $\mathrm{CO}_{2}$ through absorption by surface waters is altering ocean chemistry, increasing acidity, reducing availability of carbonate ions $\left(\mathrm{CO}_{3}{ }^{2-}\right)$, and causing increasing dissolution of calcium carbonate $\left(\mathrm{CaCO}_{3}\right)$ structures.

Because atmospheric $\mathrm{CO}_{2}$ diffuses more readily into cold water, the Southern Ocean (SO) will experience ocean acidification in a matter of decades. Warming in the SO is also occurring rapidly and represents a comparatively greater increase in temperature than elsewhere. SO marine fauna have evolved in constant, stable, cold conditions, and as a result are stenothermal and particularly at risk from ocean warming and acidification. The large infaunal bivalve Laternula elliptica is a prevalent keystone species found throughout the Antarctic benthos in high numbers, and contributes significantly to biodeposition and bentho-pelagic coupling.

This thesis examines how L. elliptica adults are affected over medium-term (5-mo) timescales by SO warming and acidification. Adult L. elliptica collected from Cape Evans in McMurdo Sound, Antarctica, were subjected to combinations of temperatures and pHs predicted for the SO by 2050 and 2100 (Temperatures: $-1.4^{\circ} \mathrm{C}$ (control); $-0.5^{\circ} \mathrm{C} ;+0.5^{\circ} \mathrm{C}$. pHs: $\mathrm{pH} 8.00$ (control); $\mathrm{pH} 7.85$; $\mathrm{pH}$ 7.65). L. elliptica were assessed at $5 \mathrm{wk}$ and 5 mo to determine their cellular, metabolic, and whole- 
organism responses to temperature increase and/or $\mathrm{pH}$ decrease. Survival parameters such as final survival percentage, survival curves, and time to $50 \%$ survival $\left(\mathrm{LD}_{50}\right)$ were compared among treatments. L. elliptica survival was severely reduced by warming of only $1-2^{\circ} \mathrm{C}$ above summer ambient temperatures. Physical and physiological condition indices were calculated to assess health, and show changes in shell and body tissue mass. Physical condition stayed similar amongst all treatments at both time points, while physiological condition decreased significantly at 5 mo with elevated temperature. Oxygen $\left(\mathrm{O}_{2}\right)$ consumption was measured as a proxy for standard metabolic rate to show whether animals had acclimatised to conditions. $\mathrm{O}_{2}$ consumption was significantly negatively correlated with physiological condition, and increased, becoming more variable, with both elevated temperature and lowered $\mathrm{pH}$. This indicated that L. elliptica experienced increased metabolic demand in response to these conditions, and there was a general lack of acclimation to these conditions over time. Overall, $\mathrm{pH}$ had no significant effect on survival, metabolic rate, or condition. Heat shock protein 70 (HSP70) gene expression levels were measured to provide a preliminary indication of how the heat shock response of L. elliptica responds to both elevated temperature and reduced $\mathrm{pH}$. Lowered $\mathrm{pH}$ appeared to stimulate an up-regulation of HSP70 gene expression at both time points, although this was smaller at 5 mo. L. elliptica did not seem to display a heat shock response at environmentally realistic levels of warming.

Overall, warming resulted in lowered survival and condition loss with no sign of acclimation after 5 mo. These responses occurred at smaller degrees of warming than are typically considered lethal for L. elliptica, indicating that successful longer-term maintenance is more thermally limited than short-term survival in this species. While physical (shell) condition was maintained in undersaturated conditions under both elevated temperature and reduced $\mathrm{pH}$, this maintenance occurred alongside increased $\mathrm{O}_{2}$ demand. Maintaining the aragonitic shell in combination with increased metabolic activity may have contributed to the decline in physiological (body mass) condition observed in L. elliptica. In combination, the results of this experiment indicate that warming of the SO may be more important than ocean acidification to the survival and functioning of adult L. elliptica. 


\section{Table of Contents}

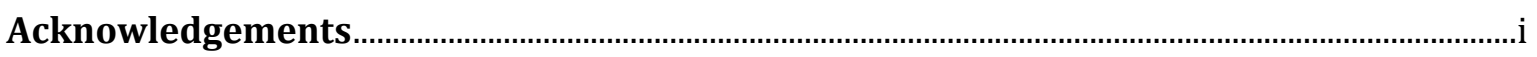

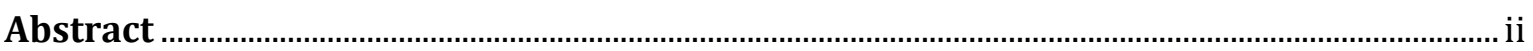

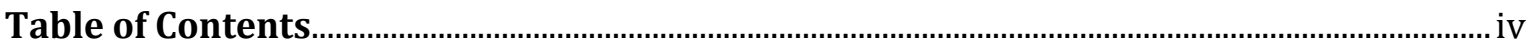

Table of Figures ......................................................................................................................vii

Table of Tables........................................................................................................................... ix

List of Abbreviations.................................................................................................................

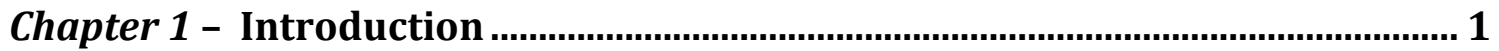

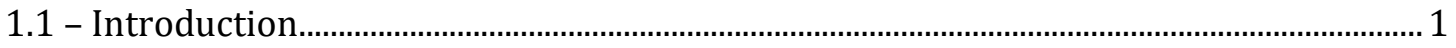

1.1.1 - Ocean warming and acidification ................................................................................. 1

1.1.2 - Southern Ocean warming and acidification.................................................................. 5

1.1.2.1 - Susceptibility of Southern Ocean fauna …………………………………….......... 7

1.1.3 - Measuring an organism's response to ocean warming and acidification................ 8

1.1.3.1 - Survival, condition, and metabolism ...................................................................... 9

1.1.3.2 - HSP70 and the heat shock response .................................................................... 10

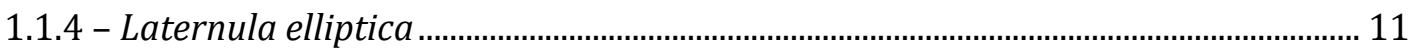

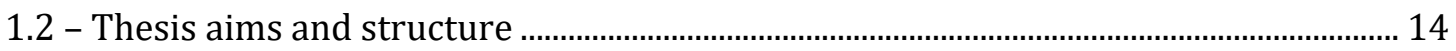

Chapter 2 - The response of Laternula elliptica to ocean warming and

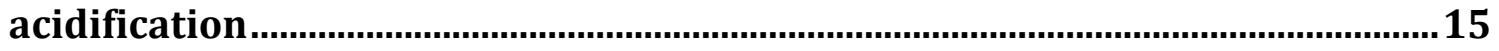

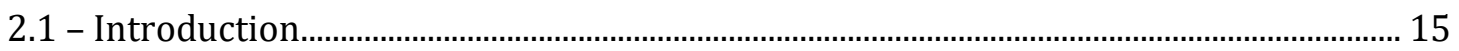

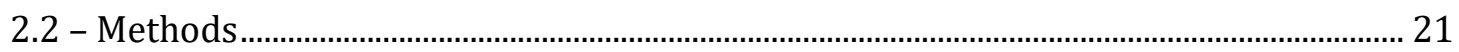

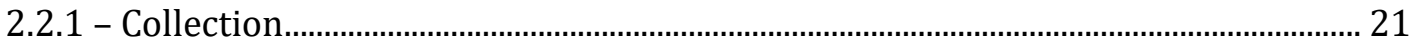

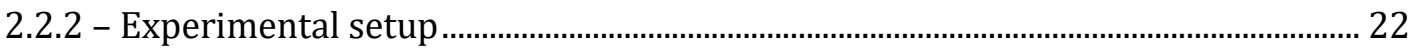

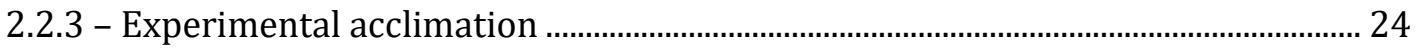

2.2.4 - Quality control and characteristics of experimental seawater .............................. 25

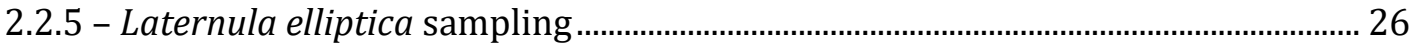

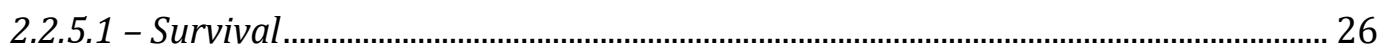

2.2.5.2 - Physical and physiological condition.................................................................. 27

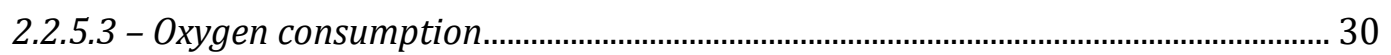

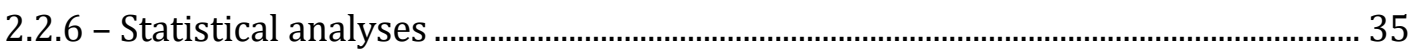

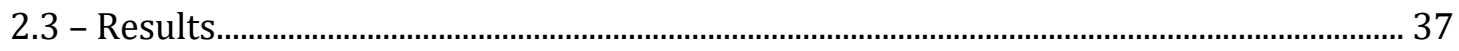

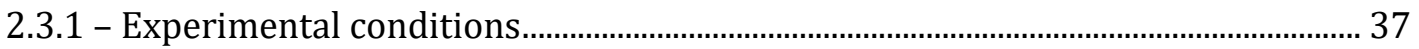


2.3.2.1 - Time to $50 \%$ survival $\left(L D_{50}\right)$.......................................................................... 42

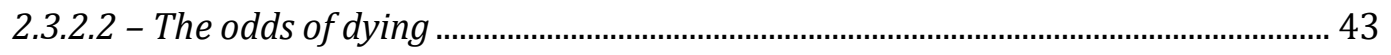

2.3.2.3 - Modelling survival .................................................................................................... 43

2.3.3 - Physiological and physical condition .......................................................................... 44

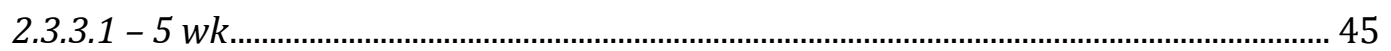

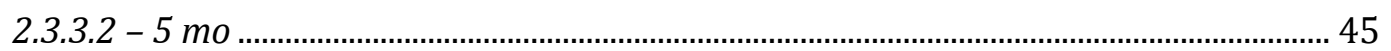

2.3.3.3 - Change between 5 wk and 5 mo .......................................................................... 46

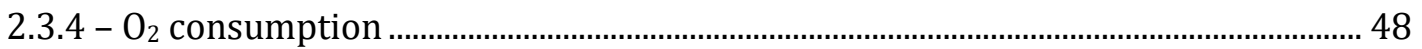

2.3.4.1 - Relationship between $\mathrm{O}_{2}$ consumption and physiological condition ................ 50

2.4 - Discussion …….................................................................................................................. 53

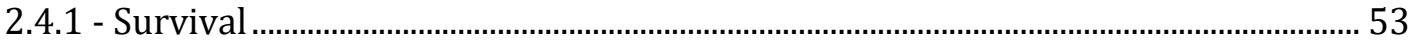

2.4.2 - Physical and physiological condition ......................................................................... 55

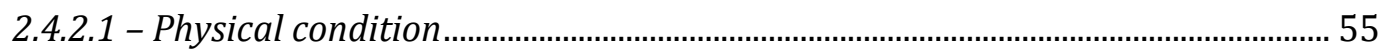

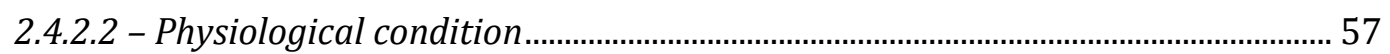

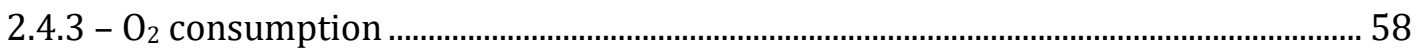

2.4.4 - Implications of sensitivity to warming in Laternula elliptica .................................. 60

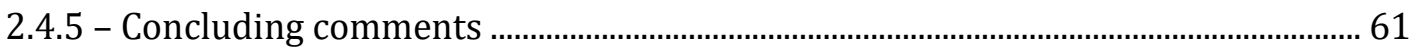

\section{Chapter 3 - HSP70 expression in Laternula elliptica in response to ocean} acidification and warming: Preliminary results ..................................................62

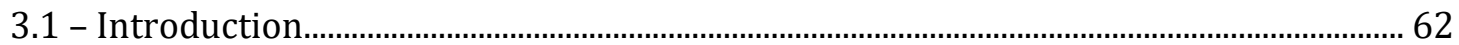

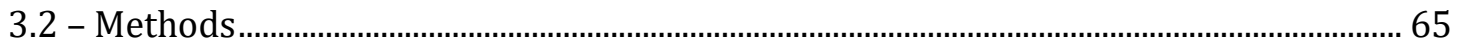

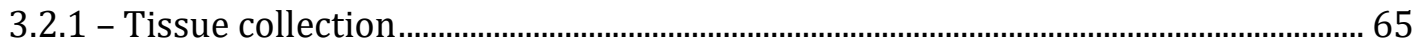

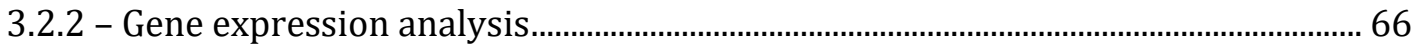

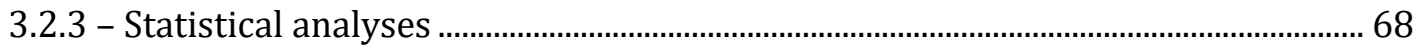

3.3 - Results and Discussion................................................................................................. 69

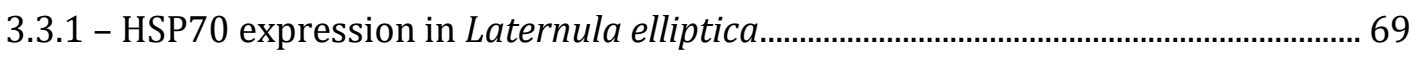

3.3.2 - HSP70 expression, physiological condition, and $\mathrm{O}_{2}$ consumption in

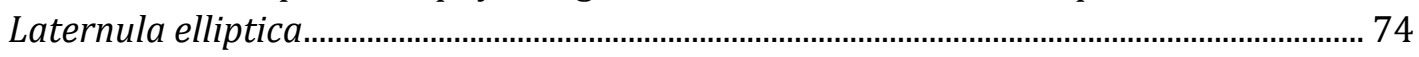

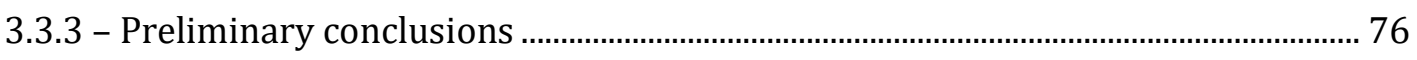

Chapter 4 - General overview and conclusions ................................................ 78

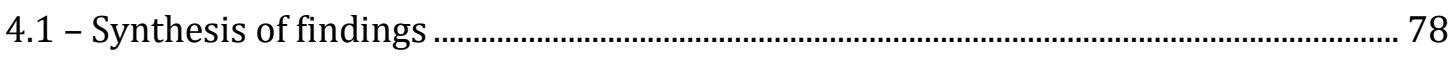

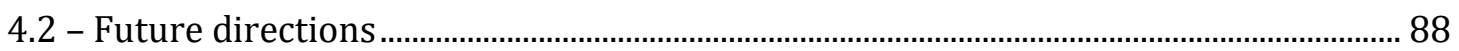

4.3 - Concluding comments ...................................................................................................... 94 


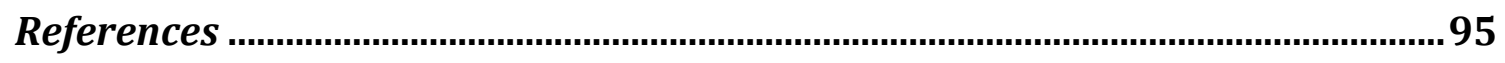

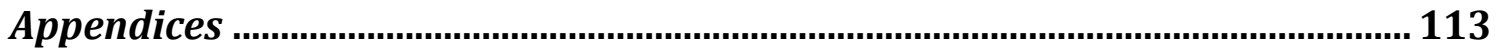

Appendix A - Adductor muscle dissection …………................................................................113

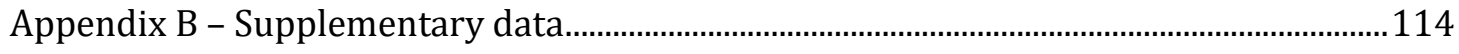




\section{Table of Figures}

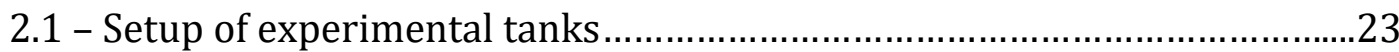

2.2 - Laternula elliptica in experimental tanks........................................................25

2.3 - Laternula elliptica individual, showing where shell length was measured

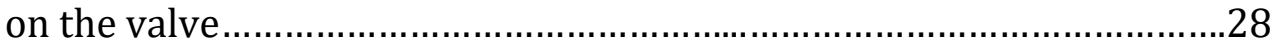

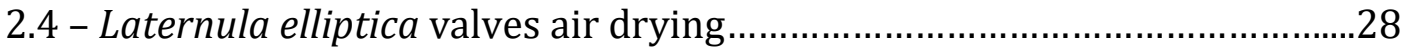

2.5 - Foil cases containing oven-dried Laternula elliptica body tissue..............29

2.6 - Closed 1 L respiration chamber containing Laternula elliptica ..................31

2.7 - Laternula elliptica acclimating to the respiration chamber in a water bath prior to the lid being attached.............................................................32

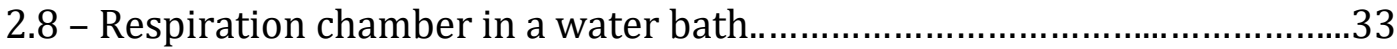

2.9 - Percent survival of Laternula elliptica in each treatment after each month of exposure to experimental conditions..............................................40

2.10 - Percent survival of Laternula elliptica over 5 mo at experimental

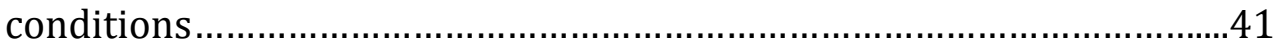

2.11 - Physiological condition of Laternula elliptica after 5 mo exposure to experimental conditions

2.12 - Percentage change of physiological condition of Laternula elliptica

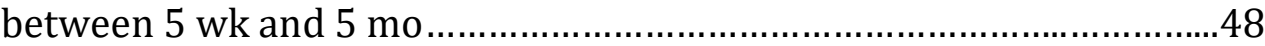

2.13 - Respiration in Laternula elliptica after 20 weeks at experimental conditions

2.14 - Respiration in Laternula elliptica compared to physiological condition at $5 \mathrm{mo}$ 
3.1 - Laternula elliptica mantle tissue dissection in progress ..........................65

3.2 - HSP70 expression in Laternula elliptica ................................................... 70

3.3 - HSP70 expression compared to physiological condition ( $\left.\mathrm{CI}_{\mathrm{FW}: \mathrm{SL}}\right)$ in

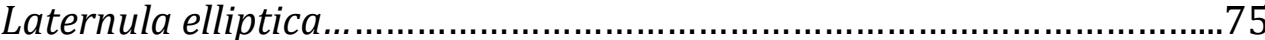

3.5 - HSP70 expression compared to $\mathrm{O}_{2}$ consumption in Laternula elliptica

4.1 - Synthesis of the main responses of Laternula elliptica exposed to elevated temperature and decreased $\mathrm{pH}$ at both $5 \mathrm{wk}$ and 5 mo .80

Appendices

S.1 - Laternula elliptica adductor muscle dissection 


\section{Table of Tables}

Chapter 2

15

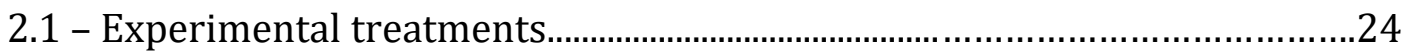

2.2 - Treatments selected for respiration measurements..................................30

2.3 - Seawater chemistry of the experimental treatments over the course of

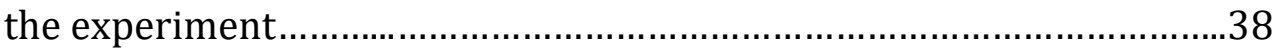

2.4 - Time to 50\% survival (LD50) in days for Laternula elliptica exposed to

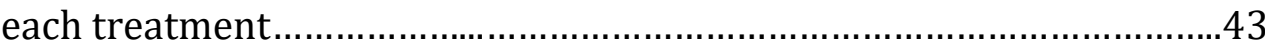

2.5 - Summary of logistic regression models fitted to survival data...................44

Chapter 3

3.1 - Oligonucleotide primers used for qPCR of genes of interest in Laternula elliptica .68

Appendices

S.1 - Annealing temperature results of Laternula elliptica HSP70 and $\beta$-actin qPCR gene amplification. 114

S. 2 - Melt curve profile data of HSP70 and $\beta$-actin qPCR gene amplification products 


\section{List of Abbreviations}

$\mathbf{\Omega}$

AFDW

AIC

ANOVA

$\mathbf{A}_{\boldsymbol{\tau}}$

$\mathrm{CaCO}_{3} \quad$ Calcium carbonate

cDNA Complementary DNA

CI

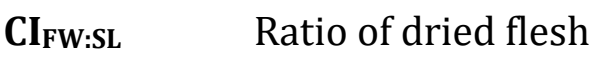
weight to shell length

CI $_{\text {FW:SW } \quad \text { Ratio of dried flesh }}$ weight to dried shell weight

CIsw:SL Ratio of dried shell weight to shell length

$\mathrm{CO}_{2} \quad$ Carbon dioxide

$\mathbf{C O}_{3}{ }^{2-} \quad$ Carbonate ion

$\mathbf{C}_{\mathbf{t}} \quad$ Cycle threshold

d

DIC

FW
Day(s)

Dissolved inorganic

carbon

Dried flesh weight
$\mathbf{H}^{+} \quad$ Hydrogen ion

$\mathrm{HCO}_{3}^{-} \quad$ Bicarbonate ion

$\mathrm{H}_{2} \mathrm{CO}_{3} \quad$ Carbonic acid

$\mathbf{H g C l}_{2}$ Mercuric chloride

HSP Heat shock protein

HSP70 $70 \mathrm{kDa}$ HSP

LD $_{50} \quad$ Time to $50 \%$ survival

mo Month(s)

mRNA Messenger RNA

NIWA National Institute of

Water \& Atmospheric

Research

$\mathbf{O}_{2} \quad$ Oxygen

OA Ocean acidification

$\boldsymbol{p C O}_{2} \quad$ Partial pressure of $\mathrm{CO}_{2}$

qPCR Quantitative polymerase

chain reaction

RT-qPCR Reverse transcription

qPCR

SE Standard error

SL Shell length

SO Southern Ocean

SW Dried shell weight

VUW Victoria University of

Wellington

wk Week(s) 


\section{Chapter 1 \\ Introduction}

\section{1 - Introduction}

\subsection{1 - Ocean warming and acidification}

Anthropogenic greenhouse gases have been accumulating in the atmosphere since the Industrial Revolution. This is predominantly from anthropogenic carbon dioxide $\left(\mathrm{CO}_{2}\right)$ emissions from fossil fuel use and deforestation, though cement production also plays a role (Doney et al., 2009; IPCC, 2013; Parker et al., 2013). Increasing greenhouse gas concentrations in the atmosphere are contributing to global temperature increase and sea level rise (IPCC, 2013). Surface warming of both land and oceans has occurred since the Industrial Revolution, and is predicted to continue at a rapid pace unless rates of anthropogenic carbon emissions are reduced (Royal Society, 2005; IPCC, 2013). The oceans have absorbed a large proportion of the increased energy of the climate system in recent years, with $\sim 70 \%$ absorbed in the upper ocean $(0-700 \mathrm{~m})$ and $\sim 30 \%$ stored in the deeper ocean (> 700 m) (IPCC, 2013; Parker et al., 2013). This has manifested in ocean warming of $0.11^{\circ} \mathrm{C}$ per decade over at least the past four decades, and likely longer, particularly in the upper 75 m (IPCC, 2013).

Atmospheric $\left[\mathrm{CO}_{2}\right]$ is not increasing at the same rate as anthropogenic outputs. Between 25 and $40 \%$ of atmospheric $\mathrm{CO}_{2}$ emitted by humans is absorbed by the ocean and removed from the atmosphere (Feely et al., 2004; Royal Society, 2005; Clark et al., 2009). Consequently atmospheric $\left[\mathrm{CO}_{2}\right]$ levels are lower than they would be without oceanic uptake, and radiative forcing is somewhat reduced. Over time, if atmospheric $\left[\mathrm{CO}_{2}\right]$ continues to increase, the oceans will become saturated with $\mathrm{CO}_{2}$, reducing their absorption potential. This will affect future rates of climate change (Royal Society, 2005; Guinotte \& Fabry, 2008; Ingels et al., 2012; IPCC, 2013). The $\mathrm{CO}_{2}$ absorbed into the ocean modifies its chemistry, such as $\mathrm{pH}$ and the availability of ions. This process, known as 'ocean acidification' (OA), was previously not well understood and is regarded 
as the secondary effect of $\mathrm{CO}_{2}$ emissions. In fact, the effects of $\mathrm{OA}$ occur in addition to, and may exacerbate, the other effects of climate change, including ocean warming (Royal Society, 2005). OA and its implications have been the focus of dedicated research efforts over the last decade.

The natural oceanic carbonate buffering system is a multi-stage equilibrium reaction. When atmospheric $\mathrm{CO}_{2}$ diffuses into the ocean across the air/sea interface, it reacts with water to form carbonic acid $\left(\mathrm{H}_{2} \mathrm{CO}_{3}\right)$, which being a weak acid disassociates readily into water. This disassociation uses up free carbonate ions $\left(\mathrm{CO}_{3}{ }^{2-}\right)$, and produces hydrogen ions $\left(\mathrm{H}^{+}\right)$and bicarbonate ions $\left(\mathrm{HCO}_{3}^{-}\right)$(Royal Society, 2005; Doney et al., 2009), as in the following equation (Doney et al., 2009):

$$
\mathrm{CO}_{2 \text { (atmos) }} \leftrightarrows \mathrm{CO}_{2(\mathrm{aq})}+\mathrm{H}_{2} \mathrm{O} \leftrightarrows \mathrm{H}_{2} \mathrm{CO}_{3} \leftrightarrows \mathrm{H}^{+}+\mathrm{HCO}_{3}-\leftrightarrows 2 \mathrm{H}^{+}+\mathrm{CO}_{3}{ }^{2-}
$$

It is this increase in $\left[\mathrm{H}^{+}\right]$ions that reduces ocean $\mathrm{pH}$ and gives $\mathrm{OA}$ its name. Over longer timescales, the $\mathrm{pH}$ of the oceans is maintained by this buffering system. However, the rapid addition of $\mathrm{CO}_{2}$ over short timescales from anthropogenic outputs is resulting in a $\left[\mathrm{CO}_{2}\right]$ increase more rapid than ocean buffering can neutralise (Caldeira \& Wickett, 2003; Royal Society, 2005; Guinotte \& Fabry, 2008; Hauck et al., 2013). The rates of $\left[\mathrm{H}^{+}\right]$ increase and $\left[\mathrm{CO}_{3}{ }^{2-}\right]$ decrease are relatively rapid, and this is changing ocean conditions at a correspondingly rapid rate. Oceanic $\mathrm{pH}$ has already decreased by $0.1 \mathrm{pH}$ units in the $250 \mathrm{y}$ since the Industrial Revolution. This corresponds to a $30 \%$ increase in $\left[\mathrm{H}^{+}\right]$, representing a significant alteration in ocean chemistry (Caldeira \& Wickett, 2003). Ocean pH is predicted to drop an additional 0.3-0.4 units by 2100, with an according $50 \%$ decrease in $\left[\mathrm{CO}_{3}{ }^{2-}\right]$ in the surface ocean (Orr et al., 2005; Ries et al., 2009; IPCC, 2013). This equates to a $\sim 100-150 \%$ increase in $\left[\mathrm{H}^{+}\right]$since the Industrial Revolution (Orr et al., 2005).

Ocean $\mathrm{pH}$ has not been more than 0.6 units below current levels in the last $300 \mathrm{M} \mathrm{y}$, and current $\mathrm{CO}_{2}$ levels have not occurred for the past $15 \mathrm{M}$ y (Caldeira \& Wickett, 2003; Wicks \& Roberts, 2012; Hauck et al., 2013). The conditions currently faced by marine organisms are changing at a pace that far outstrips previous climatic shifts. While there have been periods of warming and OA over the Earth's history, current and predicted 


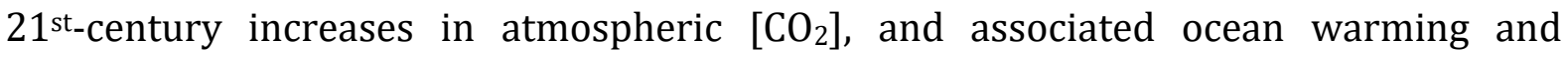
acidification, are occurring at an unprecedented rate, particularly in the Western Antarctic Peninsula region (Meredith \& King, 2005; Convey et al., 2009; Crim et al., 2011).

The combination of ocean warming and acidification presents a threat to the continued structure and function of marine ecosystems, particularly that of calcifying organisms. The construction of calcium carbonate $\left(\mathrm{CaCO}_{3}\right)$ structures is integral to the form and function of a wide range of marine taxa, which play an important role in primary production, food webs, habitat structure, and carbon cycling. Bivalves in particular, with carbonate shells, provide ecologically important sources of food, water purification, and habitat complexity over a wide range of latitudes and habitats (Wicks \& Roberts, 2012; Gazeau et al., 2013). Major calcifiers - calcareous algae, corals, coccolithophores, echinoderms, crustaceans, and molluscs - each display varying degrees of sensitivity to ocean acidification (Kroeker et al., 2013).

Calcification relies on suitable $\left[\mathrm{CO}_{3}{ }^{2-}\right]$ and the maintenance of the $\mathrm{pH}$ of internal spaces. Both of these factors are altered by $\mathrm{OA}$. In the process of forming $\mathrm{CaCO}_{3}$ from aqueous $\mathrm{HCO}_{3}{ }^{-}$, calcification releases one molecule of $\mathrm{CO}_{2}$ for every molecule of $\mathrm{CaCO}_{3}$ created (Royal Society, 2005). Consequently, calcification increases oceanic $\left[\mathrm{CO}_{2}\right]$, exacerbating $\mathrm{OA}$, and this $\mathrm{CO}_{2}$ could be released into the atmosphere if mixing brings it to the air/sea interface (Royal Society, 2005). This rate may increase as ocean $\left[\mathrm{CO}_{2}\right]$ increases over time (Royal Society, 2005). If calcifiers experience decreased survival or calcification as a result of ocean chemistry changes, the global carbon cycle will also be impacted, as dissolution and calcification of biological structures contribute to the carbon balance of the oceans (Royal Society, 2005; Wicks \& Roberts, 2012).

Calcification in bivalves is a process under tight biological control whereby the ionic balance and $\mathrm{pH}$ of an internal chamber is maintained by passive and active transport of ions across cell membranes (Roleda et al., 2012). Biomineralisation can only occur under specific conditions, and maintaining these becomes increasingly metabolically stressful and energetically costly as $\left[\mathrm{CO}_{3}{ }^{2-}\right]$ availability declines, or when internal pH drops (hypercapnia) (Fabry et al., 2008; Doney et al., 2009; Kroeker et al., 2010; Wicks 
\& Roberts, 2012). Alternatively, respired $\mathrm{CO}_{2}$ may be used by bivalves in biomineralisation after its conversion to $\mathrm{HCO}_{3}$ - by carbonic anhydrase (Roleda et al., 2012). Thus, it is the increased dissolution of shells in undersaturated conditions, not the external availability of $\mathrm{CO}_{3}{ }^{2-}$, that is the primary concern for bivalves under $\mathrm{OA}$ (Roleda et al., 2012). Resistance to hypercapnia is dependent to a large degree on the acid-base regulatory capacity of the organism, often dictated by its mode of life (e.g., active vs. passive) (Wicks \& Roberts, 2012). Bivalves in particular are affected by hypercapnia across a range of life stages (Barnes \& Peck, 2008; Gazeau et al., 2013; Matoo et al., 2013; Parker et al., 2013). They have a poor capacity to regulate their ionic and acid-base status, and are less able to compensate for changes in extracellular $\mathrm{pH}$ and ion balance than more active or higher-level organisms (Pörtner et al., 2004; Pörtner, 2008; Jakubowska \& Normant, 2015).

Calcium carbonate structures can take several forms depending on the polymorphs of $\mathrm{CaCO}_{3}$ used in their construction. In order of increasing solubility these are: low magnesium calcite, aragonite, and magnesium-rich (high-magnesium) calcite (Barnes \& Peck, 2008; Gazeau et al., 2013; Hauck et al., 2013). Bivalve shells can be solely aragonitic or calcitic, or may have layers of aragonite and calcite (Royal Society, 2005; Barnes \& Peck, 2008; Gazeau et al., 2013; Hauck et al., 2013). Calcification occurs more easily above the calcium carbonate saturation horizon, the depth where the carbonate saturation state $(\Omega)>1$, and once formed, $\mathrm{CaCO}_{3}$ does not dissolve above this horizon. Different saturation horizons exist, with different depths for aragonite and calcite. As aragonite is more soluble, its saturation horizon depth $\left(\Omega_{\mathrm{Ar}}\right)$ is consistently shallower than that of calcite $\left(\Omega_{\mathrm{Ca}}\right.$ ) (Royal Society, 2005; Wicks \& Roberts, 2012).

The aragonite saturation state is a useful proxy for the ease of biomineralisation in aragonitic calcifiers (Miller et al., 2009). Once aragonite is undersaturated $\left(\Omega_{\mathrm{Ar}}<1\right.$ ), its scarcity means it is more energetically costly to remove it from seawater, transport across cellular membranes, and utilise (Barnes \& Peck, 2008; Wicks \& Roberts, 2012). Alternatively, it is the enhanced dissolution of shells that is the most costly to compensate (Roleda et al., 2012). Aragonite undersaturation does not automatically lead to an inability to calcify, but rather increases the cellular costs of doing so, and the associated stress for the organism (Miller et al., 2009; Gazeau et al., 2013). 
Subsequently, the energetic costs of calcification and the depth restrictions this places on calcifying taxa in the future depends on the form of $\mathrm{CaCO}_{3}$ they secrete. Decreased $\mathrm{pH}$ may lead to reduced calcification rates in a range of species (Clark et al., 2009). Shifts in species composition could occur, with a loss of species unable to calcify under reduced $\mathrm{pH}$ conditions and an increase in dominance of species able to calcify, or which do not calcify at all (Clark et al., 2009). Generally, weaker skeletons, decreased growth rates, and increased metabolic demand are expected (Clark et al., 2009).

When exposed to reduced $\mathrm{pH}$, many species exhibit physiological trade-offs in responses, reducing calcification and reproductive output (Kroeker et al., 2010, 2013; Wicks \& Roberts, 2012). Subtle effects of depressed reproduction have potentially serious long-term consequences (Wicks \& Roberts, 2012; Guy et al., 2014), though if adults can acclimate to conditions then their larvae may have some adaptive advantage (Parker et al., 2011; Suckling et al., 2015). Ocean warming increases trade-offs in energy use in order to maintain basic metabolic functions such as calcification and basal metabolic rate, and if environmental temperatures rise outside a species' thermal tolerance window, reproductive output, growth, and behaviour can all be negatively affected (Clarke, 1987; Pörtner, 2008; Alcaraz et al., 2014).

\subsection{2 - Southern Ocean warming and acidification}

Warming is of particular concern in the Southern Ocean (SO). The SO comprises all ocean south of $60^{\circ} \mathrm{S}$, beyond the Polar Front (Barnes \& Peck, 2008; Lenton et al., 2009). It covers $360,000 \mathrm{~km}^{2}$ and represents $\sim 8 \%$ of the global oceans, as well as $\sim 11 \%$ of global continental shelf area (Peck, 2005b; Linse et al., 2006). SO water temperatures have been stable and cold for millennia (Barnes \& Conlan, 2007; Barnes \& Peck, 2008) and areas of the SO, particularly the Western Antarctic Peninsula, are experiencing the fastest warming in the Southern Hemisphere, with nearly $+3.0^{\circ} \mathrm{C}$ of atmospheric warming and $\mathrm{a}+1^{\circ} \mathrm{C}$ rise in summer seawater surface temperatures since 1951 (Meredith \& King, 2005; Montes-Hugo et al., 2009; IPCC, 2013). An additional $2^{\circ} \mathrm{C}$ of warming is predicted for the SO by the end of the century (IPCC, 2013). Peck et al. (2004) and Meredith \& King (2005) all suggest that a $1-2^{\circ} \mathrm{C}$ increase in ocean 
temperature in summer would place the majority of benthic Antarctic species at risk of major population loss, considering their known sensitivity to warming through reduced aerobic capacity as temperatures increase.

Elevated temperatures increase metabolic rates (Christensen et al., 2011; Doney et al., 2012; Morley et al., 2012a; Alcaraz et al., 2014), though the different processes contributing to this will respond at different rates (Alcaraz et al., 2014). This is particularly noticeable in invertebrate Antarctic marine ectotherms, as they lack the ability to adjust their internal mechanisms compared to endothermic species (Pörtner et al., 2007). As temperatures increase, metabolic demand increases until aerobic demand outstrips respiration rate, at which point there is a switch to anaerobic respiration (Pörtner \& Farrell, 2008; Pörtner, 2010). This mismatch between available energy and energy demand as temperature increases affects the total energy available to the animal for processes such as growth and reproduction (Doney et al., 2012; Alcaraz et al., 2014), and they may ultimately die.

Shallow marine Antarctic environments are regularly disturbed by iceberg scour and anchor ice, yet are very productive (Pearse et al., 1991). OA and warming pose a comparatively greater threat in the SO, where even small decreases in $\mathrm{pH}$ or increases in temperature represent extreme environmental changes. Rates of temperature increase and $\mathrm{pH}$ decrease predicted for this century are unprecedented for SO fauna on geological timescales, representing a major physiological challenge their evolutionary history has not prepared them for (Royal Society, 2005; Barnes \& Peck, 2008; Convey et al., 2009; Barnes et al., 2009).

The SO takes up a large amount of atmospheric $\mathrm{CO}_{2}$ due to its cold waters absorbing more $\mathrm{CO}_{2}$, and the high wind speeds that maximise $\mathrm{CO}_{2}$ absorption into the surface ocean (Sabine et al., 2004; Orr et al., 2005; IPCC, 2013). The SO exerts considerable influence on the global ocean system, as a large amount of its now carbon-rich water sinks and is transported northward by thermohaline circulation (Griffiths, 2010; Ingels et al., 2012). Therefore the $\mathrm{SO}$ is an area where $\mathrm{CO}_{2}$ introduction into the deep sea, usually a slow process, is relatively rapid (Royal Society, 2005), and results in particularly low carbonate saturation states. The aragonite saturation horizon in SO 
surface waters is already shallower than in temperate or tropical waters, and is predicted to shoal earlier than at lower latitudes (Barnes \& Peck, 2008). Aragonite undersaturation in the surface waters of the SO will be first reached in winter, as greater cooling results in higher aqueous $\left[\mathrm{CO}_{2}\right]$ and there is greater upwelling of carbonrich deep water (Feely et al., 2004; Orr et al., 2005). This could occur as early as 2035 (McNeill \& Matear, 2008; Mattsdotter Björk et al., 2014).

The Ross Sea is part of the East Antarctic sub-region, and is a distinct species richness hotspot (Linse et al., 2006). It is the most productive system in the SO, with high sedimentation rates, and intensely productive plankton blooms each spring and summer (Heilmayer et al., 2003; Thrush et al., 2006; Smith Jr, 2007; Smith Jr et al., 2014). McMurdo Sound, at the margin of the Ross Sea ice shelf, is only free of sea ice for part of the year, and is the most southern open water habitat (Morley et al., 2012b). It has a particularly low, stable seawater temperature range throughout the year, especially in winter (Peck, 2005a; Peck et al., 2014; Kapsenberg et al., 2015). Southward species' range shifts in McMurdo Sound in response to climate change and OA are not possible, as it is the most southerly shelf area; therefore any escape from warming is limited to depth shifts into deeper waters, and if species are unable to cope with or adapt to future ocean conditions, there is a real threat of local extinction (Barnes et al., 2009).

\subsubsection{1 - Susceptibility of Southern Ocean fauna}

The susceptibility of SO marine fauna to ocean warming and acidification, particularly of calcifying invertebrates, is due to the physical and chemical characteristics of the water, and the evolutionary history of these specialised taxa that limits their ability to cope with rapid changes. SO temperatures have been stable, cold, and constant for millennia (Peck et al., 2014). This has resulted in fauna that is highly adapted to cold environments, with slow movement, growth, reproduction and protein synthesis, as well as gigantism, long overall lifespan, long development times for gametes and larvae, and low metabolic rates all common (Pearse et al., 1991; Peck, 2005b; Aronson et al., 2007, 2009; Barnes \& Peck, 2007; Barnes et al., 2009; Convey et al., 2009; Gonzalez- 
Bernat et al., 2013). Several M y of constant cool climate have limited the thermal range of Antarctic marine biota and restricted their upper temperature limit. Functional limits can be even more stenothermal. Some SO species are unable to perform critical behaviours (e.g., predator avoidance behaviours) even at temperatures lower than their lethal upper temperature limits (Peck et al., 2004; Barnes et al., 2009; Clark \& Peck, 2009a,b).

Consequently, many Antarctic marine species are unable to acclimate to elevated temperatures, even over several months (Peck et al., 2014). Metabolic repression is an adaptation to allow SO marine fauna to survive the limited energy and intense seasonality of primary production and light availability in their environment (Brockington, 2001; Peck, 2005b; Thrush et al., 2006; Morley et al., 2007). This metabolic repression may now become a hindrance (Peck, 2005a,b). As a consequence of their low metabolic rates and slow way of life, SO organisms may struggle to regulate internal ion concentrations, necessary to preserve function under OA (Gazeau et al., 2013; Gonzalez-Bernat et al., 2013; Parker et al., 2013).

\subsection{3 - Measuring an organism's response to ocean warming and acidification}

Multiple effects to OA and warming are expected, with stresses at the cellular level, such as increased energy demand or protein production, influencing metabolic processes such as respiration which, in turn, affect the whole-organism response (function and survival) (Clarke, 1991; Llabres et al., 2013; Morley et al., 2009). Ultimately, the survival and performance of an animal are constrained by the efficiency of its cellular processes, such as acid-base regulation, and how well these adjust to changes in $\mathrm{pH}$ and temperature (Pörtner \& Farrell, 2008; Pörtner, 2002; Pörtner et al., 2007; Pörtner, 2010; Pan et al., 2015). 


\subsubsection{1 - Survival, condition, and metabolism}

Death is the definitive measure of whether environmental conditions are tolerable. Extended exposure to sufficiently stressful conditions beyond an organism's tolerance limits can result in death, sometimes with a decline in health beforehand (Peck et al., 2002; Beukema et al., 2009). This occurs in molluscs as a result of both OA and warming. For example, the survival rates of large juvenile paua (Haliotis iris) were negatively affected by reduced pH (7.6) (Cunningham et al., 2015), and the bivalve Macoma balthica experienced increased mortality with warming (Beukema et al., 2009). Consequently, measuring survival is a useful metric for determining how tolerable a stressor is over the long term. However, there are other measures of stress that may become apparent while the animal is still alive.

A decline in the general health of an organism is a clear indication that environmental circumstances are stressful and that it is unable to maintain condition. Health in bivalves is measured by various condition indices (Crosby \& Gale, 1990; Roper et al., 1991). Physical (shell) condition is a measure of relative weight change of the shell, while physiological (flesh) condition shows whether flesh mass has changed relative to shell length or internal shell volume (Crosby \& Gale, 1990; Roper et al., 1991; Cunningham et al., 2015). OA is predicted to increase shell dissolution (Green et al., 2004; Orr et al., 2005; McClintock et al., 2009) and bivalve shells may be thinner and more brittle under reduced pH (Fitzer et al., 2014). This would result in reduced physical condition. Body mass loss has been noted in bivalves as a result of warmerthan-average temperatures (Beukema et al., 2009). Increased energy expenditure under $\mathrm{OA}$ and warming will likely result in an associated decline in physiological condition.

Respiration rate is the final product of a number of processes operating at the molecular, cellular, and whole-organism level. Consequently, it is a good holistic measure of energy demand. Energy demand increases with $\mathrm{OA}$ and warming as marine calcifiers must maintain their acid-base balance to calcify under reduced $\mathrm{pH}$, and elevated temperature results in an elevated aerobic demand (Pörtner, 2010; Jakubowska \& Normant, 2015). Oxygen consumption is a standard measure of basal 
metabolic rate (e.g., Brockington [2001]; Peck et al. [2002]; Heilmayer et al. [2004]; Morley et al. [2007, 2009]; Wood et al. [2008]; Zittier et al. [2015]). Metabolic rate increases as a result of elevated aerobic demand, which increases with temperature increase (Heilmayer et al., 2004; Pörtner, 2010; Doney et al., 2012), as do all physiological processes (Clarke, 1991). In Antarctic bivalves, temperature elevation increases respiration rates; in response to $+2.0^{\circ} \mathrm{C}$ in Yoldia eightsi (Abele et al., 2001) and to $+3^{\circ} \mathrm{C}$ and to $+6-9^{\circ} \mathrm{C}$ in L. elliptica (Peck et al., 2002).

Metabolic rate has increased in response to OA in nearly all mollusc species tested to date (Parker et al., 2013), though see Cunningham et al. (2015) and Jakubowska \& Normant (2015) (both found no change). Alternatively, metabolic rate can be depressed if hypercapnia continues uncompensated, and this can be lethal if continued long-term (Christensen et al., 2011; Gazeau et al., 2013; Parker et al., 2013). Oxygen uptake can also be repressed under both $\mathrm{OA}$ and warming, as in the brittle star Ophionereis schayeri (Christensen et al., 2011). Consequently, measuring respiration rates to determine metabolic demand in response to both $\mathrm{OA}$ and warming in Antarctic bivalves is an interesting and valuable metric.

\subsubsection{2 - HSP70 and the heat shock response}

When exposed to environmental conditions outside their tolerance envelope, the homeostasis of an organism can be disturbed (Clark et al., 2008a,b; Fabbri et al., 2008). If this disruption continues, species can experience a loss in performance, reduced population size, and reduced species ranges (Pörtner, 2008, 2010; Pörtner et al., 2007). Understanding a species' heat shock response helps identify its lower and upper tolerance limits to specific environmental variables. These are the boundaries for a species' range, and indicate how this range may change with environmental stress, such as the changes predicted to occur as a result of ocean warming and acidification (Pörtner et al., 2007; Clark \& Peck, 2009b). Measuring the expression levels of the inducible $70 \mathrm{kDa}$ heat shock protein (HSP70) is a good way to achieve this. 
The induction of HSP70 is a highly-conserved measure of both cellular and physiological stress in an organism that indicates the necessity of the additional energy expenditure of producing this protein (Clark \& Peck, 2009b; Tomanek, 2010). While absent in a number of Antarctic species, heat-stimulated HSP70 up-regulation is found in two Antarctic mollusc species; the infaunal bivalve Laternula elliptica and the gastropod Nacella concinna both show a strong heat shock response at +10 and $+15^{\circ} \mathrm{C}$, respectively (Park et al., 2007; Clark et al., 2008a; Clark \& Peck, 2009b). L. elliptica also induces HSP70 gene expression in response to both raised and lowered pH (Cummings et al., 2011).

\subsection{4 - Laternula elliptica}

Laternula elliptica is a large infaunal bivalve that has a shell considerably longer than most other Antarctic molluscs. It is one of the largest bivalves in the SO ecosystem (the other being the scallop Adamussium colbecki), with a maximum shell length of $120 \mathrm{~mm}$ (Berkman et al., 1991; Ahn, 1993, 1994; Urban \& Mercuri, 1998; Clark et al., 2010). L. elliptica dates from the Cretaceous and produces a thin aragonitic shell of a primitive, simple structure (Berkman et al., 1991; Sato-Okoshi et al., 2010). The relatively thick periostracum helps protect the shell, but the shell itself is thin, forming the minimum protection needed, possibly to reduce production costs in the cold Antarctic environment (Sato-Okoshi et al., 2010). It exhibits slow rates of shell growth and shell repair (Brey \& Mackensen, 1977; Sleight et al., 2015). L. elliptica also displays the low metabolic rate, extended lifespan (up to $36 \mathrm{y}$ ), extended gametogenesis, and long larval development time typical of Antarctic species (Ahn \& Shim, 1998; Urban \& Mercuri, 1998; Peck et al., 2004; Peck, 2005a; Morley et al., 2007; Kang et al., 2009).

L. elliptica is a common species with a circumpolar distribution, and is found in high densities ( $\sim 70-100$ ind $\left.\mathrm{m}^{-2}\right)$ in soft sediments, representing high biomass ( $\sim 4800 \mathrm{~g}$ wet weight $\mathrm{m}^{-2}$ ) (Ahn, 1993, 1994; Ahn et al., 2001). L. elliptica buries itself upright in sediment and uses its extendable siphon to reach the benthic/demersal interface to breathe and feed. Therefore its internal structures will be exposed to any change in water conditions, because despite its body being buried, it still takes in water from the 
pelagic environment above it. The response of L. elliptica to future SO warming and acidification is of concern because it is a key species in the SO benthos, playing a dominant role in biodeposition and bentho-pelagic coupling (Ahn, 1993; Clark et al., 2010). L. elliptica already relies on metabolic repression to survive resource-limited winters with little to no food (Ahn et al., 2001, 2003; Brockington, 2001; Morley et al., 2007), so any increased metabolic demand resulting from rising temperatures and declining $\mathrm{pH}$ (as discussed above) may negatively impact this species.

As a highly stenothermal species, L. elliptica is strongly negatively affected by temperature increase. The lethal limit for this species is $+7.5-12.5^{\circ} \mathrm{C}$ (Peck et al., 2004; Peck, 2005a,b; Morley et al., 2009). Not only does L. elliptica die if taken $\sim 10^{\circ} \mathrm{C}$ above its normal temperature range, but it is unable to rebury itself at $2-5^{\circ} \mathrm{C}$ (Peck et al., 2004; Morley et al., 2012a,b). Burial is an important behaviour that allows it to avoid iceberg scour (Ahn, 1994; Peck et al., 2004; Morley et al., 2012a,b). Only 50\% of L. elliptica can bury at $+2-3^{\circ} \mathrm{C}$, and there is $100 \%$ failure to bury at $+5^{\circ} \mathrm{C}$ (Peck et al., 2004). L. elliptica is also unable to acclimate to increased temperatures of $+3.0^{\circ} \mathrm{C}$ over 3 mo timescales (Morley et al., 2012a). Therefore even small temperature changes, such as the $+2^{\circ} \mathrm{C}$ warming predicted for the Ross Sea by 2100 (IPCC, 2013), would leave the species unable to perform vital behaviours and may greatly increase the risk of mortality.

L. elliptica also appears vulnerable to reductions in $\mathrm{pH}$. The only current study on the effect of $\mathrm{pH}$ change on adult L. elliptica revealed that basal metabolism (measured via oxygen consumption rate) at 4 mo and HSP70 gene expression levels at $3 \mathrm{wk}$ increased with both elevated ( $\mathrm{pH} 8.32)$ and reduced $(\mathrm{pH}$ 7.78) $\mathrm{pH}$ relative to ambient conditions (pH 7.99) (Cummings et al., 2011). In addition, chitin synthase, an enzyme involved in biomineralisation in bivalves, was up-regulated after 4 mo at $\mathrm{pH} 7.78\left(\Omega_{\mathrm{Ar}}=0.71\right)$ (Cummings et al., 2011). These responses are expected to be energetically expensive to maintain over the long term, especially in water undersaturated with aragonite (Cummings et al., 2011), and this has the potential to reduce reproductive potential and subsequent population size in this species (Guy et al., 2014).

Most knowledge of species' reactions to expected environmental changes is currently based on short-term, single-stressor experiments (e.g., studies by Barnes \& Conlan 
[2007] and Barnes \& Peck [2008]) (Kroeker et al., 2013). Multi-stressor responses are important in OA research (e.g., Parker et al. [2013]; Byrne et al. [2014]; Kapsenberg \& Hoffman [2014]; Suckling et al. [2015]; Zittier et al. [2015]). L. elliptica is a common and regionally dominant bivalve in the SO benthos whose response to future predicted ocean conditions is of concern given its susceptibility. The response of common species with high biomass is of interest as any changes in behaviour, survival, or biomass of that species will influence a large number of other species and processes in the system. $L$. elliptica is therefore an ideal study species to examine the effects of future predictions of comparatively rapid ocean $\mathrm{pH}$ and temperature change in the SO.

This thesis will focus on adult L. elliptica and fill several knowledge gaps in ocean acidification and warming research, namely the need for: multi-stressor studies; studies for periods longer than 1-3 mo; and studies on crucial, common species in an ecosystem. By focusing on processes at both the cellular level (HSP70 production) and the wholeorganism level $\left(\mathrm{O}_{2}\right.$ consumption, health, condition, and survival $)$, this thesis elucidates the functional response of L. elliptica to SO warming and acidification, and will examine its ability to acclimate to these conditions over time.

Specifically, the hypotheses of this thesis are that:

1. Both an increase in temperature and a decrease in $\mathrm{pH}$ will induce a negative stress response in L. elliptica across all processes (increased HSP70 gene expression, increased $\mathrm{O}_{2}$ consumption, reduced physical and physiological condition, and reduced survival).

2. This negative response will be exacerbated when warming is combined with acidification.

3. L. elliptica will be unable to acclimate over time, and over the course of the study the magnitude of this negative response will stay constant or increase, but not decrease. 


\section{2 - Thesis aims and structure}

Chapter 2 describes the results of multiple medium-term (5 mo) experiments on adult $L$. elliptica exposed to levels of $\mathrm{pH}$ and temperature predicted for 2050 and 2100. The experiments show how L. elliptica survival, $\mathrm{O}_{2}$ consumption, and overall health (assessed using physical and physiological condition indices) respond to elevated temperature, lowered $\mathrm{pH}$, and combinations of these stressors. The change in functional status of L. elliptica between $5 \mathrm{wk}$ and 5 mo was used to ascertain whether they can acclimate to conditions over time, and if there were indications of individual phenotypic plasticity. This work is presented in manuscript form in preparation for submission, and there may be some repetition of information also provided in Chapters 1 and 4 .

Chapter 3 presents preliminary work on HSP70 expression of L. elliptica using tissue samples collected during the experiments in Chapter 2, and is presented in short note format. The time-consuming nature of these analyses limited the sample size to $n=1$; additional analysis was not possible within the timeframe of this thesis. This preliminary experiment refines RNA extraction and quantitative polymerase chain reaction (qPCR) techniques for L. elliptica, and shows trends of how the heat shock response of $L$. elliptica responds to both elevated temperature and lowered $\mathrm{pH}$.

An overall synthesis and recommendations for future work are discussed in Chapter 4 . 


\section{Chapter 2}

\section{The response of Laternula elliptica to ocean warming and acidification}

\section{1 - Introduction}

In the 250 y since the Industrial Revolution, anthropogenic emissions of greenhouse gases, particularly carbon dioxide $\left(\mathrm{CO}_{2}\right)$, have increased, and are accumulating in the atmosphere at an alarming rate. As a result, global average temperatures have risen by $0.85^{\circ} \mathrm{C}$ in the last 130 years (IPCC, 2013). $\mathrm{CO}_{2}$ dissolves into the ocean at a greater rate under high atmospheric loadings, and this causes changes in ocean chemistry, unbalancing ion concentrations. As a result, carbonate ions $\left(\mathrm{CO}_{3}{ }^{2-}\right)$ decrease and hydrogen ions $\left(\mathrm{H}^{+}\right)$and bicarbonate ions $\left(\mathrm{HCO}_{3}^{-}\right)$increase. The increase in $\left[\mathrm{H}^{+}\right]$ ultimately reduces the $\mathrm{pH}$ (on the total hydrogen scale, hereafter referred to as ' $\mathrm{pH}$ ') of the oceans, a process termed 'ocean acidification' (OA) (Orr et al., 2005; Royal Society, 2005; IPCC, 2013).

As $\left[\mathrm{CO}_{3}^{2-}\right]$ decreases, the saturation states of calcite and aragonite $\left(\Omega_{\mathrm{Ca}}\right.$ and $\Omega_{\mathrm{Ar}}$, respectively) decrease and calcification becomes more difficult (Miller et al., 2009; Barnes \& Peck, 2008; Gazeau et al., 2013; Bednaršek et al., 2014). Dissolution due to undersaturation $\left(\Omega_{\mathrm{Ar}}\right.$ or $\left.\Omega_{\mathrm{Ca}}<1\right)$ is also considered to be challenging for calcifiers (Green et al., 2004; Roleda et al., 2012). This is especially problematic for calcifiers that use aragonite, a highly soluble form of calcium carbonate $\left(\mathrm{CaCO}_{3}\right)$ (Parker et al., 2013; Bednaršek et al., 2014). Decreases in pH also affect marine organisms by reducing the pH of internal fluids (hypercapnia), disrupting their acid-base balance (Pörtner et al., 1998; Wicks \& Roberts, 2012; Parker et al., 2013). pH has already decreased by 0.1 units since the Industrial Revolution, representing a 30\% increase in $\left[\mathrm{H}^{+}\right]$, and is predicted to drop by a further 0.3-0.4 units by 2100 (Clark et al., 2009; IPCC, 2013). This rate of change is unprecedented, occurring faster than at any time in the last $25 \mathrm{M} \mathrm{y}$. 
Oceanic temperature and pH changes are felt most strongly at high latitudes, such as the Southern Ocean (SO). The oceans are a significant oceanic carbon sink, responsible for an estimated $30 \%$ of annual global oceanic uptake of $\mathrm{CO}_{2}$, and the $\mathrm{SO}$ absorbs $\mathrm{CO}_{2}$ at an elevated rate, due to cold surface waters and high wind speeds maximising the absorption at the air/sea interface (Sabine et al., 2004; Orr et al., 2005; IPCC, 2013). This high $\mathrm{CO}_{2}$ concentration in cold $\mathrm{SO}$ waters combined with the upwelling of cold, carbonrich deepwater is hastening OA (Orr et al., 2005; Clark et al., 2009; Lenton et al., 2009). Undersaturation of aragonite at high latitudes will occur first in winter (Feely et al., 2004; Orr et al., 2005) perhaps as early as 2035 (McNeill \& Matear, 2008; Mattsdotter Björk et al., 2014). Consequently, calcifying organisms at high latitudes are likely to be affected by $\mathrm{OA}$ and climate change before more temperate or tropical species (Clark et al., 2009; Gonzalez-Bernat et al., 2013).

Temperature is the main factor affecting species ranges and functional envelopes in marine invertebrates, particularly in Antarctica, where seawater temperatures are very cold and stable (Alcaraz et al., 2014; Peck et al., 2014). McMurdo Sound water temperatures vary by only $1.5^{\circ} \mathrm{C}$ per annum (Hunt et al., 2003), and have done so for 15 25 M y (Peck et al., 2014), with more thermally variable Antarctic sites typically experiencing a temperature range of just $3-4^{\circ} \mathrm{C}$ in a year (Peck et al., 2014). Many Antarctic marine invertebrates exhibit slow rates of metabolism, growth, and reproduction as a result of the cold temperatures and extreme seasonality of resources they experience (Pearse et al., 1991; Peck, 2005a; Thrush et al., 2006; Barnes \& Peck, 2007; Barnes \& Conlan, 2008; Barnes et al., 2009). Consequently, evolving in such stable, constant, cold environmental conditions, Antarctic marine organisms are stenothermal, and may be unable to adapt or acclimate to even small increases in temperature (Peck et al., 2004; Morley et al., 2012a). In the SO, species are therefore ill-adapted to the magnitude and speed of predicted ocean changes (Barnes \& Peck, 2008; Convey et al., 2009; Barnes et al., 2009).

Alongside the scallop Adamussium colbecki, Laternula elliptica is one of the two largest and most abundant species in the Ross Sea coastal benthos. L. elliptica is a long-lived infaunal bivalve with a shell length of up to $120 \mathrm{~mm}$ and a maximum recorded lifespan of 36 y (Urban \& Mercuri, 1998). It buries deep (5-50 cm depending on location) in soft 
sand and gravel sediments, extending its siphons to the benthos/demersal interface to breathe and feed (Ahn, 1993, 1994; Clark et al., 2010). This burying behaviour has the added benefit of allowing L. elliptica to avoid physical disturbance by icebergs and anchor ice, which regularly disturb the productive shallow Antarctic environment, allowing it to exploit food while avoiding injury (Pearse et al., 1991; Ahn, 1994; Ahn et al., 2001; Barnes \& Conlan, 2007; Barnes \& Peck, 2007). L. elliptica feeds on large phytoplankton species that are only available for a short period in the summer (Brockington, 2001). They must survive up to 9 mo without food over winter, experiencing high seasonality of resources (Ahn \& Shim, 1998; Ahn et al., 2001, 2003). Despite this, L. elliptica is a common species throughout the Antarctic continental shelf, with a circumpolar distribution, and often reaches particularly high densities in shallow coastal environments (e.g., $\sim 70$ to $>100$ ind $\mathrm{m}^{-2}$, with an estimated biomass of $\sim 4800 \mathrm{~g}$ wet weight $\mathrm{m}^{-2}$ (Ahn, 1993, 1994; Ahn et al., 2001). As a filter-feeder of high abundance and biomass that links the pelagic and benthic ecosystems, it exerts considerable influence and plays a prominent role in bentho-pelagic coupling (Ahn, 1993; Clark et al., 2010). Its biodeposits may also serve as an important substrate and food source for other bivalves and deposit feeders (Ahn, 1993), thereby increasing local diversity (Gazeau et al., 2013). Endemic to the Antarctic, L. elliptica has a low metabolic rate and a particularly narrow thermal tolerance envelope, and as a result it is unable to perform critical functions at temperatures only a few degrees above ambient (Ahn \& Shim, 1998; Ahn et al., 2001; Peck et al., 2004; Peck, 2005a,b). It produces a thin aragonitic shell that is similar in structure to that of primitive bivalves (Sato-Okoshi et al., 2010; Clark et al., 2010). These characteristics mean that L. elliptica is at risk of metabolic and physiological stress in the near future.

Calcification in bivalves involves the nucleation of $\mathrm{CaCO}_{3}$ crystals in an internal compartment, the extrapallial cavity, using respired $\mathrm{CO}_{2}$ (Roleda et al., 2012; Wicks \& Roberts, 2012). This cavity is located between the mantle and the shell, and is separated from the surrounding seawater and filled with pallial fluid specific to calcification (Wicks \& Roberts, 2012; Gazeau et al., 2013). Ions are then diffused or actively pumped in and out of this cavity to maintain the correct concentration for crystal synthesis. Under decreased $\mathrm{pH}$ conditions the subsequent $\mathrm{CO}_{2}$ increase in both the external seawater and the internal fluid makes maintaining this concentration increasingly 
difficult (Gazeau et al., 2013; Parker et al., 2013). The exact chemical and molecular processes controlling biomineralisation are still poorly understood, but this process is fundamental to calcifiers, tightly controlled, and energetically costly (Wicks \& Roberts, 2012). Under reduced pH, calcification rates can slow, as comparatively more energy is required to maintain the correct ionic and acid-base balance of the extrapallial cavity (Wicks \& Roberts, 2012). This is turn can affect long-term growth and reproduction, with flow-on effects for population size (Pörtner et al., 2004; Pörtner, 2008; Guy et al., 2014). Bivalves in general have little ability for acid-base compensation (Pörtner et al., 2004, 2007). Therefore L. elliptica, as an Antarctic bivalve, would be expected to have little capacity to compensate for hypercapnia associated with OA. L. elliptica grows rapidly over the austral spring/summer period when sources of food (and therefore energy) are readily accessible, but over the resource-limited austral winter, it reduces its energetic expenditure and slows calcification, resulting in a slow average growth rate (Brey \& Mackensen, 1997; Ahn et al., 2001, 2003; Morley et al., 2007). Of concern are the effects of reduced $\mathrm{pH}$ on L. elliptica, as associated increased metabolic costs will potentially be detrimental, both during periods of active feeding necessary to build up reserves (summer), and periods of torpor necessary to survive extensive periods of food shortage (winter) (Ahn et al., 2001, 2003; Brockington, 2001; Peck et al., 2004; Morley et al., 2007).

Increased metabolic demand as a result of increased aerobic demand is a common bivalve response to environmental changes such as temperature increase. If stress levels continue, the organism can depress other functions, such as reproduction and growth, to compensate. Maintaining basal metabolic function is also a priority. High temperatures may necessitate the diversion of energy normally allocated towards such processes in order to fulfil these needs (Clarke, 1987; Alcaraz et al., 2014). The repression of reproductive output to maintain long-term metabolic function has severe implications for the long-term persistence of populations, and in L. elliptica, this tradeoff could significantly decrease population sizes (Guy et al., 2014).

Environmental changes do not occur singularly; understanding the synergistic effects of environmental changes is therefore vital, as organisms must cope with all stresses they experience in order to survive. Combined stressors can act additively, synergistically, or 
antagonistically to augment or repress certain functions, either increasing or decreasing a species' performance and fitness. The magnitude of these changes, and whether they positively or negatively impact a species, is highly dependent on species-specific physiological constraints, and its resilience to the environmental variables it experiences. Ocean warming will not act in isolation upon organisms; instead, acidification will occur alongside temperature increase (Hendriks et al., 2010). Other environmental challenges for Antarctic species may also include increased UV-B radiation, sedimentation, and salinity fluctuations from melting of sea ice and glaciers (Camus et al., 2005; Barnes \& Conlan, 2007; Barnes \& Peck, 2008; Griffiths, 2010; Ingels et al., 2012; Llabres et al., 2013). When considering ecologically relevant responses to $\mathrm{OA}$ and warming, it is therefore important and useful to consider how both stressors act together as well as in isolation (Gazeau et al., 2013; Byrne et al., 2014).

Several laboratory studies have examined the effects of elevated temperature on $L$. elliptica adults, and these have shown lower survival and poorer burial ability in experiments ranging from $24 \mathrm{~h}$ to $63 \mathrm{~d}$ in duration (Peck et al., 2002, 2004; Peck, 2005a; Morley et al., 2012a). Only one study has examined the effect of reduced pH, and noted an increase in oxygen $\left(\mathrm{O}_{2}\right)$ consumption rates and chitin synthase gene expression levels at $4 \mathrm{mo}$, and heat shock protein (HSP70) gene expression levels at $3 \mathrm{wk}$ (Cummings et al., 2011). To date there have been no studies investigating the effects of both stressors in combination. Consequently, there is an urgent need to determine how L. elliptica will be affected over medium to long-term timescales by SO warming and acidification.

Adults were collected from Cape Evans, McMurdo Sound and exposed in the laboratory to a range of temperatures and pHs predicted for the region in both 2050 and 2100 (IPCC, 2013), for a 5 mo period. I hypothesised that L. elliptica would exhibit responses consistent with elevated stress as temperature increased and $\mathrm{pH}$ decreased, and that this would be most apparent with the combination of both stressors (as in Kroeker et al. [2013]). I did not anticipate that they would be able to acclimate over the duration of this experiment $(5 \mathrm{mo})$, based on the results of previous single stressor experiments (Cummings et al., 2011; Morley et al., 2012a). This study fills a valuable knowledge gap 
on an important species, investigating the combined effect of $\mathrm{OA}$ and warming on a common stenothermal Antarctic species. 


\section{2 - Methods}

\subsection{1 - Collection}

Laternula elliptica adults were collected from Cape Evans, McMurdo Sound, Ross Sea, Antarctica $\left(77.635258^{\circ} \mathrm{S}, 166.414382^{\circ} \mathrm{E}\right)$ on 14 and 17 November 2013. They were collected from coarse sand and gravel sediments at $6 \mathrm{~m}$ depth by SCUBA divers. Collected animals (average shell length [SL] $81.3 \mathrm{~mm}$, range 65.5-99.8 $\mathrm{mm}$ ) were transported to Wellington, New Zealand on 29 November 2013. The animals were held for 6 mo (until June 2014) in a flow-through system fed by seawater chilled to Ross Sea ambient temperature $\left(-1.6^{\circ} \mathrm{C}\right.$ ), at $\mathrm{pH}$ ranging from $\sim 8.00$ (ambient Cape Evans level at the time of sampling) to $\sim 8.30$. These $\mathrm{pH}$ values are within the range experienced by these animals in their natural habitat at Cape Evans over the summer months (Kapsenberg et al., 2015). L. elliptica specimens were housed in multiple sediment-free tanks, held with their siphons upwards in mesh baskets to mimic their natural orientation. This allowed them to extend their siphons and feed and respire freely. They were fed several times per wk with a liquid commercial mix of algae tailored to bivalves (Instant Algae Shellfish Diet 1800, Reed Mariculture Inc.).

Individuals were moved to a new specialised aquarium facility on 6 June 2014. They were re-acclimated to ambient Antarctic conditions for $10 \mathrm{wk}$ at $-1.63 \pm 0.0004^{\circ} \mathrm{C}$ and pH $8.02 \pm 0.0002$ units (mean \pm SE). In all cases, L. elliptica specimens were housed in tanks as described above, and fed twice weekly, with $3 \mathrm{~mL}$ of $0.5 \%$ dry weight liquid Shellfish Diet 1800 delivered via pipette into the water above each animal's siphon. Immediately following the move to the new facility, they underwent a mass spawning event, releasing both sperm and eggs into their tanks. This event lasted approximately $3 \mathrm{~d}$. 


\subsection{2 - Experimental setup}

Filtered $(1 \mu \mathrm{m})$ seawater from Evans Bay, Wellington Harbour, was chilled to $-1.6^{\circ} \mathrm{C}$, then fed to separate header tanks constructed from $55 \mathrm{~L}$ insulated bins, with one header tank per treatment. Treatment water was adjusted to a range of temperature and $\mathrm{pH}$ conditions (Table 2.1) in each header tank before being fed to the experimental tanks at a rate of $120 \mathrm{~mL} \mathrm{~min}^{-1}$ in a flow-through system. Nine separate header tanks supplied seventy-two $4 \mathrm{~L}$ tanks (eight replicate tanks per treatment, arranged in a randomised block design). Both temperature and $\mathrm{pH}$ were directly controlled by Jumo dTrans $\mathrm{pH} 02$ industrial controllers, remotely controlled and monitored by a LabView server communicating via a MODBUS serial interface. Water was circulated in each header tank with a pump, and the temperature and $\mathrm{pH}$ of the header tanks was constantly logged using $\mathrm{pH}$ and temperature probes. Analogue controller inputs from each experimental header tank were measured with precision PT100 temperature probes and Sensorex S150C pH probes. Seawater pH was adjusted in each header tank by diffusing foodgrade $\mathrm{CO}_{2}$ gas through thin-walled $(0.5 \mathrm{~mm})$ silicone tubing, and the temperature of the $-1.6^{\circ} \mathrm{C}$ seawater supply stock was adjusted in the header tanks with submerged $500 \mathrm{~W}$ heater elements connected via solid state relays to the $\mathrm{pH}$ controllers. The $\mathrm{pH}$ probes in each header tank were calibrated fortnightly with Tris(hydroxymethyl)aminomethane (TRIS) and 2-animo-2-methyl-1-propanol (AMP) buffers, matched to the salinity of seawater. Salinity was measured every 15 minutes from chilled harbour seawater immediately prior to it entering the system.

The $4 \mathrm{~L}$ replicate tanks containing L. elliptica were insulated with a matrix of interlocking sheets of foam mat; details of the tank setup are provided in Fig. 2.1. 


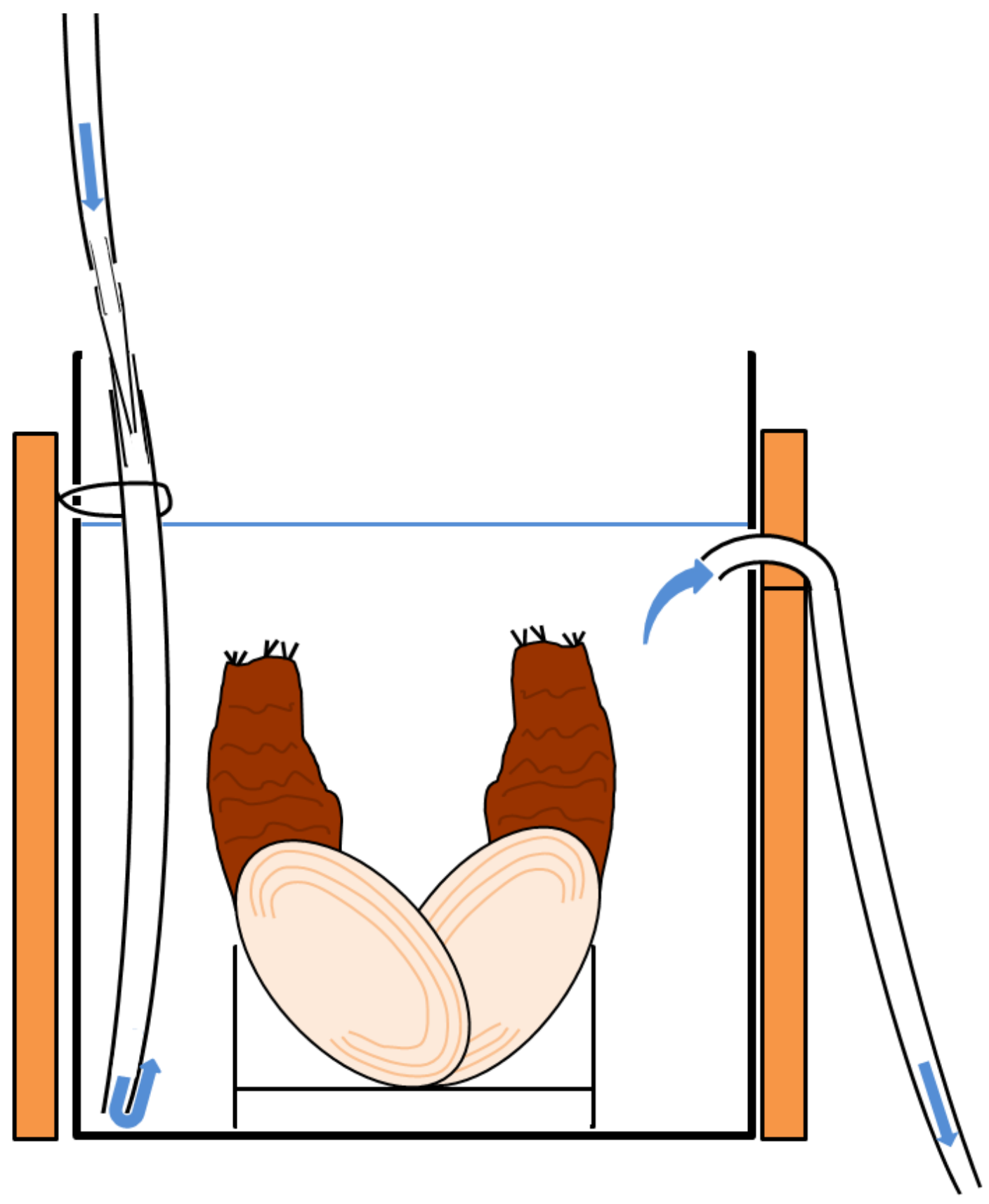

Figure 2.1 - Setup of experimental tanks. Note the mesh basket supporting Laternula elliptica individuals in their natural orientation, insulating foam (orange) around the tank, and details of entry and exit tubing. Flow was controlled to a rate of $120 \mathrm{~mL} \mathrm{~min}^{-1}$. The position of the inflow and outflow tubing in the tank ensured that the water was well-mixed, and that animals received well-oxygenated water.

A $3 \times 3$ matrix of temperatures and pHs was chosen in a fully crossed design (Table 2.1). Temperatures included current conditions for the Ross Sea $\left(-1.4^{\circ} \mathrm{C}\right.$; as cold as the system allowed) and two levels of warming $\left(-0.5\right.$ and $\left.+0.5^{\circ} \mathrm{C}\right)$. The intermediate value of $-0.5^{\circ} \mathrm{C}$ represents less severe warming predictions of $+1^{\circ} \mathrm{C}$ for the Ross Sea, while $+0.5^{\circ} \mathrm{C}$ 
$\left(+2^{\circ} \mathrm{C}\right.$ warming) is predicted for the region by 2100 (IPCC, 2013). pH levels spanned from current spring levels in the field (pH 8.00) to include two levels of decreased pH ( $\mathrm{pH} 7.85$ and 7.65). A pH of 7.65 (a -0.35 unit drop) is predicted for the Ross Sea by 2100 (IPCC, 2013).

Table 2.1 - Experimental treatments. Green = ambient Ross sea value; orange = intermediate value; red $=$ predicted in the Ross Sea for 2100 (IPCC, 2013). As experimental temperatures increase and pHs decline, the amount of stress experienced is expected to increase. This is indicated by the colour gradation from green (low-stress control treatment) to red (predicted high-stress end-of-century treatment).

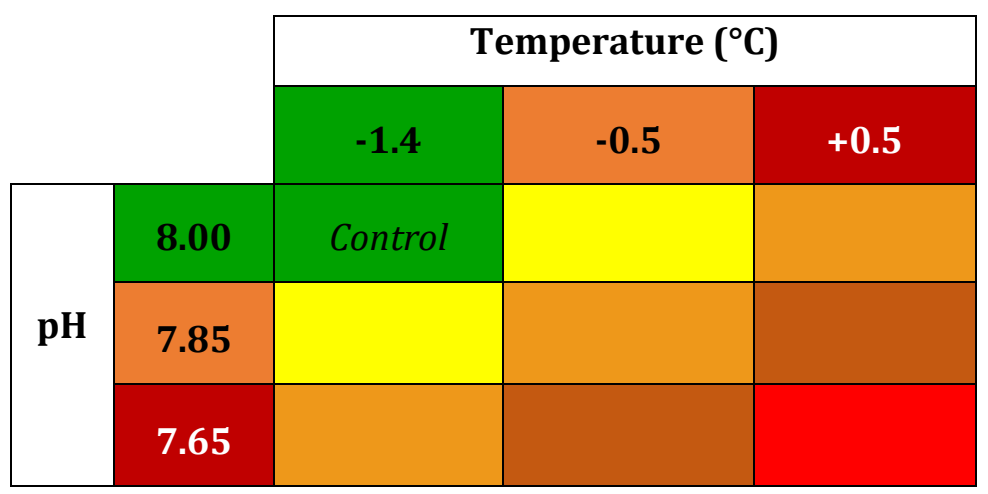

\subsection{3 - Experimental acclimation}

Seawater temperatures and pHs were changed gradually over $18 \mathrm{~d}$ prior to the start of the experiment. Once re-acclimated to ambient conditions, 144 L. elliptica individuals were randomly redistributed amongst multiple $50 \mathrm{~L}$ holding tanks to enable temperature change to the target levels. There were three tanks for each target temperature, with 16 animals per tank. Temperatures were changed as appropriate over $11 \mathrm{~d}$ at a rate of $0.2^{\circ} \mathrm{C} \mathrm{d}^{-1}$. Animals were held at their target temperature $\left(-1.4^{\circ} \mathrm{C}\right.$, ambient; $-0.5^{\circ} \mathrm{C}$; and $+0.5^{\circ} \mathrm{C}$ ) for at least $48 \mathrm{~h}$. Individuals were then randomly distributed amongst the $4 \mathrm{~L}$ replicate tanks, with two per tank held upright in small mesh baskets (Figures 2.1, 2.2). pH was changed over the next $7 \mathrm{~d}$ at a rate of 0.05 units $\mathrm{d}^{-1}$, until target treatment conditions were reached $(\mathrm{pH} 8.00$, ambient; $\mathrm{pH} 7.85$; and $\mathrm{pH}$ 7.65). The experiment began on 11 September 2014, once every animal had experienced final treatment conditions for at least $48 \mathrm{~h}$. The experiment concluded 143 d (5 mo) later, on 2 February 2015. 
Tanks were cleaned monthly. Individuals continued to spawn sporadically throughout the experiment, and tanks were also cleaned after these events.

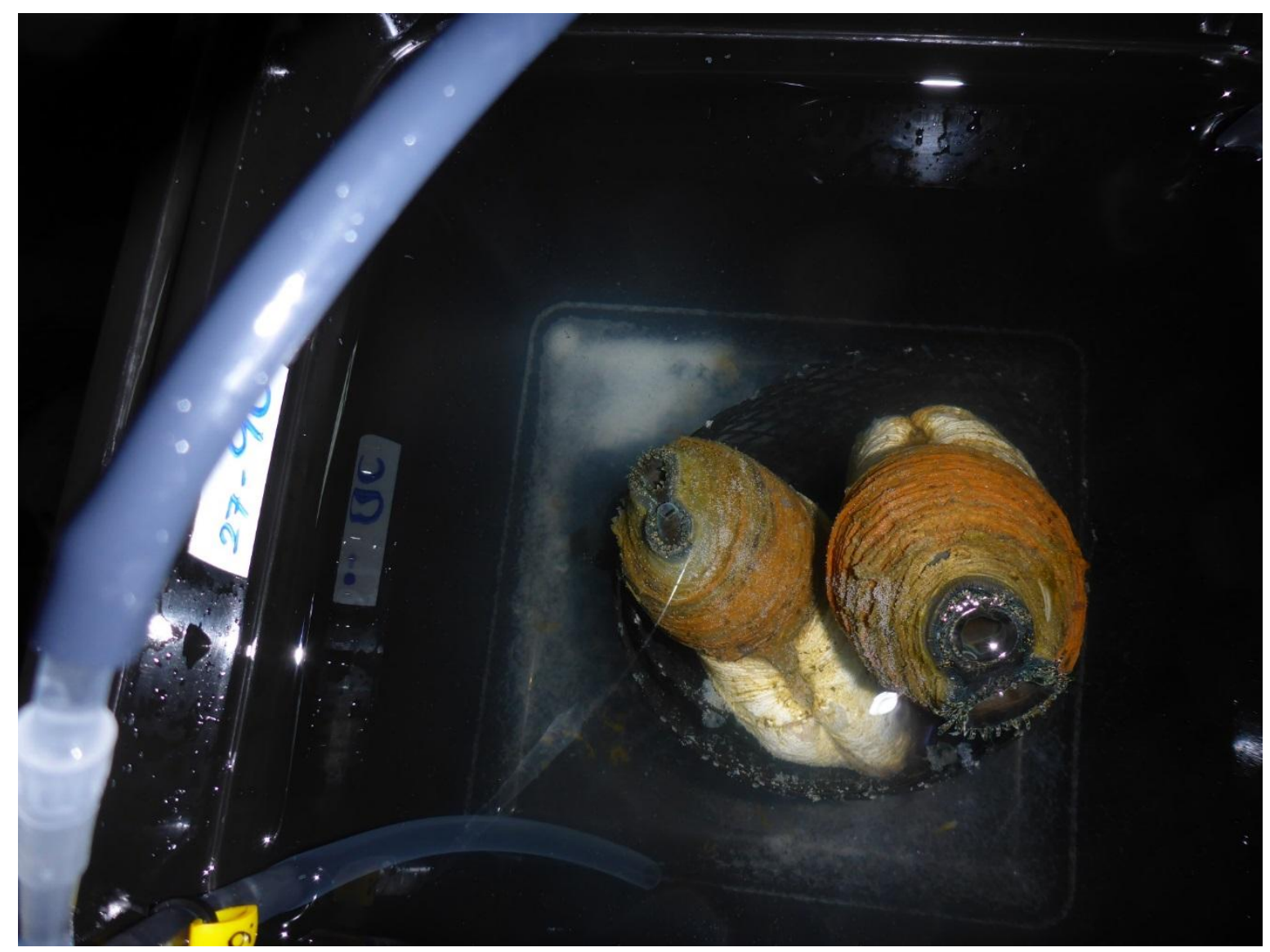

Figure 2.2 - Laternula elliptica in experimental tanks, respiring with siphons open. White material visible on the floor of the tank is a mixture of eggs and sperm from a recent spawning event.

\subsection{4 - Quality control and characteristics of experimental seawater}

For the first seven days of the experiment, temperature was monitored daily in each experimental tank with a handheld probe (RTD Thermometer, Center 376 Data Logger, TP-R04) to verify that temperatures recorded automatically in the header tanks were accurately representing in-tank conditions. Once it was established that temperatures were consistently stable and distinct between the three temperature levels, then 
temperature was checked 1-2 times per week in four randomly identified experimental tanks per treatment, representing half the total number of tanks.

Water samples were taken from each treatment on Day 42, and at the conclusion of the experiment (Day 143). They were fixed with one drop of $1 \mathrm{M}$ mercuric chloride $\left(\mathrm{HgCl}_{2}\right)$ per sample and analysed for dissolved inorganic carbon (DIC) and total alkalinity $\left(\mathrm{A}_{\tau}\right)$, using methods described in Cummings et al. (2011). Aragonite and calcite saturation state $\left(\Omega_{\mathrm{Ar}}\right.$ and $\Omega_{\mathrm{Ca}}$, respectively), partial pressure of $\mathrm{CO}_{2}\left(p \mathrm{CO}_{2}\right)$, and carbonate $\left(\mathrm{CO}_{3}{ }^{2-}\right)$ and bicarbonate $\left(\mathrm{HCO}_{3}^{-}\right)$ion concentrations were calculated for each treatment using measured $A_{\tau}, \mathrm{pH}$, and salinity.

\subsection{5 - Laternula elliptica sampling}

L. elliptica were sacrificed at two time points during the experiment: after $5 \mathrm{wk}$ and 5 mo, to ascertain their response to short- and medium-term exposure to experimental conditions, respectively. At each time point, one individual per replicate tank was used to determine various measures of organism health and function. At both time points, physical and physiological condition were determined (see below), and expression of heat shock protein (HSP70) was assessed (see Chapter 3). Prior to the last time point, individuals from seven specific treatments were used to assess respiration rates (see below). Oxygen $\left(\mathrm{O}_{2}\right)$ consumption was assessed over 9 days (from Day 133 to Day 141); the full suite of treatments and replicates could not be processed in this timeframe due to the large number of individuals and the length of time required for each assessment. Mortalities were recorded as the experiment progressed.

\subsubsection{1 - Survival}

Replicate tanks were examined daily, and any mortalities were recorded. These data were summarised and presented as cumulative percentage survival after each month of the experiment. Survival curves of week-by-week cumulative survival were also constructed for each treatment. In addition, the time to $50 \%$ survival $\left(\mathrm{LD}_{50}\right)$ was 
calculated for each treatment, or projected when survival was $>50 \%$ at the end of the experiment. Results are presented as average values $\left(\mathrm{n}=8\right.$, except for $-1.4^{\circ} \mathrm{C} / \mathrm{pH} 7.85$, $-1.4^{\circ} \mathrm{C} / \mathrm{pH} 7.65,-0.5^{\circ} \mathrm{C} / \mathrm{pH} 8.00$ and $+0.5^{\circ} \mathrm{C} / \mathrm{pH} 7.85$, where $\mathrm{n}=7$, due to mortalities during acclimation).

\subsubsection{2 - Physical and physiological condition}

Immediately prior to dissection, SL ( $\mathrm{mm}$ ) and total wet weight (g) were measured (Fig. 2.3). Post-dissection, valves were air-dried to a constant weight (Fig. 2.4), and left and right valve weights were summed to give a total shell weight (SW, g) for each animal. Tissue was oven-dried at $50-60^{\circ} \mathrm{C}$ for $48 \mathrm{~h}$ to give dried flesh weight (FW, g). Pre-weighed foil packets were used to contain tissue during the drying process (Fig. 2.5). FW did not include dissected mantle and adductor tissue, which had been removed for HSP70 analyses (see Chapter 3). However, the amount of adductor and mantle tissue removed from each individual was very small in each case (average 1.01\% of total tissue wet weight, range 0.41-2.09\%). Dried flesh of all replicates from the 5 mo time point was then ashed at $470^{\circ} \mathrm{C}$ for $24 \mathrm{~h}$ to give ash-free dry weight (AFDW, g); AFDW = FW - ashed weight, which was used to calculate oxygen consumption (see below). 


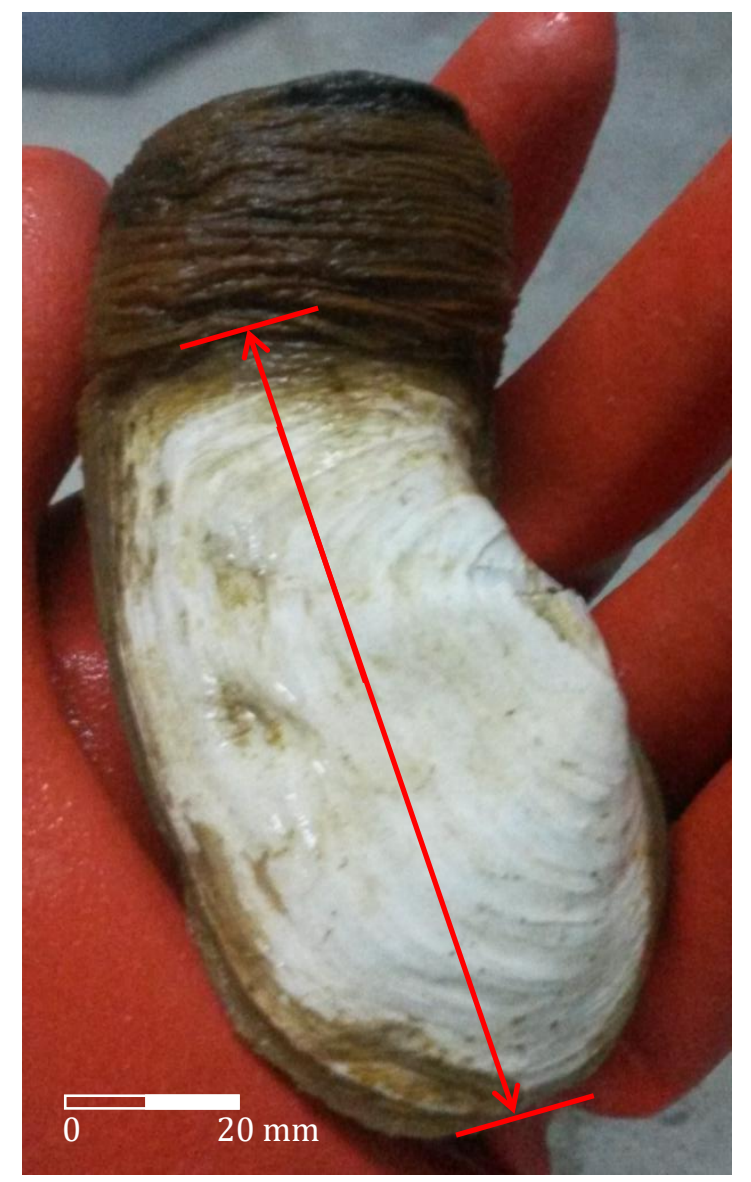

Figure 2.3 - Laternula elliptica individual, showing where shell length was measured on the valve: from the centre point of the anterior edge to the centre point of the posterior edge.

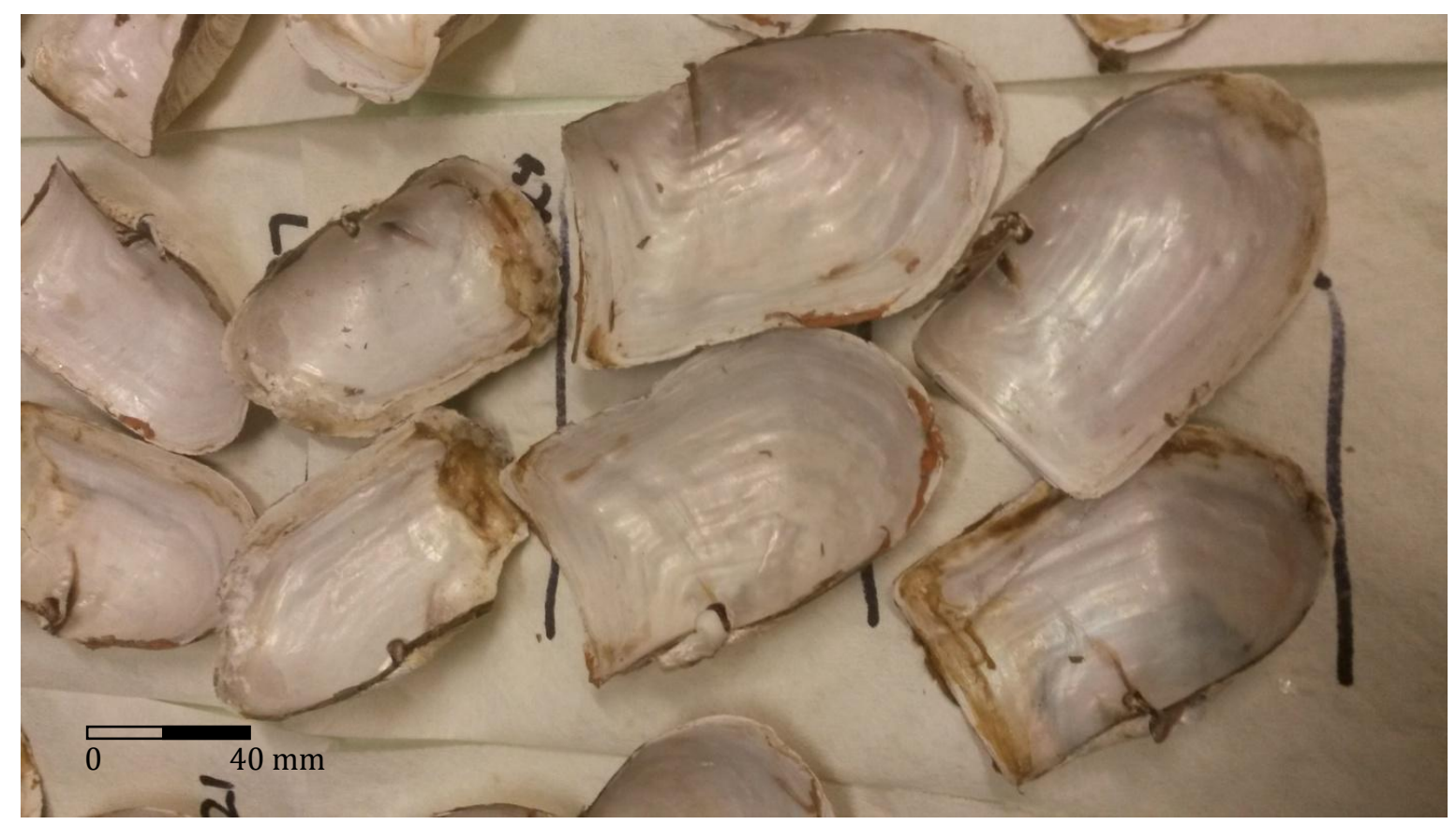

Figure 2.4 - Laternula elliptica valves air drying. Note the slightly iridescent nacreous layer on the inner surface of the valve. 


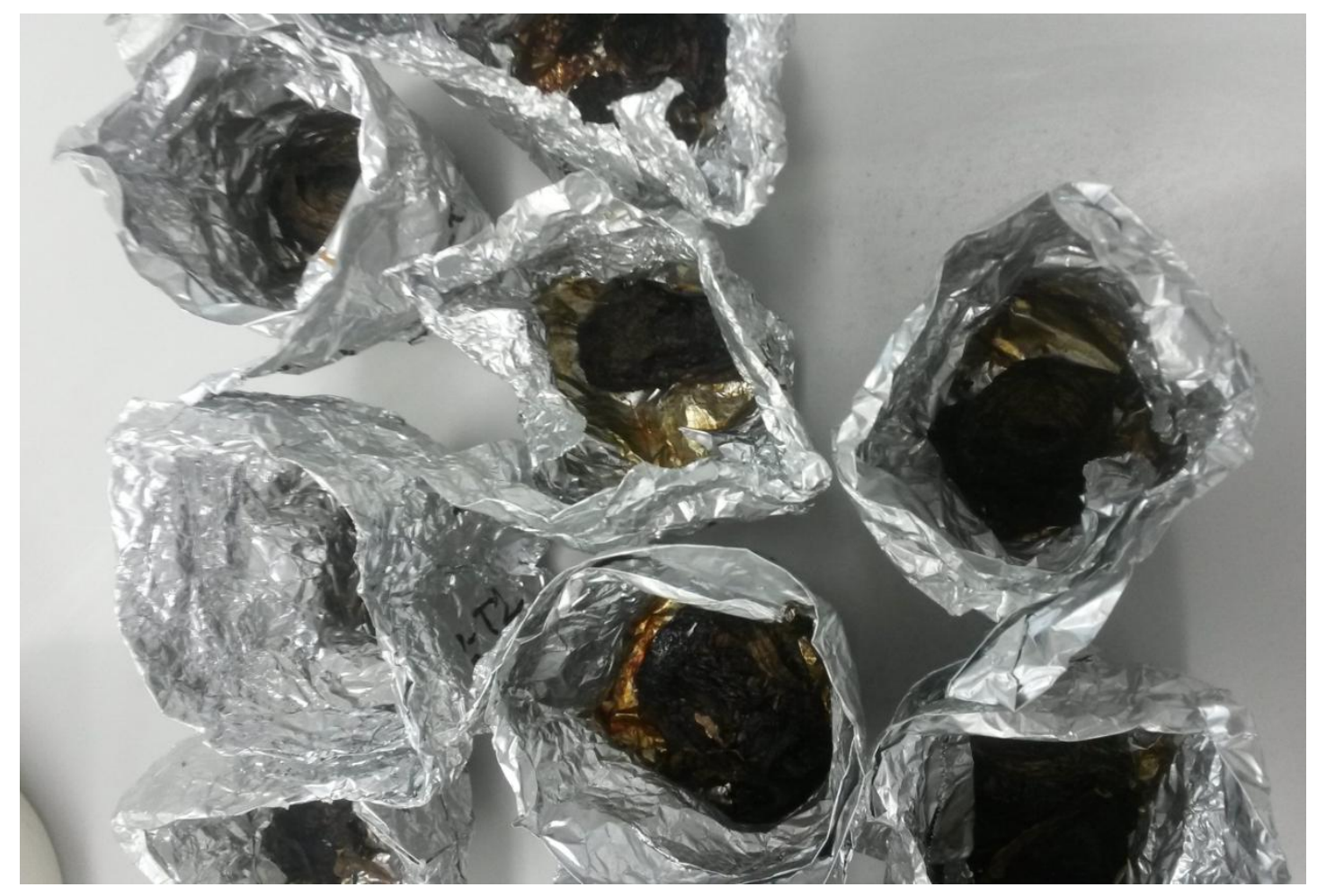

Figure 2.5 - Foil cases containing oven-dried Laternula elliptica body tissue.

Condition indices (CI) were calculated to measure any fluctuation in condition, potentially indicating stress (Roper et al., 1991), over the course of the experiment. Both physical and physiological indices were used. Ratios between FW, SL and SW were calculated to give a measure of shell weight change (physical condition; SW:SL), and tissue weight change (physiological condition; FW:SL and FW:SW). $\mathrm{CI}_{\mathrm{FW}}$ :SL gives the weight change of body tissue relative to $\mathrm{SL}$, and $\mathrm{CI}_{\mathrm{FW}} \mathrm{SW}$ gives tissue weight change relative to $\mathrm{SW}$. $\mathrm{CI}_{\mathrm{FW}: \mathrm{SL},} \mathrm{CI}_{\mathrm{FW}: \mathrm{SW}}$, and $\mathrm{CI}_{\mathrm{SW}}$ :SL were calculated for $5 \mathrm{wk}$ and $5 \mathrm{mo}$, and the percentage change in each condition index over the course of the experiment $(5 \mathrm{wk}-5$ mo) was also calculated relative to condition at $5 \mathrm{wk}$.

Other condition indices used to indicate recent stress in bivalves that focus on the proportion of shell cavity capacity utilised by soft tissue (Crosby \& Gale, 1990; Roper et al., 1991) were not suitable for L. elliptica. The valves of L. elliptica do not shut completely, and siphon tissue extends through an opening in the valves beyond the shell 
boundary. Therefore comparing body tissue volume to internal shell capacity volume was not relevant for this species.

\subsubsection{3 - Oxygen consumption}

Respiration in L. elliptica was measured as oxygen $\left(\mathrm{O}_{2}\right)$ consumption $\mathrm{h}^{-1}$. Fibre optic temperature and $\mathrm{O}_{2}$ sensors (PreSens Precision Sensing GmbH, Regensburg, Germany) were inserted through a rubber bung in the lid of a $1 \mathrm{~L}$ respiration chamber until they extended 5-7 cm into the chamber (Fig. 2.6). The sensors were connected to a Fibox-3 oxygen meter (PreSens Precision Sensing GmbH, Regensburg, Germany) located outside the chambers. The number of animals and treatments selected for respiration measurements are detailed in Table 2.2.

Temperature and $\mathrm{O}_{2}$ sensors were calibrated before use with water saturated with hydrogen sulphite (no dissolved $\mathrm{O}_{2}$ ), and with water that had previously had air bubbled through it for 5 minutes (fully $\mathrm{O}_{2}$ saturated).

Table 2.2 - Treatments selected for respiration measurements, and the number of Laternula elliptica used for that treatment.

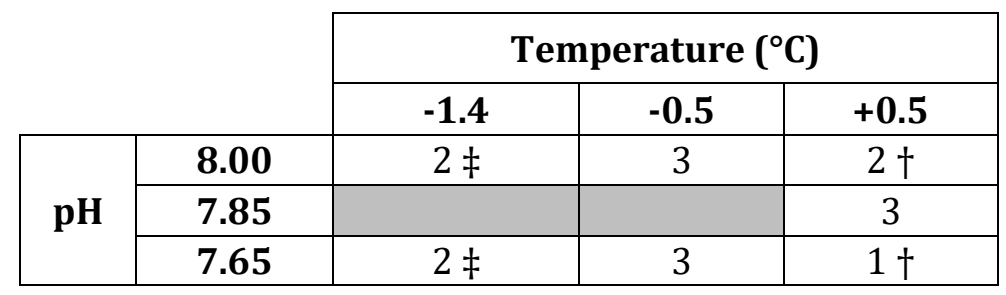

Key: $\dagger=$ Sample size reduced by mortalities; $\ddagger=$ Sample size was initially 3 but an individual was omitted as values were unrealistic. 


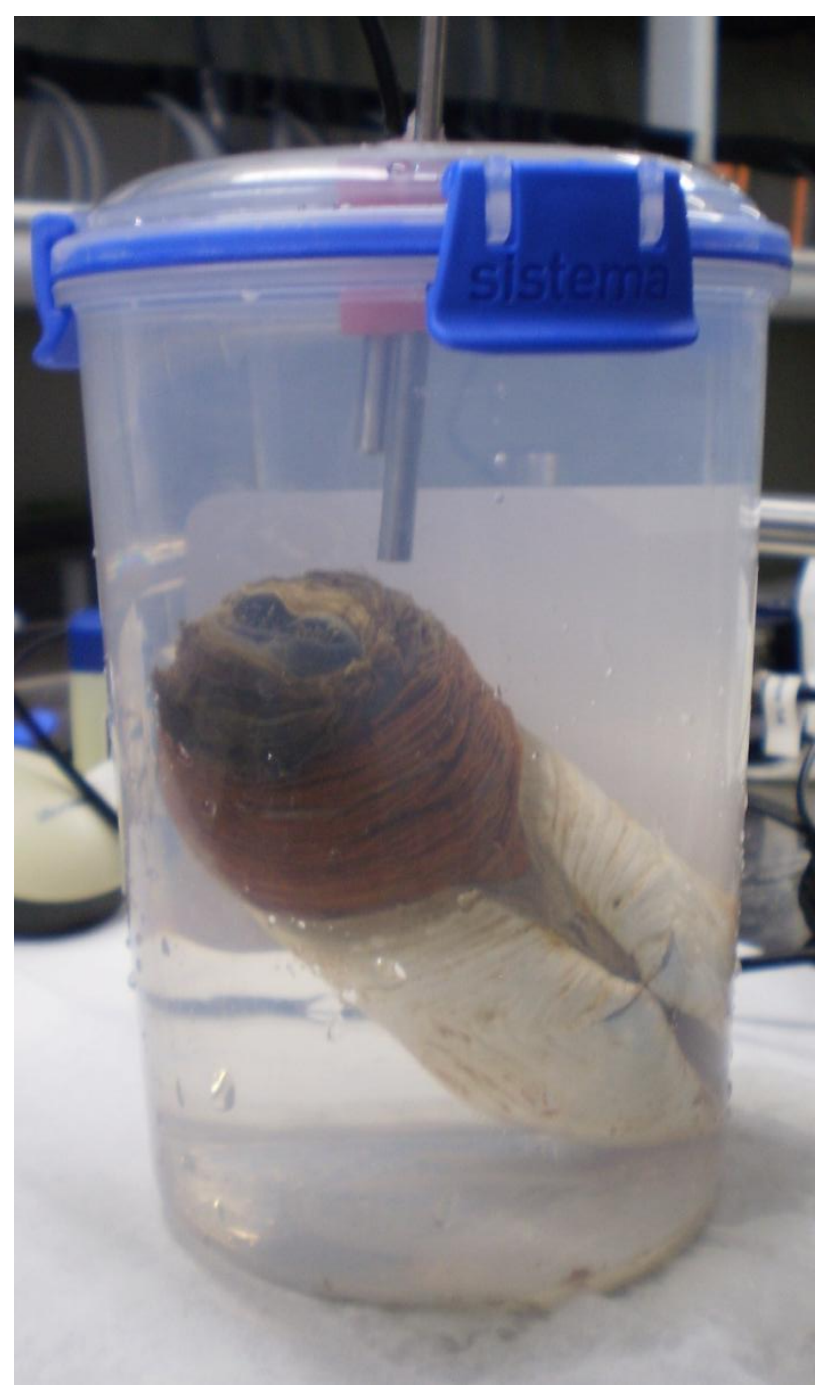

Figure 2.6 - Closed $1 \mathrm{~L}$ respiration chamber containing Laternula elliptica. Temperature and $\mathrm{O}_{2}$ fibre optic probes (grey rods) are visible inserted into the chamber.

Animals were placed in the respiration chamber without a lid or probes to acclimate for 15 min. The chamber was held in a water bath at the appropriate treatment temperature with water flowing through it (Fig 2.7). After this time, individuals had extended their siphons again and had resumed normal pumping behaviour. The lid with its attached probes was then fixed in place, ensuring no air bubbles were trapped inside the chamber, and the chamber was returned to the water bath (Fig. 2.8). The animal and probes were allowed to acclimate for $30 \mathrm{~min}$, and $\mathrm{O}_{2}$ concentration (\% air saturation) and temperature $\left({ }^{\circ} \mathrm{C}\right)$ were recorded every minute for the following 3.5 hours. $\mathrm{O}_{2}$ saturation was not allowed to drop below 50\%. Individuals were disturbed as little as possible to ensure respiration could continue unperturbed. 


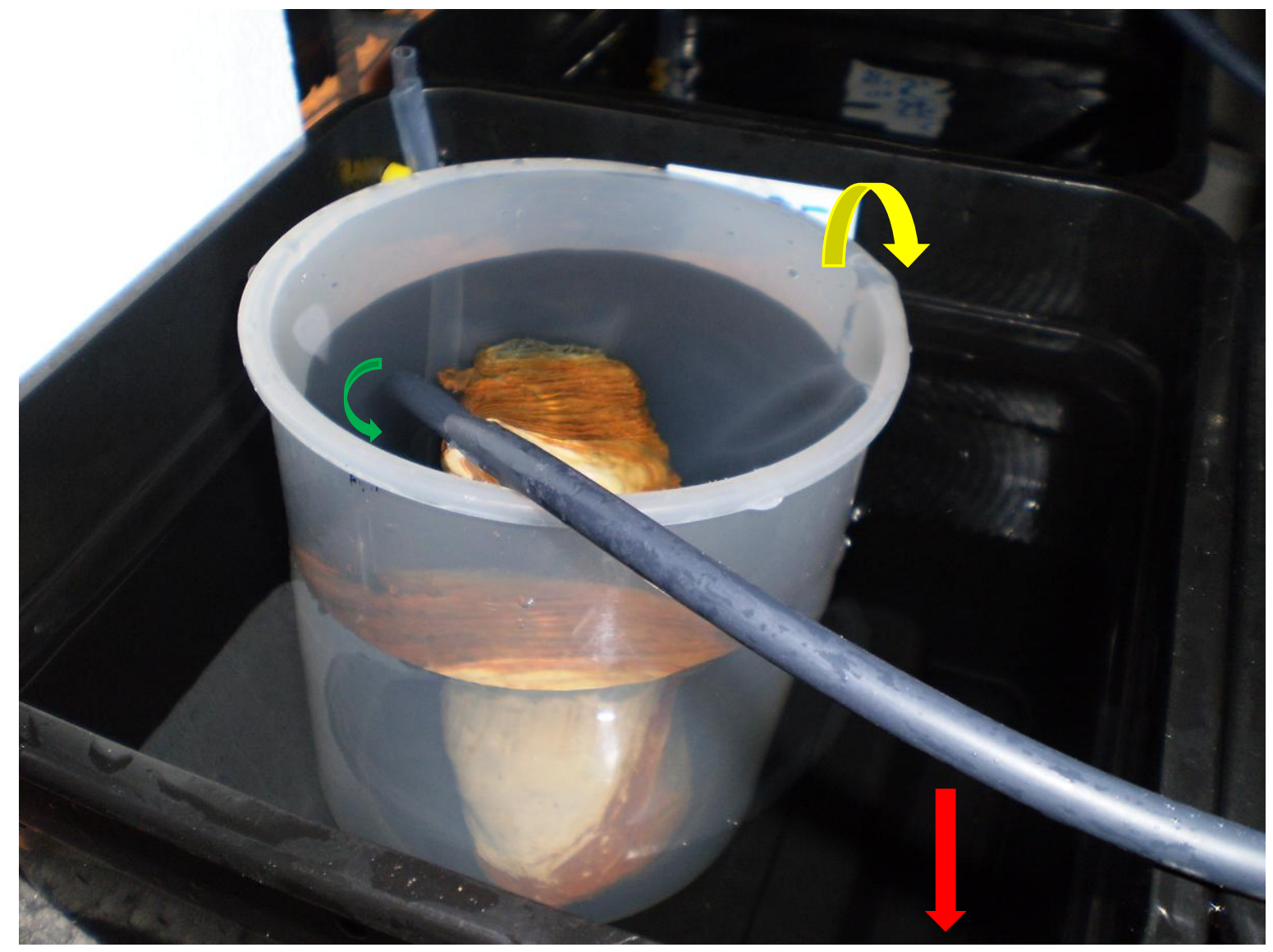

Figure 2.7 - Laternula elliptica acclimating to the respiration chamber in a water bath prior to the lid being attached. Treatment temperature- and $\mathrm{pH}$-specific water entered the chamber (green arrow) via the grey tube at $120 \mathrm{~mL} \mathrm{~min}^{-1}$, spilled over the lip of the chamber (yellow arrow) after circulating through it, replenished the chilled water in the water bath, and flowed out though the exit tubing (not pictured) (red arrow). 


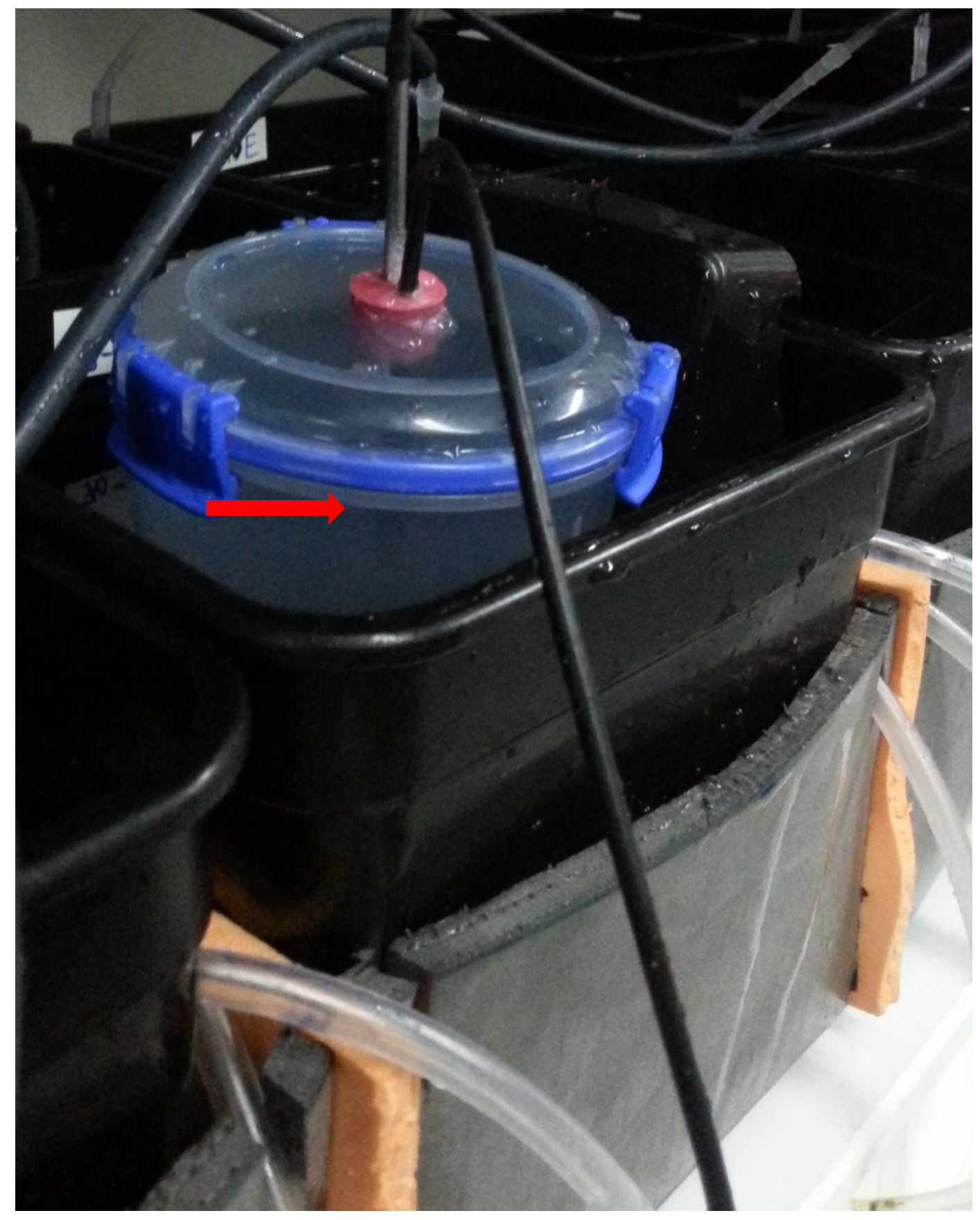

Figure 2.8 - Respiration chamber in a water bath, with measurements underway. Most of the respiration chamber is submerged in the water bath of treatment-specific temperature to keep its temperature stable. The water bath level extends nearly to the lip of the chamber; the water-line in the water bath is indicted by a red arrow.

The raw temperature and air saturation values at the beginning (after $30 \mathrm{~min}$ ) and end (after $4 \mathrm{~h}$ ) of the assessment were converted to $\mathrm{O}_{2}$ concentration $\left(\mu \mathrm{mol} \mathrm{L} \mathrm{L}^{-1}\right.$ ) and 
subtracted to give total $\mathrm{O}_{2}$ consumption. Equations used for this conversion were from Huber \& Krause (2004), adapted to a saline, cold medium. First, the vapour pressure of water at temperature $\mathrm{T}\left(\mathrm{p}_{\mathrm{w}}(\mathrm{T})\right)$, where $\mathrm{T}$ is in Kelvin, was calculated as given in equation 2:

$$
\mathrm{p}_{w}(\mathrm{~T})=\exp \left(\mathrm{A}-\frac{\mathrm{B}}{\mathrm{T}}-\mathrm{C} \times \ln \mathrm{T}\right)
$$

where $\mathrm{T}$ is the temperature in Kelvin and A, B, and C are the constants 52.57, 6690.9, and 4.681, respectively (Huber \& Krause, 2004). Second, the Bunsen absorption coefficient at temperature $\mathrm{T}(\alpha(\mathrm{T}))$, where $\mathrm{T}$ is in ${ }^{\circ} \mathrm{C}$, compensated by the salt concentration of the water, was calculated as given in equation 3.

$$
\alpha(\mathrm{T})=\frac{\left(\exp \left[\left(\mathrm{A}+\frac{\mathrm{B}}{\mathrm{T}}+\mathrm{C} \times \ln \mathrm{T}+\mathrm{D} \times \mathrm{T}\right)-\left[\mathrm{Cl}^{-}\right]\left(\mathrm{P}+\frac{\mathrm{Q}}{\mathrm{T}}+\mathrm{R} \times \ln \mathrm{T}+\mathrm{S} \times \mathrm{T}\right)\right]\right)}{10^{3}}
$$

T is the temperature in ${ }^{\circ} \mathrm{C},\left[\mathrm{Cl}^{-}\right]$is the concentration of chloride ions, and the constants are: $\mathrm{A}=-7.424 ; \mathrm{B}=4.417 \times 10^{3} ; \mathrm{C}=-2.927 ; \mathrm{D}=4.238 \times 10^{-2} ; \mathrm{P}=-0.1288 ; \mathrm{Q}=53.44 ; \mathrm{R}=$ $-4.442 \times 10^{-2}$; and $\mathrm{S}=7.145 \times 10^{-4}$ (Huber $\&$ Krause, 2004). [Cl-] was calculated from the average salinity value for that day, converted to $\left[\mathrm{Cl}^{-}\right]$via equation 4 , adapted from Huber \& Krause (2004), where $\mathrm{S}$ is salinity in \%o.

$$
\left[\mathrm{Cl}^{-}\right]=\frac{\mathrm{S}-0.03}{1.805}
$$

Finally, $\mathrm{O}_{2}$ concentration $(\mu \mathrm{mol} \mathrm{L}-1)$ was calculated from these calculated values as given in equation 5:

$\mathrm{O}_{2}\left[\mu \mathrm{mol} \mathrm{L}{ }^{-1}\right]=\left[\frac{\mathrm{p}_{\mathrm{atm}}-\mathrm{p}_{\mathrm{w}}(\mathrm{T})}{\mathrm{p}_{\mathrm{N}}} \times \frac{\begin{array}{c}\% \text { air } \\ \text { saturation }\end{array}}{100} \times 0.2095 \times \alpha(\mathrm{T}) \times 1000 \times \frac{\mathrm{M}\left(\mathrm{O}_{2}\right)}{\mathrm{V}_{\mathrm{M}}}\right] \times 31.25$ 
where: $p_{\text {atm }}$ (actual atmospheric pressure) $=1013.25$ mbar, given the experiment was conducted near sea level; $\mathrm{p}_{\mathrm{N}}$ (standard pressure) = 1013 mbar (constant); \% air saturation $=$ the value measured by the probe; $0.2095=$ volume content of oxygen in air (constant); $\mathrm{M}\left(\mathrm{O}_{2}\right)$ (molecular mass of oxygen) = $32 \mathrm{~g} \mathrm{~mol}^{-1}$ (constant); and $\mathrm{V}_{\mathrm{M}}$ (molar volume $)=22.414 \mathrm{~L} \mathrm{~mol}^{-1}$ (constant) (Huber \& Krause, 2004).

Respiration assessments were conducted over 9 days, with 3-4 runs per day. The treatments and blanks sampled each day were randomly determined. One blank run, where the chamber contained only treatment water, was performed for each of the seven treatments and converted as above. Oxygen consumption values for measurements containing animals were adjusted using these blanks by subtracting the average consumption of the blanks for all treatments from the total oxygen consumption of each individual. Oxygen use was then converted to $\mu \mathrm{mol} \mathrm{L}^{-1} \mathrm{~h}^{-1}$, and adjusted to the g AFDW of each individual.

\subsection{6 - Statistical analyses}

All survival analyses were conducted on the animals used for the 5 mo sample point. Differences in percentage survival to 5 mo between treatments were investigated using a Kaplan-Meier analysis. The effect of temperature and $\mathrm{pH}$ on the odds of survival was further examined with a binary logit generalised linear model. Generalised linear regression models were used to assess which of the factors (temperature, $\mathrm{pH}$, and temperature* $\mathrm{pH}$ interaction) explained a significant amount of variation in survival. The Akaike Information Criterion (AIC) and $\triangle$ AIC were then used to select which of the significant models was the most parsimonious (Richards, 2005).

The significance of the effect of $\mathrm{pH}$ and temperature on survival, physical and physiological condition and respiration were tested with a between-groups factorial ANOVA when assumptions of normality and homogeneity of variances were met. When these assumptions were violated, a Kruskal-Wallis test was used. The relationships between respiration rate and each physiological condition index $\left(\mathrm{CI}_{\mathrm{FW}: \mathrm{SL}}\right.$ and $\left.\mathrm{CI}_{\mathrm{FW}: \mathrm{SW}}\right)$ were also investigated. Spearman's correlation coefficient was used, as even with 
transformation, data did not meet assumptions of homoscedasticity. Analyses were conducted with SPSS Version 22, and $\alpha=0.05$ in all cases. 


\section{3 - Results}

\subsection{1 - Experimental conditions}

Temperature, $\mathrm{pH}$, and salinity data were averaged over the whole experiment (Temperature and $\mathrm{pH}: \mathrm{n} \geq 14,331$; salinity: $\mathrm{n}=12,432$ ). Average salinity was $34.66 \pm$ 0.004 psu (mean $\pm \mathrm{SE}$ ). Experimental seawater conditions are presented in Table 2.3. Temperatures were distinctly separate among all three temperature levels. While the target of the coldest temperature treatment was $-1.7^{\circ} \mathrm{C}$, the coldest average temperature that could be achieved was $-1.4^{\circ} \mathrm{C}$. However, this coldest temperature was still consistently separate from the other treatments. Each pH level was consistent with target levels and separate from the other levels (Table 2.3). A $\tau$ ranged from 2218.8 to 2286.1 on average (Table 2.3). There was a well-defined difference in $\Omega_{\mathrm{Ar}}$ with $\mathrm{pH}$ treatment. $\Omega_{\mathrm{Ar}} \approx 1$ (average $\Omega_{\mathrm{Ar}}$ of 1.19 , range $=0.91-1.06$ ) at ambient $\mathrm{pH}(\mathrm{pH} 8.00)$, while pH 7.85 produced an average $\Omega_{\mathrm{Ar}}$ of 0.73 (range $=0.66-0.78$ ), and $\Omega_{\mathrm{Ar}}$ was consistently lowest at pH 7.65 (average $\Omega_{\mathrm{Ar}}$ of 0.46 , range $=0.43-0.51$; Table 2.3). 


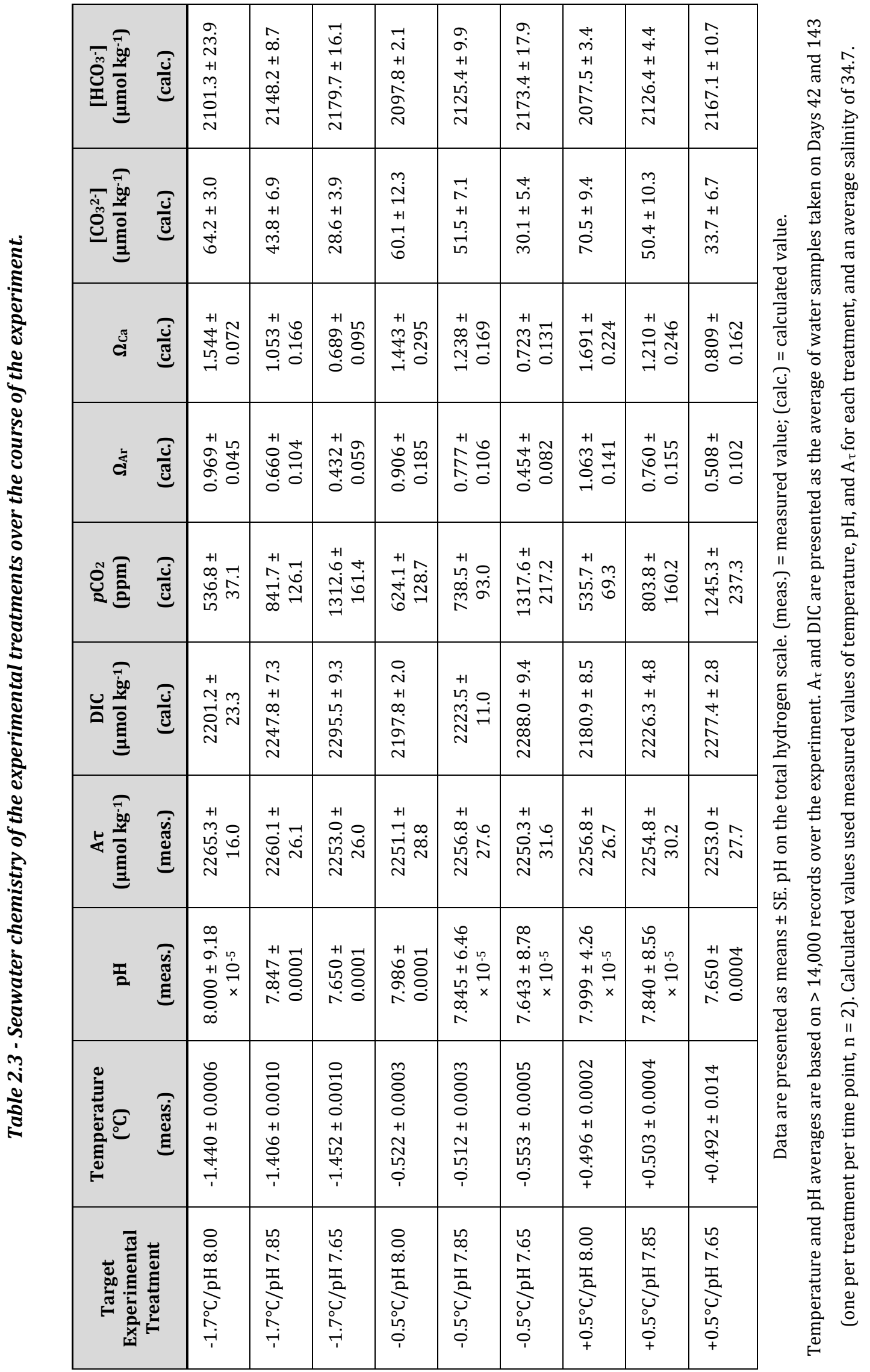




\subsection{2 - Survival}

There were four mortalities during the $11 \mathrm{~d}$ temperature acclimation phase of the experiment. One occurred at $-1.4^{\circ} \mathrm{C}$, two at $-0.5^{\circ} \mathrm{C}$, and one at $+0.5^{\circ} \mathrm{C}$. Mortalities were observed in every treatment throughout the experiment. Survival percentages are shown month-by-month for each treatment in Fig. 2.9, colour-coded to elucidate patterns. At the end of the experiment, survival was highest in the $-1.4^{\circ} \mathrm{C} / \mathrm{pH} 7.85$ treatment, and lowest in the $+0.5^{\circ} \mathrm{C} / \mathrm{pH} 7.65$ treatment (85.7 and $12.5 \%$, respectively). Control animals $\left(-1.4^{\circ} \mathrm{C} / \mathrm{pH} 8.00\right)$ exhibited good survival, with $75 \%$ still alive at the conclusion of the experiment, while most other treatments had less than $60 \%$ survival. Of particular note are the low survival rates after 5 mo at the highest temperature $\left(37.5 \%\right.$ at $+0.5^{\circ} \mathrm{C} / \mathrm{pH} 8.00 ; 57.1 \%$ at $+0.5^{\circ} \mathrm{C} / \mathrm{pH} 7.85$, and $12.5 \%$ at $\left.+0.5^{\circ} \mathrm{C} / \mathrm{pH} 7.65\right)$. The $-0.5^{\circ} \mathrm{C} / \mathrm{pH} 8.00$ and $-0.5^{\circ} \mathrm{C} / \mathrm{pH} 7.65$ treatments also had particularly low survival, with both at $<45 \%$. Smaller increases in temperature and decreases in $\mathrm{pH}$ also generally reduced survival (Fig. 2.9, 5 mo).

Not only did some treatments have lower survival than others, but the path to reaching these final values was different. Survival curves for all treatments are presented in Fig. 2.10. There was generally good survival across treatments for the first two mo, with mortalities beginning to occur at 3-4 mo. The exception was an immediate reduction in survival at $+0.5^{\circ} \mathrm{C} / \mathrm{pH} 8.00$, declining to $75 \%$ just 1 mo into the experiment. There was a consistent decline in survival for this treatment throughout the experiment. By contrast, the $+0.5^{\circ} \mathrm{C} / \mathrm{pH} 7.65$ treatment demonstrated good survival until 4-5 mo, after which animals suddenly and rapidly died off. The most severe mortalities occurred between 4 and $5 \mathrm{mo}$, with the percentage of animals alive in the $-0.5^{\circ} \mathrm{C} / \mathrm{pH} 8.00$ treatment halving between these two times. This die-off was visible in the lowest $\mathrm{pH}$ at all temperatures: i.e., $-1.4^{\circ} \mathrm{C} / \mathrm{pH} 7.65 ;-0.5^{\circ} \mathrm{C} / \mathrm{pH} 7.65$; and $+0.5 / \mathrm{pH} 7.65$ (Fig. 2.10c). 


\begin{tabular}{|c|c|c|c|c|c|}
\hline & \multirow{2}{*}{\multicolumn{2}{|c|}{ Temp }} & \multirow{3}{*}{$\begin{array}{l}\left({ }^{\circ} \mathrm{C}\right) \\
+0.5\end{array}$} \\
\hline & & & & & \\
\hline & & & -1.4 & -0.5 & \\
\hline \multirow{3}{*}{$1 \mathrm{mo}$} & \multirow{3}{*}{$\mathrm{pH}$} & 8.00 & 100 & 85.7 & 75 \\
\hline & & 7.85 & 100 & 100 & 100 \\
\hline & & 7.65 & 100 & 100 & 100 \\
\hline \multirow{5}{*}{$2 \mathrm{mo}$} & & & & Temp & $\left({ }^{\circ} \mathrm{C}\right)$ \\
\hline & & & -1.4 & -0.5 & +0.5 \\
\hline & \multirow{3}{*}{$\mathrm{pH}$} & 8.00 & 100 & 85.7 & 75 \\
\hline & & 7.85 & 100 & 100 & 100 \\
\hline & & 7.65 & 100 & 75 & 100 \\
\hline \multirow{5}{*}{$3 \mathrm{mo}$} & & & & Temp & $\left({ }^{\circ} \mathrm{C}\right)$ \\
\hline & & & -1.4 & -0.5 & +0.5 \\
\hline & \multirow{3}{*}{$\mathrm{pH}$} & 8.00 & 87.5 & 85.7 & 75 \\
\hline & & 7.85 & 85.7 & 87.5 & 100 \\
\hline & & 7.65 & 85.7 & 75 & 100 \\
\hline
\end{tabular}

\begin{tabular}{|c|c|}
\hline \multicolumn{2}{|c|}{ Key (\% alive): } \\
\hline & $80-100$ \\
\hline & $60-79$ \\
\hline & $40-59$ \\
\hline & $20-39$ \\
\hline & $0-19$ \\
\hline
\end{tabular}

\begin{tabular}{|c|c|c|c|c|c|}
\hline \multirow{5}{*}{$4 \mathrm{mo}$} & & & \multicolumn{2}{|r|}{ Temp } & $\left({ }^{\circ} \mathrm{C}\right)$ \\
\hline & & & -1.4 & -0.5 & +0.5 \\
\hline & \multirow{3}{*}{$\mathrm{pH}$} & 8.00 & 75 & 85.7 & 62.5 \\
\hline & & 7.85 & 85.7 & 87.5 & 85.7 \\
\hline & & 7.65 & 85.7 & 75 & 75 \\
\hline \multirow{5}{*}{$\begin{array}{l}5 \text { mo } \\
\text { (end) }\end{array}$} & & & & Temp & $\left({ }^{\circ} \mathrm{C}\right)$ \\
\hline & & & -1.4 & -0.5 & +0.5 \\
\hline & \multirow{3}{*}{$\mathrm{pH}$} & 8.00 & 75 & 42.9 & 37.5 \\
\hline & & 7.85 & 85.7 & 75 & 57.1 \\
\hline & & 7.65 & 57.1 & 37.5 & 12.5 \\
\hline
\end{tabular}

Figure 2.9 - Percent survival of Laternula elliptica in each treatment after each month of exposure to experimental conditions. 
a) $\mathrm{pH} 8.00$

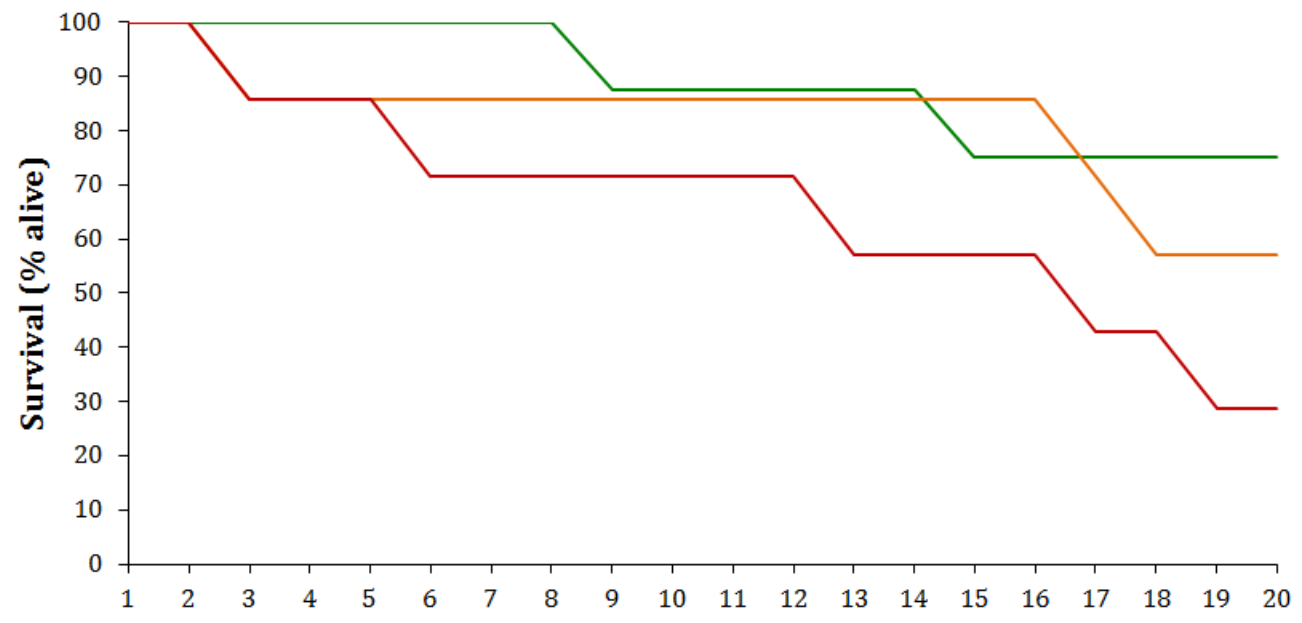

b) pH 7.85

Week

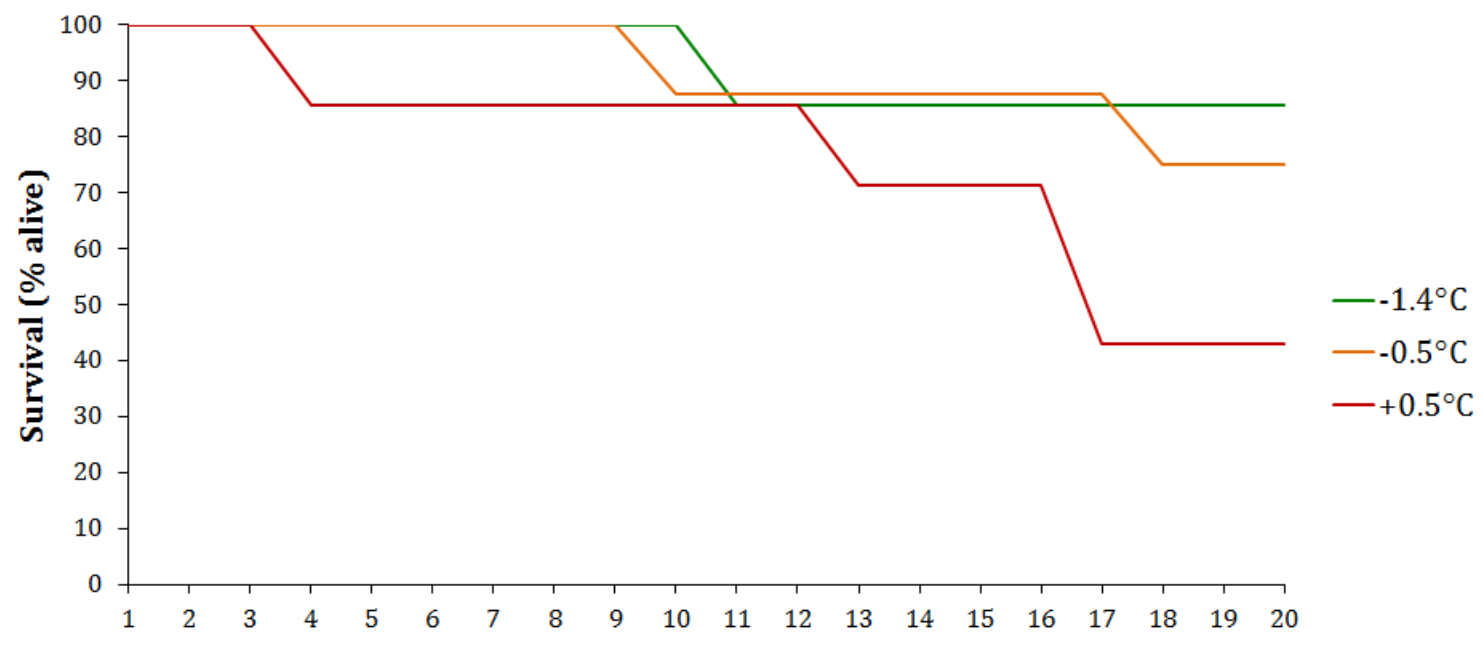

c) $\mathrm{pH} 7.65$

Week

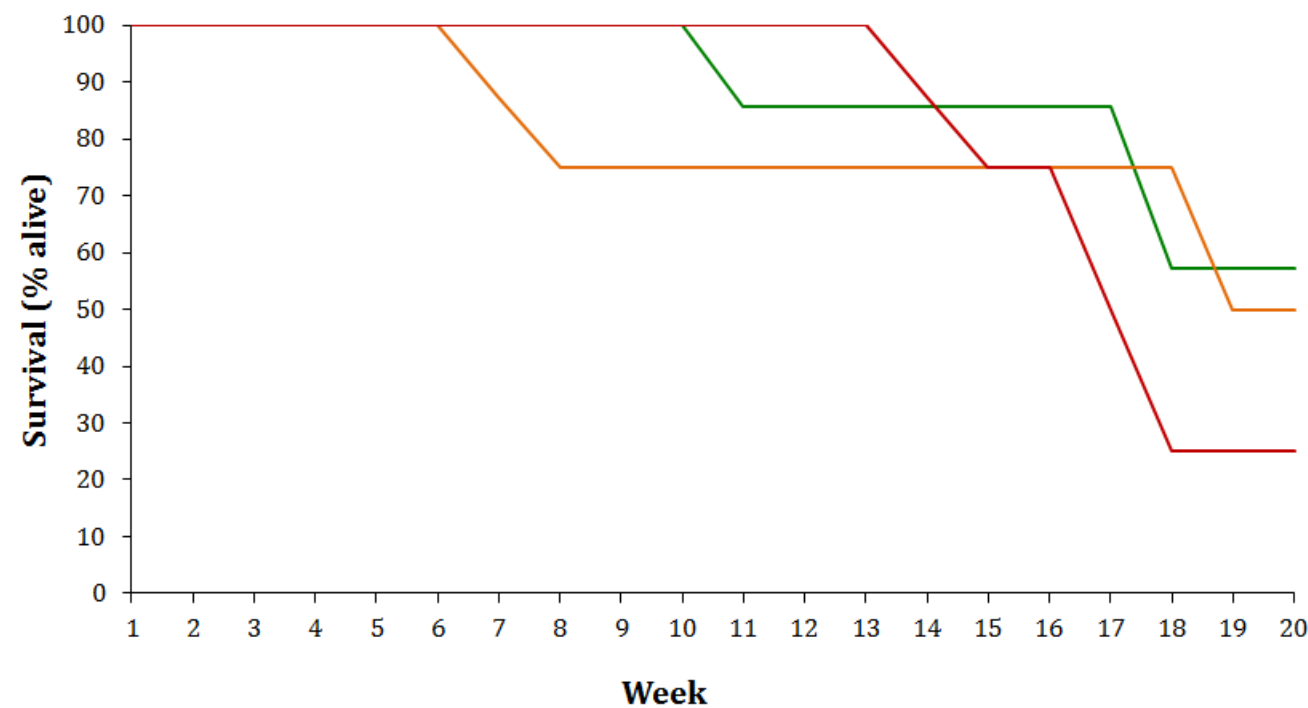

Figure 2.10 - Percent survival of Laternula elliptica over 5 mo at experimental conditions. Results are plotted by pH: a) pH 8.00; b) pH 7.85; and c) pH 7.65. 
There were also patterns in survival with temperature. This is clearly illustrated when temperatures are considered at each pH level (Fig. 2.10); survival decreased with temperature at each $\mathrm{pH}$ level, being greatest at ambient temperature and least at the highest temperature. This pattern was evident throughout the experiment, and was particularly distinct for the final three wk. Animals at $+0.5^{\circ} \mathrm{C}$ generally had an earlier onset of mortalities than those at ambient temperature at $\mathrm{pH} 8.00$ and $\mathrm{pH}$ 7.85. $L$. elliptica at $+0.5^{\circ} \mathrm{C} / \mathrm{pH} 7.65$ survived extremely well throughout much of the experiment, with $100 \%$ survival up until $13 \mathrm{wk}$, after which time survival plummeted abruptly to the lowest survival of all treatments (Fig. 2.10c). Increases in temperature negatively affected survival in L. elliptica adults. By contrast, $\mathrm{pH}$ did not have as great an effect on survival as temperature. Despite the patterns discussed above, when the survival curves were compared with a Kaplan-Meier analysis they were non-significant across treatments $\left(\log \operatorname{rank} \chi^{2}(8)=14.66, p=0.066\right)$.

\subsubsection{1 - Time to $50 \%$ survival $\left(L D_{50}\right)$}

The $50 \%$ survival times ( $\mathrm{LD}_{50}$ ) for L. elliptica in each treatment are noted in Table 2.4 . While statistical analyses could not be applied to these data $(n=1)$, there is an apparent trend of decreasing survival time with increasing temperature, at all $\mathrm{pH}$ levels. The lowest $\mathrm{LD}_{50}$ occurred in the $+0.5^{\circ} \mathrm{C}$ treatments, with $50 \%$ survival reached in an average of 108 days. The $-0.5^{\circ} \mathrm{C}$ treatments had the next-lowest $\mathrm{LD}_{50}$, with an average $\mathrm{LD}_{50}$ of 136 days. All $-1.4^{\circ} \mathrm{C}$ treatments exhibited the best survival, with none having reached $50 \%$ mortality by the end of the experiment, and projected values indicating a mean $\mathrm{LD}_{50}$ across all $\mathrm{pH}$ levels of 220 days. In contrast, there was no clear effect of $\mathrm{pH}$. 
Table 2.4 - Time to $50 \%$ survival (LD50) in days for Laternula elliptica exposed to each treatment.

\begin{tabular}{|c|c|c|c|c|c|}
\hline & \multicolumn{3}{|c|}{ Temperature $\left({ }^{\circ} \mathrm{C}\right)$} & \multirow{2}{*}{ Average } \\
\hline & & -1.4 & -0.5 & +0.5 & \\
\hline \multirow{3}{*}{ pH } & 8.00 & $206 \dagger$ & 134 & 87 & 142 \\
\hline & 7.85 & $288 \dagger$ & 141 & 119 & 183 \\
\hline & 7.65 & $165 \dagger$ & 132 & 118 & 138 \\
\hline \multicolumn{2}{|c|}{ Average } & $220 \dagger$ & 136 & 108 & \\
\hline
\end{tabular}

Key: $\dagger=$ Projected value, extrapolated because $\mathrm{LD}_{50}$ had not yet been reached at the conclusion of this 5 mo-long experiment

\subsubsection{2 - The odds of dying}

An increase in temperature from $-1.4^{\circ} \mathrm{C}$ to $+0.5^{\circ} \mathrm{C}$ increased the odds of L. elliptica dying by 7.55 times. When a binomial probability distribution with a logit link function was fitted to the data at $5 \mathrm{mo}$, the odds of dying at ambient $\left(-1.4^{\circ} \mathrm{C}\right)$ temperature were significantly lower than at elevated $\left(+0.5^{\circ} \mathrm{C}\right)$ temperature $(\mathrm{p}=0.011)$. There was no significant effect of $\mathrm{pH}$ on the odds of dying $(\mathrm{p}=0.075)$.

\subsubsection{3 - Modelling survival}

Logistic regression models were fitted to survival data and compared using AIC values. Changes in temperature explained most of the patterns in survival observed throughout the experiment, with $\mathrm{pH}$ approaching significance but ultimately not affecting survival. Six models tested relevant combinations of temperature, $\mathrm{pH}$, and temperature* $\mathrm{pH}$ against survival. Models were compared using AIC and $\triangle \mathrm{AIC}$ values, and the four best are presented in Table 2.5. Each model's AIC was subtracted from the AIC of the reference model (chosen because it had the smallest AIC and was therefore the best fit) to give $\triangle$ AIC. Provided the model is significant overall, $\triangle$ AIC of $<2$ indicates equally good fit to the reference model, $\triangle \mathrm{AIC}$ of 4-7 indicates the model is probably not a good fit, and $\triangle \mathrm{AIC}$ of $>10$ indicates the model is highly unlikely to be the best model and can 
be ignored (Richards, 2005). Consequently the reference model, with temperature as the only factor, was the best fit to L. elliptica survival data. A model with only $\mathrm{pH}$ had a $\Delta$ AIC of $<2$ (Table 2.5 ) but was not significant overall, meaning that $\mathrm{pH}$ did not significantly explain patterns in survival. When other models were significant, temperature was the only significant factor, although $\mathrm{pH}$ was significant at the $10 \%$ level; however the large $\Delta \mathrm{AIC}$ value for these models rendered them unsuitable (Table $2.5)$. Two other models poorly explained observed patterns in survival $(\Delta \mathrm{AIC}>20$; data not shown) and were rejected (Richards, 2005).

Table 2.5 - Summary of logistic regression models fitted to survival data. comparing combinations of temperature, $\mathrm{pH}$, and temperature* $\mathrm{pH}$ that best explained changes in survival. The model of best fit, temperature ("Temp"), is contrasted with the other models. Models are listed in order of best fit.

\begin{tabular}{|c|c|c|c|c|c|}
\hline Model & $\begin{array}{c}\text { Akaike } \\
\text { Information } \\
\text { Criterion } \\
\text { (AIC) }\end{array}$ & $\begin{array}{c}\Delta A I C \dagger \\
\text { (cf. "Temp" } \\
\text { model) }\end{array}$ & $\begin{array}{c}\text { Overall } \\
\text { Model } \\
\text { Significance }\end{array}$ & $\begin{array}{c}\text { Factors in } \\
\text { Model }\end{array}$ & $\begin{array}{c}\text { Factor } \\
\text { Significance }\end{array}$ \\
\hline $\begin{array}{c}\text { Temp } \\
\text { (Reference model } \\
\text { used in analysis) }\end{array}$ & 16.31 & & $0.006 * *$ & Temp & $0.011 *$ \\
\hline $\mathrm{pH}$ & 16.55 & 0.24 & 0.075 & $\mathrm{pH}$ & 0.087 \\
\hline \multirow{2}{*}{ Temp $+\mathrm{pH}$} & \multirow{2}{*}{30.87} & \multirow{2}{*}{14.56} & \multirow{2}{*}{$0.003 * *$} & Temp & $0.010 *$ \\
\hline & & & & $\mathrm{pH}$ & 0.073 \\
\hline Temp*pH & 38.60 & 22.29 & $0.039 *$ & Temp*pH & 0.134 \\
\hline
\end{tabular}

Key: ${ }^{*}=$ significant at the $5 \%$ level; ${ }^{* *}=$ significant at the $1 \%$ level; $\uparrow=$ difference between the AIC of each model and the AIC of the reference model (the model with the smallest AIC).

\subsection{3 - Physiological and physical condition}

The L. elliptica adults in this study had full stomachs and full gonads when dissected at each time point, indicating that they were sufficiently fed throughout the experiment and were able to sustain gamete production. Spawning was occasionally observed in all treatments throughout the experiment. The L. elliptica specimens were generally large and heavy and in good health at the start of the study. Two physiological condition indices were assessed: $\mathrm{CI}_{\mathrm{FW}} \mathrm{SL}$ and $\mathrm{CI}_{\mathrm{FW}} \mathrm{SW}$. Individuals with high ratios of flesh weight to 
the weight or length of their shell were considered healthy and in good condition. Physical condition concerns the weight of the shell relative to its length ( $\mathrm{CI}_{\mathrm{SW}: \mathrm{SL}}$ ), with a decrease in SW relative to shell length SL indicating dissolution, and an increase indicating calcification, provided SL remains constant.

\subsubsection{1 - $5 w k$}

After 5 wk exposure to experimental conditions, there was no significant difference in CIsW:SL among treatments (Temperature: $\mathrm{F}_{(2,62)}=0.21, \mathrm{p}=0.813 ; \mathrm{pH}: \mathrm{F}_{(2,62)}=0.36, \mathrm{p}=$ 0.700; Temperature*pH: $\left.\mathrm{F}_{(4,62)}=0.20 ; \mathrm{p}=0.936\right)$. There was also no effect of treatment on either of the physiological CIs (i.e., $\mathrm{CI}_{\mathrm{FW}: \mathrm{SL}}$ : Temperature: $\mathrm{F}_{(2,62)}=1.58, \mathrm{p}=0.215$; $\mathrm{pH}$ : $\mathrm{F}_{(2,62)}=0.64, \mathrm{p}=0.529 ;$ Temperature ${ }^{*} \mathrm{pH}: \mathrm{F}_{(4,62)}=0.14 ; \mathrm{p} 0.969 ; \mathrm{CI}_{\mathrm{FW}} \mathrm{sW}$ : Temperature: $\mathrm{F}_{(2,62)}=1.35, \mathrm{p}=0.267 ; \mathrm{pH}: \mathrm{F}_{(2,62)}=0.36, \mathrm{p}=0.703$; Temperature* $\mathrm{pH}: \mathrm{F}_{(4,62)}=0.209 ; \mathrm{p}=$ 0.933).

\subsubsection{2 - $5 \mathrm{mo}$}

There was no significant difference in $\mathrm{CI}_{\mathrm{SW}: \mathrm{SL}}$ treatments at 5 mo (Kruskal-Wallis $\chi^{2}(8)=$ $9.254, \mathrm{p}=0.321$ ). The physiological condition of animals exposed to ambient conditions was relatively high, and there was a noticeable decline in condition at higher temperatures (Fig. 2.11). This pattern was noted for both $\mathrm{CI}_{\mathrm{FW}} \mathrm{SL}$ and $\mathrm{CI}_{\mathrm{FW}} \mathrm{SW}$, indicating that flesh weight declined relative to both shell weight and length over 5 mo. $\mathrm{CI}_{\mathrm{FW}: \mathrm{SL}}$ of $L$. elliptica held at ambient temperature was significantly different to those from the -0.5 and $+0.5^{\circ} \mathrm{C}$ treatments $(\mathrm{p}=0.026$ and $\mathrm{p}=0.004$, respectively) at $5 \mathrm{mo}$, but did not differ between -0.5 and $+0.5^{\circ} \mathrm{C}$ treatments $(\mathrm{p}=0.477$ ) (Fig. 2.11a). $\mathrm{pH}$ did not significantly affect $\mathrm{CI}_{\mathrm{FW}: \mathrm{SL}}\left(\mathrm{F}_{(2,29)}=0.92, \mathrm{p}=0.410\right)$, and there was no interaction between factors (Temperature*pH: $\left.\mathrm{F}_{(4,29)}=0.60, \mathrm{p}=0.664\right)$. The highest $\mathrm{CI}_{\mathrm{FW}} \mathrm{SW}$ was found in ambient temperature animals (Fig. 2.11b), and decreased significantly with temperature $\left(\mathrm{F}_{(2,29)}=\right.$ 6.61, $\mathrm{p}=0.004$; Fig. 2.11b), again with no effect of $\mathrm{pH}\left(\mathrm{F}_{(2,29)}=0.62, \mathrm{p}=0.544\right)$ and no interaction $\left(\mathrm{F}_{(4,29)}=1.19, \mathrm{p}=0.338\right)$. There were significant losses in soft tissue relative to shell weight at $+0.5^{\circ} \mathrm{C}$, but not at $-0.5^{\circ} \mathrm{C}$, as evidenced by a significant decrease in 
CIFw:Sw between the -1.4 and $+0.5^{\circ} \mathrm{C}$ treatments $(\mathrm{p}=0.002)$, while the $-0.5^{\circ} \mathrm{C}$ treatments were similar to both -1.4 and $+0.5^{\circ} \mathrm{C}(\mathrm{p}=0.133$; Fig. $2.11 \mathrm{~b})$.
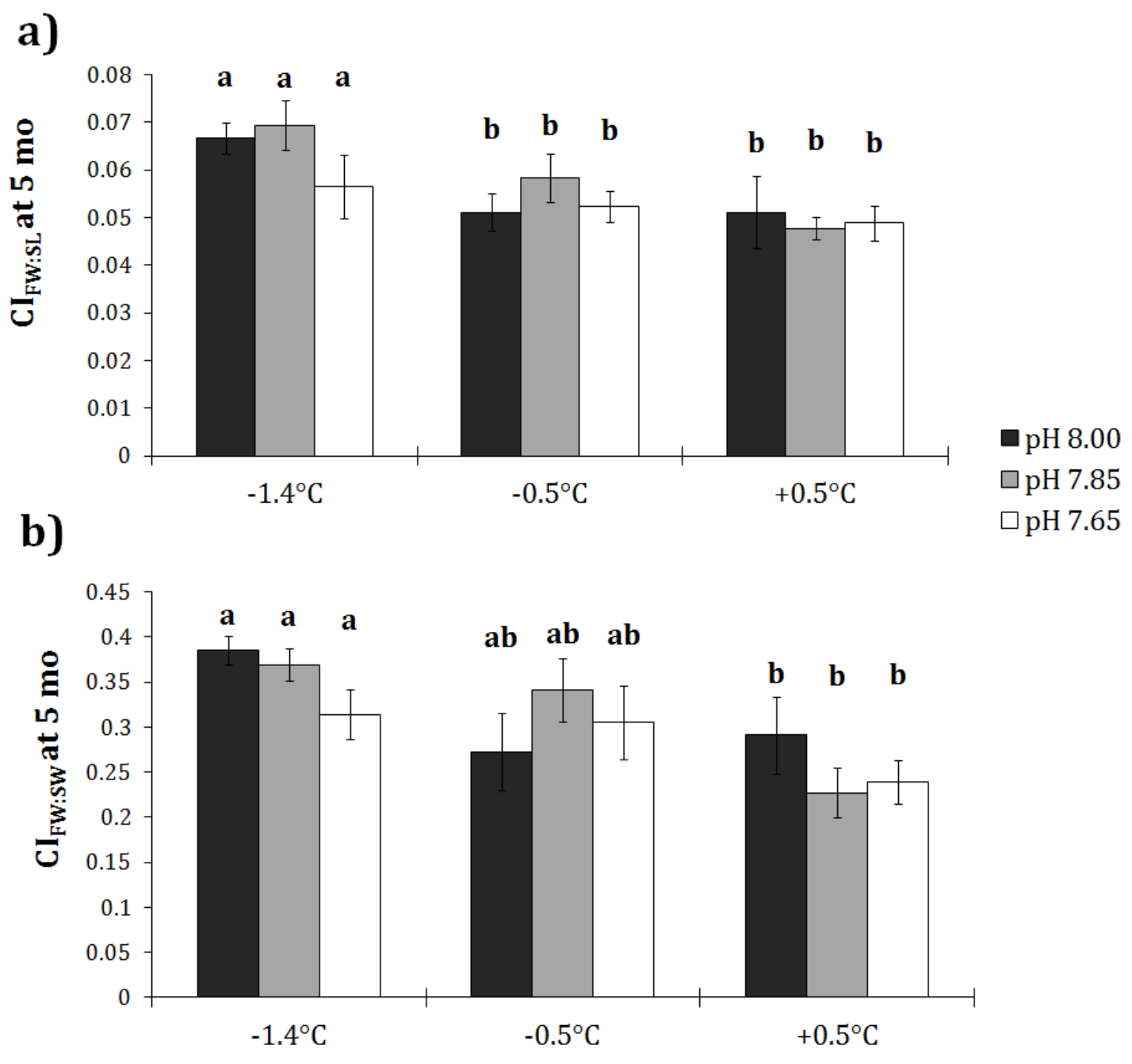

Figure 2.11 - Physiological condition of Laternula elliptica after 5 mo exposure to experimental conditions: a) $\mathrm{CI}_{\mathrm{FW}: \mathrm{SL}}$; b) $\mathrm{CI}_{\mathrm{FW}: S W}$. Statistically different means at $\alpha<0.05$ are indicated by different letters. Data are presented as means $\pm \mathrm{SE}$.

\subsubsection{3 - Change between 5 wk and $5 \mathrm{mo}$}

In the 16 wk between the $5 \mathrm{wk}$ and 5 mo time points, change in $\mathrm{CI}_{\text {sw:SL }}$ was similar across treatments. $\mathrm{CI}_{\mathrm{SW}}$ :SL ranged from 0.11-0.25 in all treatments over the course of the 
experiment and there was no significant percentage change in CIsw:SL with $\mathrm{pH}$ or temperature over this period (Kruskal-Wallis $\chi^{2}(8)=12.41, \mathrm{p}=0.134$ ). Consequently, neither elevated temperature nor lowered $\mathrm{pH}$ affected the change in the ratio of shell weight to shell length in adult $L$. elliptica during the experiment.

While there were relatively small decreases in both $\mathrm{CI}_{\mathrm{FW}: \mathrm{SL}}$ and $\mathrm{CI}_{\mathrm{FW}: S W}$ at ambient temperature (Fig. 2.12), these indices declined significantly in individuals from elevated temperature treatments between $5 \mathrm{wk}$ and $5 \mathrm{mo}$ (Fig. 2.12). There was a significant percentage loss of CIFW:SL at increased temperature (Temperature: $\mathrm{F}_{(2,29)}=4.83, \mathrm{p}=$ $0.016)$ but not with $\mathrm{pH}$, and nor was there any interaction between stressors $\left(\mathrm{pH}: \mathrm{F}_{(2,29)}\right.$ $=1.96, \mathrm{p}=0.160$; Temperature* $\mathrm{pH}: \mathrm{F}_{(4,29)}=0.68, \mathrm{p}=0.614$; Fig. 2.12a). Percent loss of $\mathrm{CI}_{\mathrm{FW}: \mathrm{SL}}$ at ambient temperature was significantly different to both -0.5 and $+0.5^{\circ} \mathrm{C}$ treatments $\left(\mathrm{p}=0.020\right.$ and $\mathrm{p}=0.038$, respectively), while -0.5 and $+0.5^{\circ} \mathrm{C}$ produced similar condition loss ( $\mathrm{p}=0.987$; Fig. $2.12 \mathrm{a})$. $\mathrm{CI}_{\mathrm{FW}: \mathrm{SL}}$ declined by $15-28 \%$ at $-0.5^{\circ} \mathrm{C}$, and by $20-25 \%$ in the $+0.5^{\circ} \mathrm{C}$ treatments (Fig. 2.12a).

Similarly, $\mathrm{CI}_{\mathrm{FW}} \mathrm{SW}$ was deleteriously affected at elevated temperature $\left(\mathrm{F}_{(2,29)}=4.47, \mathrm{p}=\right.$ 0.020 ; Fig. 2.12b), but $\mathrm{pH}$ and the interaction between stressors were both nonsignificant $\left(\mathrm{pH}: \mathrm{F}_{(2,29)}=0.62, \mathrm{p}=0.546\right.$; Temperature* $\left.\mathrm{pH} \mathrm{F}_{(4,29)}=1.18 ; \mathrm{p}=0.341\right)$. The

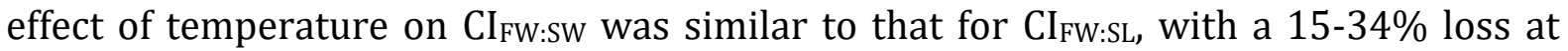
$+0.5^{\circ} \mathrm{C}$ (Fig. $\left.2.12 \mathrm{~b}\right)$. This was due to significant differences between -1.4 and $+0.5^{\circ} \mathrm{C}(\mathrm{p}=$ 0.015; Fig. 2.12b). These percentage changes in CIFw:SL (Fig. 12.2a) and CIFw:sw (Fig. $2.12 \mathrm{~b}$ ) represent a $\sim 4-8 \%$ reduction in initial body weight per month relative to SL and SW. There are indications of greater loss of condition at the lowest $\mathrm{pH}$ (7.65) at ambient temperature for both indices (Fig. 2.12a,b). Similarly, at pH 7.65 the loss in CIFw:sw was greater at higher temperatures. However, neither of these trends were statistically significant, and $\mathrm{pH}$ ultimately had no significant impact on physiological condition in $L$. elliptica. 
a)

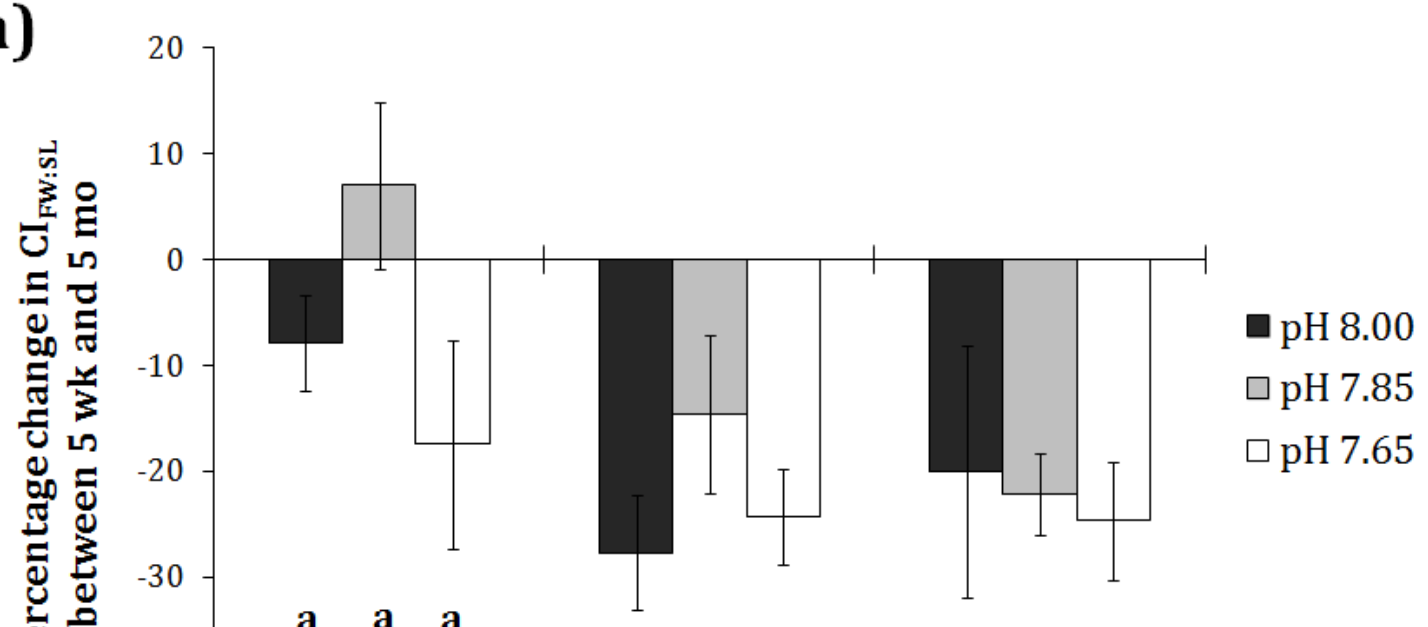

a $\mathbf{a}$ a

b b b

b $\quad \mathbf{b} \quad \mathbf{b}$

b)

$-1.4^{\circ} \mathrm{C}$

$-0.5^{\circ} \mathrm{C}$

$+0.5^{\circ} \mathrm{C}$

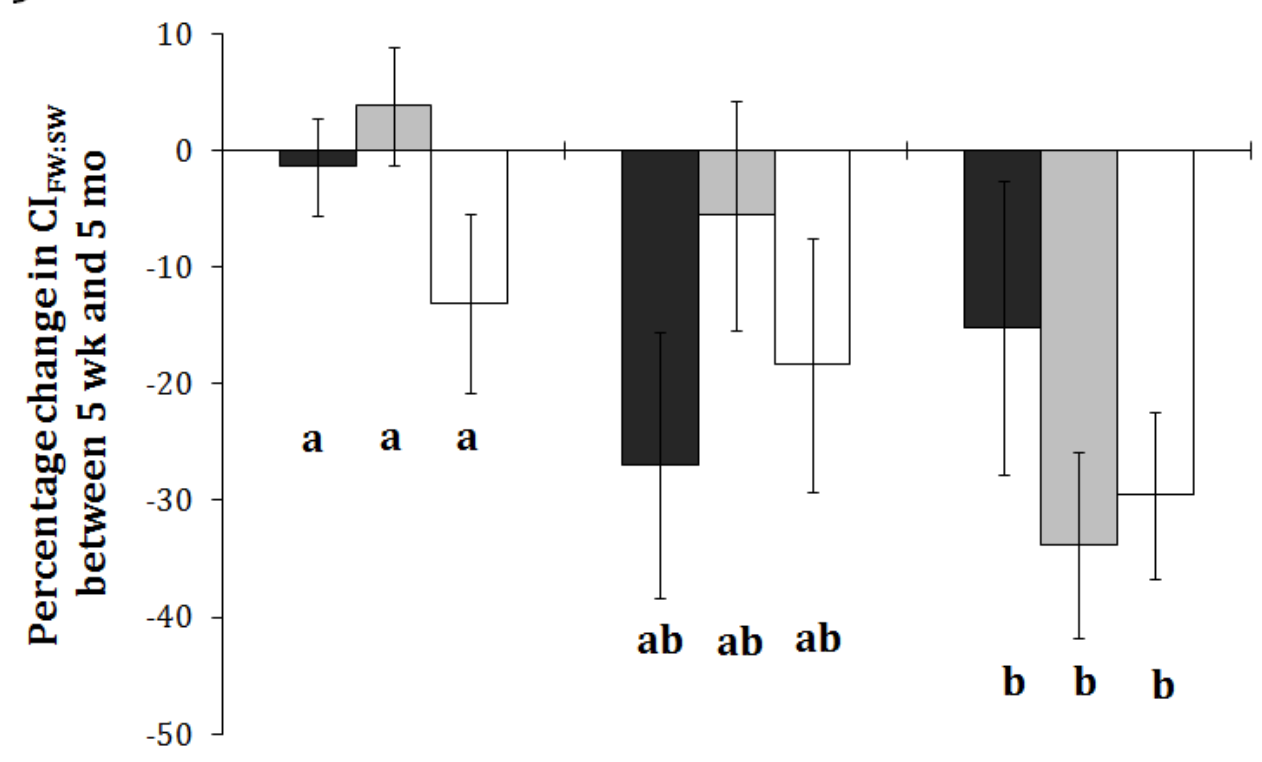

Figure 2.12 - Percentage change of physiological condition of Laternula elliptica between $5 \mathrm{wk}$ and 5 mo: a) CIFW:SL; b) CIFW:SW. Statistically different means at $\alpha<0.05$ are indicated by different letters. Data are presented as means \pm SE.

\subsection{4 - $\mathrm{O}_{2}$ consumption}

By Day 133, when $\mathrm{O}_{2}$ consumption measurements started, there had been 15 mortalities in the $+0.5^{\circ} \mathrm{C}$ treatments ( 6 individuals at $\mathrm{pH} 8.00,4$ at $\mathrm{pH} 7.85$, and 5 at $\mathrm{pH}$ 7.65) and 9 mortalities at $-0.5^{\circ} \mathrm{C}(3$ individuals at $\mathrm{pH} 8.00,2$ at $\mathrm{pH} 7.85$, and 4 at $\mathrm{pH}$ 
7.65). Consequently, and because of the time consuming nature of the $\mathrm{O}_{2}$ consumption measurements, a limited number of $\mathrm{pH}$ treatments were targeted for these assessments: predominantly $\mathrm{pH} 8.00$ and 7.65 , with one 7.85 treatment also assessed $\left(+0.5^{\circ} \mathrm{C} / \mathrm{pH}\right.$ 7.85).

Overall, $\mathrm{O}_{2}$ consumption was not significantly affected by the experimental treatments (Kruskal-Wallis $\chi^{2}{ }_{(6)}=3.67, \mathrm{p}=0.722$ ). This was in part due to the high inter-individual variation within the elevated temperature and lowered $\mathrm{pH}$ treatments (Fig. 2.13). In contrast, control animals had extremely consistent respiration rates (note the extremely small SE for respiration rates in the ambient treatment in Fig 2.13). The $+0.5^{\circ} \mathrm{C} / \mathrm{pH} 8.00$ animals had respiration rates similar to each other and comparable to those of control animals (Fig. 2.13). Individuals from all other treatments exhibited variable and relatively high rates. The exception was the $+0.5^{\circ} \mathrm{C} / \mathrm{pH} 7.65$ treatment, which was represented by a single individual. Relative to the mean respiration rate of the control $\left(-1.4^{\circ} \mathrm{C} / \mathrm{pH} 8.00\right)$ animals, $\mathrm{O}_{2}$ consumption of $-1.4^{\circ} \mathrm{C} / \mathrm{pH} 7.65$ animals increased by $111 \% ;-0.5^{\circ} \mathrm{C} / \mathrm{pH} 8.00$ increased by $80 \% ;-0.5^{\circ} \mathrm{C} / \mathrm{pH} 7.65$ increased by $67 \%$; and $+0.5^{\circ} \mathrm{C} / \mathrm{pH} 7.85$ increased by $119 \%$ (Fig. 2.13) . 


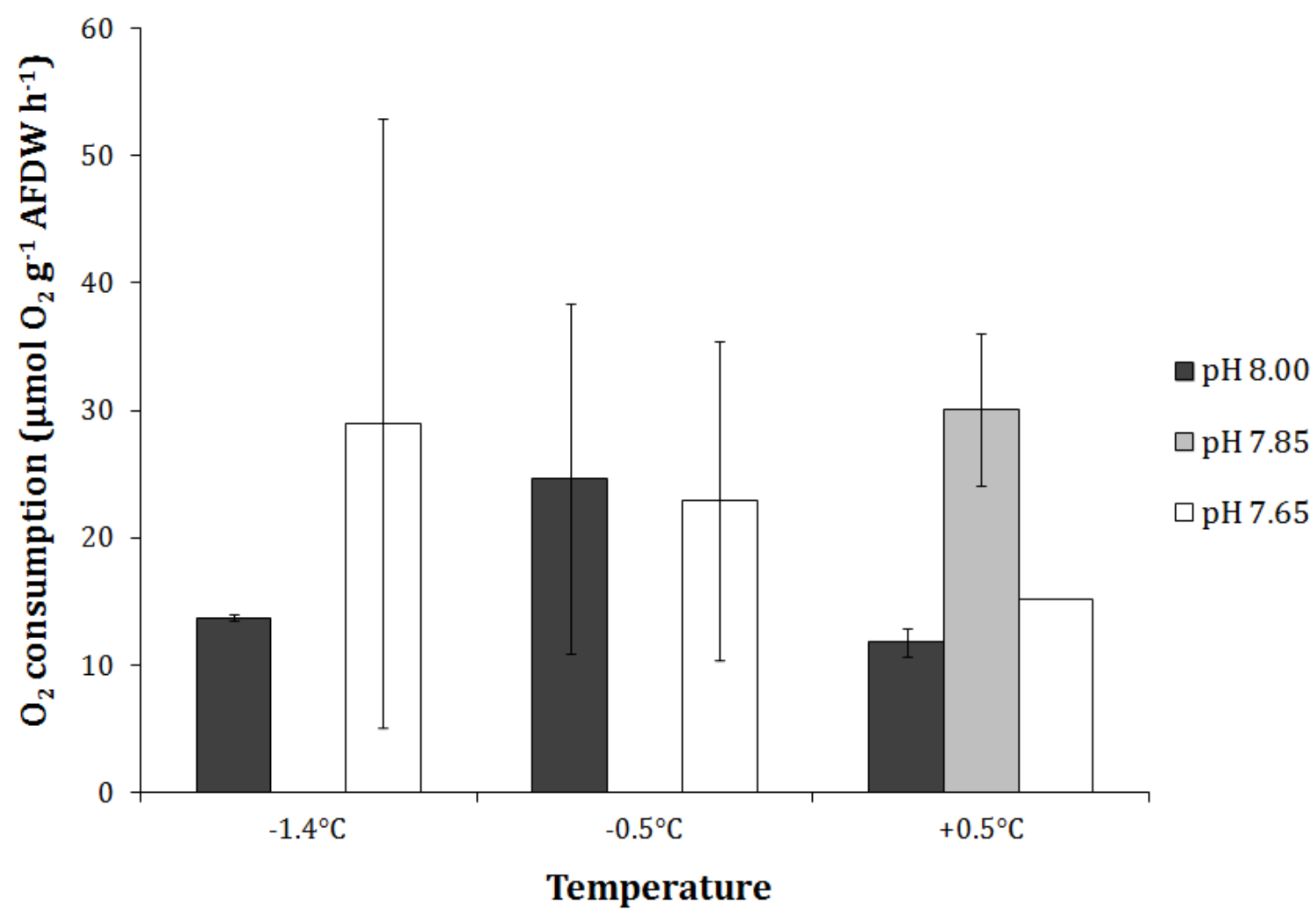

Figure 2.13 - Respiration in Laternula elliptica after 20 weeks at experimental conditions, expressed as $\mu \mathrm{mol} \mathrm{O} \mathrm{g}^{-1} \mathrm{AFDW} \mathrm{h}{ }^{-1}$; means \pm SE. For sample sizes, refer to Table 2.2 .

\subsubsection{1 - Relationship between $\mathrm{O}_{2}$ consumption and physiological condition}

$\mathrm{O}_{2}$ consumption was significantly negatively correlated with $\mathrm{CI}_{\mathrm{FW}} \mathrm{SL}$ (Spearman's rho = -0.647, $\mathrm{p}=0.007, \mathrm{n}=16$; Fig. 2.14a). As condition decreased, there was a strong increase in $\mathrm{O}_{2}$ consumption, to levels $\sim 10 \times$ that of the animal with the highest CI. This relationship exhibits heteroscedastic funnelling: when condition was relatively high, respiration was fairly tightly clustered and consistently low; but as $\mathrm{CI}_{\mathrm{FW}: \mathrm{SL}}$ decreased, $\mathrm{O}_{2}$ demand increased, and variability in this demand also increased (Fig. 2.14a). There was a much greater variation in $\mathrm{O}_{2}$ consumption in lower-condition animals, regardless of treatment. Within this main relationship, not only were ambient-pH individuals in better condition generally (note circled symbols in Fig. 14a), but those at lower pHs (crosses and circles) were generally in worse condition. Furthermore, increased variability in $\mathrm{O}_{2}$ demand with reduced condition was most often evident at $\mathrm{pH} 7.85$ and 7.65. All pH 8.00 individuals except one exhibited similar (low) $\mathrm{O}_{2}$ consumption rates, 
regardless of temperature. When comparing $\mathrm{CI}_{\mathrm{FW}: \mathrm{SL}}$ with respiration rate, $\mathrm{pH}$ patterns emerged that are more apparent than when condition indices alone are examined between treatments (see Section 2.3.3 above).

A similar relationship was observed between $\mathrm{O}_{2}$ consumption rate and $\mathrm{CI}_{\mathrm{FW}} \mathrm{sw}$ (Fig. 2.14b). While a negative trend was also suggested, it was not statistically significant (Spearman's rho $=-0.376, \mathrm{p}=0.151, \mathrm{n}=16$ ). Similar to the pattern noted for $\mathrm{CI}_{\mathrm{FW}: \mathrm{SL}}$, there was an increase in $\mathrm{O}_{2}$ consumption rate with a decrease in $\mathrm{CI}_{\mathrm{FW}} \mathrm{SW}$, and this relationship was heteroscedastic. There was also a pH-specific response in $\mathrm{O}_{2}$ demand with condition change; $\mathrm{pH} 8.00$ treatments had low, tightly-clustered $\mathrm{O}_{2}$ consumption rates, particularly in control individuals, which were so similar they overlap in Fig. 2.14b. Individuals from the ambient-pH treatments generally retained low $\mathrm{O}_{2}$ consumption rates across all temperatures, irrespective of $\mathrm{CI}_{\mathrm{FW}}$ :SW. 


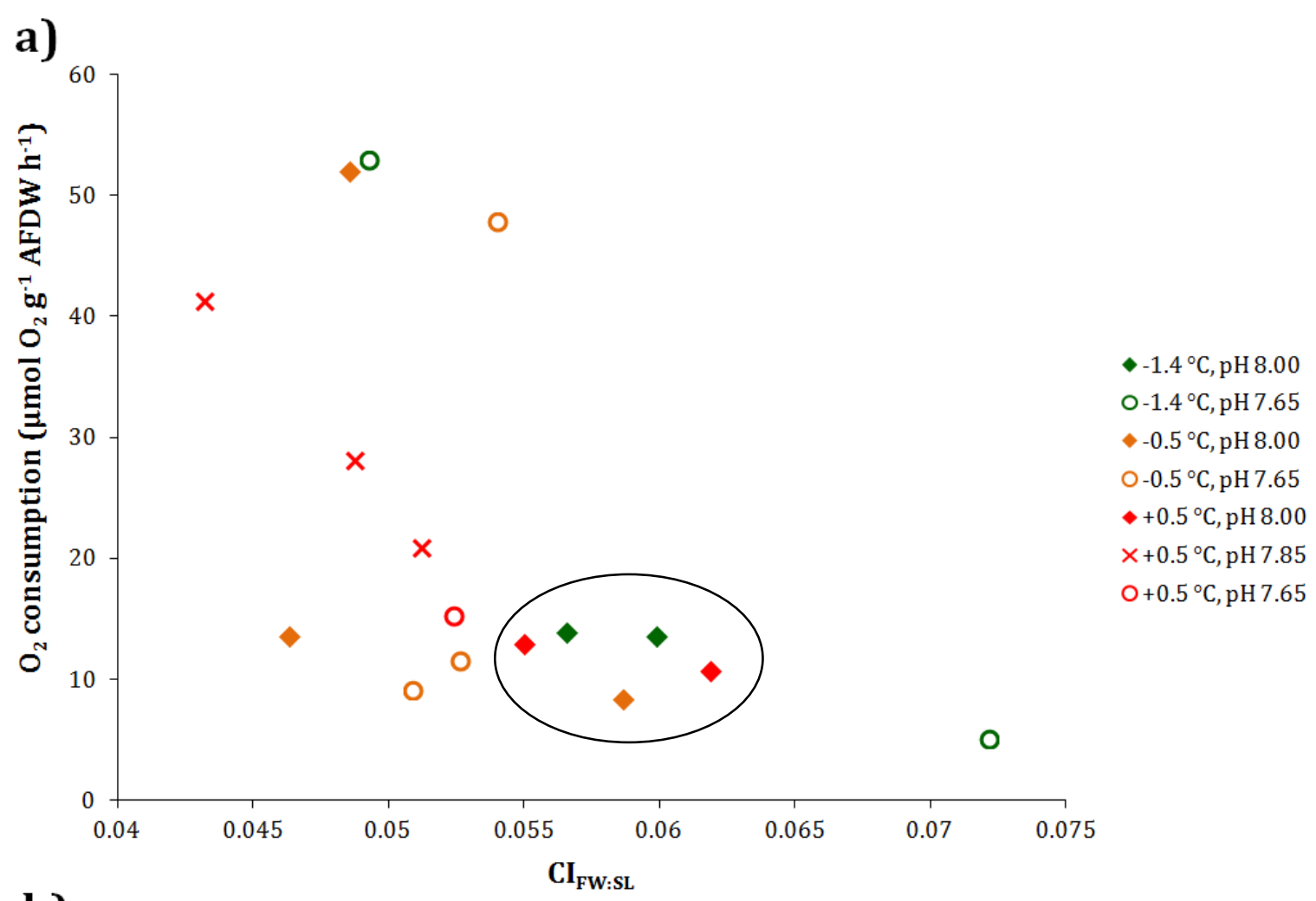

b)

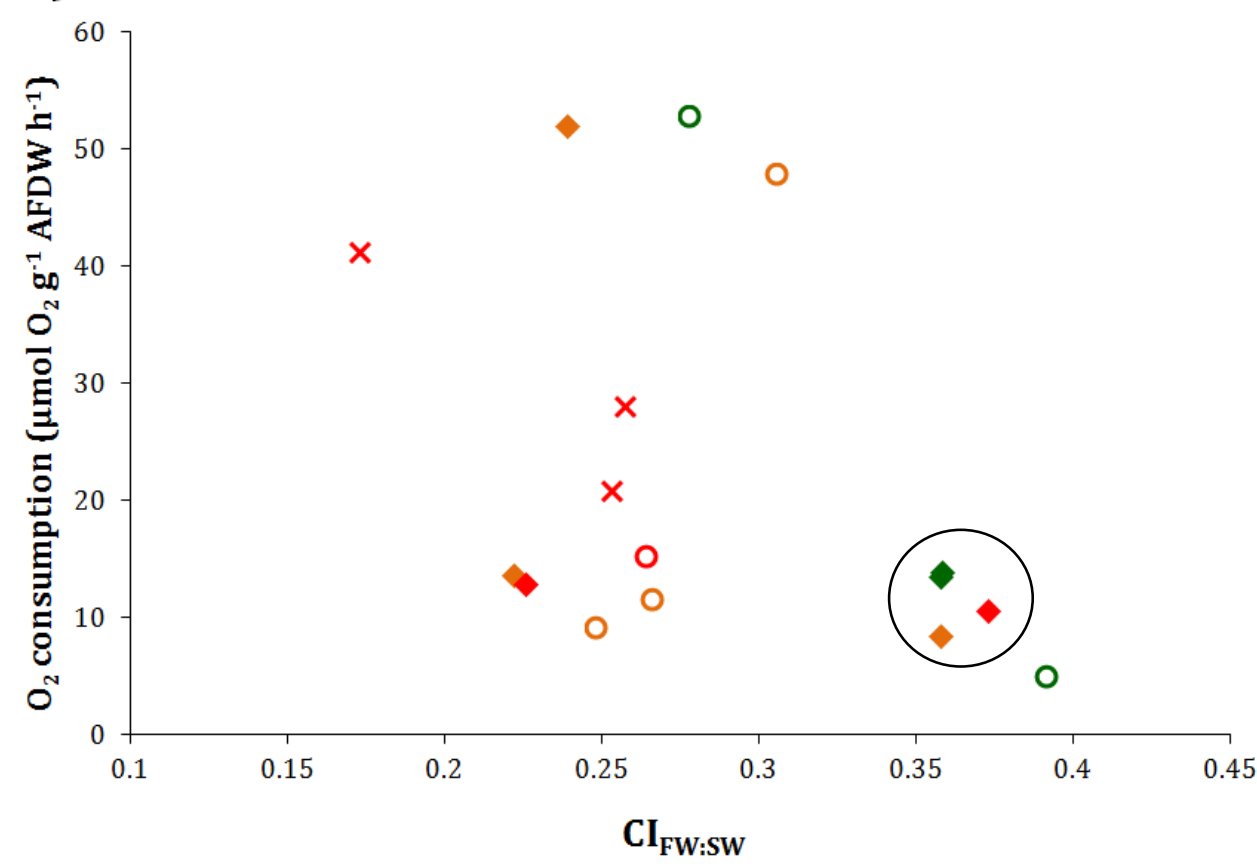

Figure 2.14 - Respiration in Laternula elliptica compared to physiological condition at 5 mo: a) ratio of flesh weight to shell length $\left(\mathrm{CI}_{\mathrm{FW}: \mathrm{SL}}\right)$; b) ratio of flesh weight to shell weight $\left(\mathrm{CI}_{\mathrm{FW}: \mathrm{SW}}\right)$. Respiration is measured as $\mathrm{O}_{2}$ consumption $\left(\mu \mathrm{mol} \mathrm{O} \mathrm{g}^{-1} \mathrm{AFDW} \mathrm{h}{ }^{-1}\right)$. The oval and circle show the low, tight grouping of most $\mathrm{pH} 8.00$ individuals. 


\section{4 - Discussion}

Increased temperature negatively affected the survival, physiological condition, and functioning of adult $L$. elliptica. In contrast, lowered $\mathrm{pH}$ had a comparatively minor effect. L. elliptica physiological condition was not affected after $5 \mathrm{wk}$ at experimentally elevated temperatures and lowered pHs. Consistent maintenance of physical condition was noted among treatments at both $5 \mathrm{wk}$ and 5 mo, however by 5 mo there were strong trends of increasing mortality and a significant loss in physiological condition with elevated temperature. After $5 \mathrm{mo}$, respiration was also affected by temperature increase and a reduction in $\mathrm{pH}$, with an increase in both average $\mathrm{O}_{2}$ consumption and the variability of this consumption with increased temperature and reduced $\mathrm{pH} . \mathrm{O}_{2}$ consumption was negatively correlated with physiological condition, and was particularly high when temperature was elevated and $\mathrm{pH}$ was lowered, but stayed constant under ambient $\mathrm{pH}$ conditions. Multiple aspects of health and function were negatively impacted by warming in this stenothermal bivalve; temperature increases predicted for 2050 and 2100 had a greater impact on adult L. elliptica than $\mathrm{pH}$ reductions predicted for this period.

\subsection{1 - Survival}

Bivalves generally experience higher survival with lowered pH (Hendriks et al., 2010), but in the present study, survival rates in L. elliptica adults did not change with $\mathrm{pH}$. Elevated temperatures, however, had a negative effect on survival. Mortalities occurred earliest, and were highest and most constant at $+0.5^{\circ} \mathrm{C}$. In addition, L. elliptica were 7.55 times more likely to die when exposed to this temperature, $2^{\circ} \mathrm{C}$ above ambient conditions. The effect of temperature on survival is consistent with L. elliptica being strongly stenothermal (Peck et al., 2004; 2014). Considering that a 2.5-5\% decrease in survival was modelled to reduce population sizes to less than $30 \%$ of current levels in McMurdo Sound L. elliptica within 60 y (Guy et al., 2014), the 87.5\% decreases in survival found here with only $+2^{\circ} \mathrm{C}$ warming represent a potentially catastrophic loss in 
L. elliptica population sizes, not only immediately, but also beyond the end of the century as a result of a hugely reduced spawning stock.

Decreases in $\mathrm{pH}$ from ambient levels did not significantly affect L. elliptica survival (Fig. 2.9). Interestingly, in the lowest $\mathrm{pH}$ treatments ( $\mathrm{pH} 7.65,-0.35$ units below ambient), survival was initially high before rapid die-offs occurred near the end of the experiment (Fig. 2.10), indicating that reduced $\mathrm{pH}$ accelerated the rate of declines in survival once they occurred. Were this phenomenon to occur in wild populations in response to ocean warming and acidification, these results indicate that even if L. elliptica populations were initially able to withstand the effects of these stressors, over timescales of greater than 5 mo they would likely experience significantly reduced population sizes. In contrast, an intermediate decrease in pH seemed to improve survival in L. elliptica; at pH 7.85 (-0.15 units below ambient) survival was higher overall than at pH 8.00 or 7.65. Reductions in $\mathrm{pH}$ (-0.33 units below ambient) also prevented metabolic repression and improved the tolerance of blue mussels (M. edulis) to warming (Zittier et al., 2015). The exact reasons for this are yet unknown (Zittier et al., 2015), but if they are also occurring in L. elliptica, these mechanisms may confer the improved survival with slight $\mathrm{pH}$ reduction (and the associated hypercapnia) seen here. Intermediate decreases in $\mathrm{pH}$ may actually have allowed L. elliptica to compensate for negative effects of temperature, at least in the short term.

Some treatments (especially $+0.5^{\circ} \mathrm{C} / \mathrm{pH} 8.00$ and $+0.5^{\circ} \mathrm{C} / \mathrm{pH} 7.85$ ) exhibited a constant rate of mortality throughout the experiment (Fig. 2.10), as in Morley et al. (2012a), while others (particularly $+0.5^{\circ} \mathrm{C} / \mathrm{pH}$ 7.65) produced few mortalities initially before sudden heavy losses occurred after 3 mo of exposure (Figs. 2.9, 2.10). Survival patterns similar to the latter trend were associated with decreased $\mathrm{pH}$ in the clam Ruditapes decussatus (Range et al., 2011). For $R$. decussatus, survival in reduced pH treatments declined after energy output could no longer be maintained. This occurred suddenly, following an energetically costly spawning event (Range et al., 2011). R. decussatus showed a constant rate of mortality at pH 7.53 (an experimental -0.7 change in $\mathrm{pH}$ units) and good initial survival at pH 8.16 and 7.82 (ambient $\mathrm{pH}$ and a -0.4 unit change, respectively; Range et al., 2011). These two latter treatments produced noticeably reduced survival after spawning occurred partway through the experiment. The 
differences in ultimate survival and the sudden onset of mortalities (for both pH 8.16 and 7.82) was linked to the energetic cost of spawning observed in these two treatments (Range et al., 2011). L elliptica in this study experienced comparable patterns but in response to different stressors: consistently reduced survival occurred at elevated temperatures $\left(+0.5^{\circ} \mathrm{C}\right.$ ), while $\mathrm{pH} 7.65$ (a -0.35 unit $\mathrm{pH}$ change) produced good initial survival and sudden declines later in the experiment (Figs. 2.9, 2.10). The fact that L. elliptica in this study spawned before and during the experiment represents a potential drain on energy resources. However, as spawning occurred throughout all treatments, the costs of spawning alone do not fully explain the sudden onset of mortalities.

\subsection{2 - Physical and physiological condition}

\subsubsection{1 - Physical condition}

L. elliptica adults maintained physical condition throughout the experiment, with no significant change with $\mathrm{pH}$ and temperature. L. elliptica calcifies slowly, and minimal if any net shell weight gain or length increase would typically occur over this period (Brey \& Mackensen, 1997; Ahn et al., 2001, 2003; Peck, 2005b; Sleight et al., 2015), particularly in the adults used here. Mussels and sea urchins can dissolve in response to internal acidification (Doney et al., 2009), and dissolution rates in excess of calcification rates can potentially result in thinner and lighter shells with the same surface area (Gazeau et al., 2013). However, L. elliptica adults maintained their relative shell weight under reduced $\mathrm{pH}$ in this experiment. Since empty L. elliptica valves exhibited significant dissolution after $4 \mathrm{wk}$ at pH 7.4 (McClintock et al., 2009), constant shell mass here is evidence that the live animal is successfully compensating when exposed to reduced $\mathrm{pH}$. This resilience may be partially due to the protection afforded by the 10 $\mu \mathrm{m}$-thick periostracum surrounding the outer surface of the thin shell in L. elliptica (Clark et al., 2010; Sato-Okoshi et al., 2010). This retention of physical condition was also found by Cummings et al. (2011) after exposing L. elliptica to pHs both above and below current ambient levels for $4 \mathrm{mo}$, and has also been found in other species (Range et al., 2011; Langer et al., 2014). 
All treatments with ambient $\mathrm{pH}(\mathrm{pH}$ 8.00) were supersaturated with respect to aragonite at one time point and only just undersaturated at the other, resulting in a mean $\Omega_{\text {Ar }}$ close to 1 , and signifying that aragonite supersaturation occurred for periods during the experiment (Table 2.3). On the contrary, both reduced $\mathrm{pH}$ treatments were consistently undersaturated, with a mean $\Omega_{\mathrm{Ar}}$ of 0.73 and 0.46 , at $\mathrm{pH} 7.85$ and 7.65 , respectively (Table 2.3). Consequently, L. elliptica adults were able to maintain physical condition under extended exposure to conditions considered stressful for calcifiers; undersaturation requires additional energy for shell maintenance, as shell dissolution can occur at $\Omega_{\mathrm{Ar}}<1$ (Green et al., 2004; Miller et al., 2009; Roleda et al., 2012).

While L. elliptica adults maintained shell mass in response to both OA and warming, there is likely an associated energetic cost for the organism. Bivalves, as extracellular calcifiers, rely on the active transport of ions to produce conditions suitable for calcification (Miller et al., 2009; Thomsen et al., 2015). Calcification becomes more energetically costly under acidification as the correct ionic balance becomes harder to maintain with internal pH change (Guinotte \& Fabry, 2008; Miller et al., 2009; Pan et al., 2015). Nonetheless, some adult and larval bivalves can calcify even in acidic (pH < 7) estuarine environments, indicating species-specific calcification abilities (Miller et al., 2009; Ries et al., 2004; Hendriks et al., 2010). In some cases, acidification even promotes calcification, as $\left[\mathrm{H}^{+}\right]$increase in the surrounding seawater can make ion transport across cell membranes, and calcification, easier (Ries et al., 2009; Hendriks et al., 2010; Christensen et al., 2011). Temperature increase, provided it is within a species' tolerance level, can reduce negative effects of acidification, such as hypercapnia (Byrne et al., 2014). However, the response of L. elliptica in this study to both warming and acidification involved the maintenance of shell condition, likely due to continued biomineralisation. Preserving physical condition in this way potentially comes at the cost of physiological condition, as detailed below. 


\subsubsection{2 - Physiological condition}

While L. elliptica grow relatively rapidly when resources are available, they are typically resource-limited (the summer burst in primary productivity is short in duration), growing very slowly and only laying down growth rings annually (Brey \& Mackensen, 1997; Ahn et al., 2001, 2003). Consistent with this, SL was constant throughout the experiment; therefore any change in physiological condition is due to a change in mass, not length, of an individual. The lack of change in condition among treatments at $5 \mathrm{wk}$ is not particularly surprising, as animals had only been exposed to experimental conditions for a relatively short time. L. elliptica adults proved resilient over $5 \mathrm{wk}$, but it is their response to longer-term 5-mo exposure that is more biologically meaningful and of more interest in this study.

Temperature increases resulted in significant loss of physiological condition in $L$. elliptica. $\mathrm{CI}_{\mathrm{FW}} \mathrm{SW}$ and $\mathrm{CI}_{\mathrm{FW}} \mathrm{SL}$ are valuable indices for comparing metabolism used for calcification (shell weight) with that used for the maintenance and growth of gametic and somatic tissue (flesh weight) (Crosby \& Gale, 1990) and are an indication of relative physiological stress and health in bivalves (Roper et al., 1991). Both CIs decreased by 15-30\% with warming (Fig. 2.12). This tissue loss is potentially due to the utilisation and reduction of muscle proteins, particularly from the siphons, which form the bulk of the muscle tissue in L. elliptica (Ahn et al., 2003). Conversely, $\mathrm{pH}$ did not significantly affect physiological condition in L. elliptica in this experiment (Fig. 2.12). Similarly, Cummings et al. (2011) found no significant change in $\mathrm{CI}_{\mathrm{FW}} \mathrm{SL}$ in L. elliptica with a decrease in $\mathrm{pH}$ to 7.78. Warming is therefore the main driver of reduced physiological condition in L. elliptica in this study. This loss of soft tissue indicates that L. elliptica are losing crucial sources of protein (Brockington, 2001; Ahn et al., 2003), and are not able to acclimate to increased temperature. With longer-term exposure to warmed conditions, L. elliptica would likely continue to lose body mass (here, at the rate of $\sim 4$ $8 \%$ reduction in initial body weight relative to SL per month) and eventually die.

This significant weight loss may be due in part to the physical cost of maintaining the aragonite shell in undersaturated conditions. This rationale is supported by Wood et al. (2008), who found that a brittle star burned calories to maintain $\mathrm{CaCO}_{3}$ structures 
under acidification, and lost muscle mass as a result. Other studies found no change in weight with acidification (clam Ruditapes decussatus, Range et al., 2011; gastropod Subninella undulata, Coleman et al., 2014). However, other species have experienced weight loss with warming (bivalve Macoma balthica, Beukema et al., 2009; gastropod Austrocochlea porcata, Coleman et al., 2014). The ability of a species to maintain the weight of their soft tissue, typically by keeping levels of energy expenditure below energy gain, is variable, depending on species and environmental context, and has consequences for long-term survival (Beukema et al., 2011).

\subsection{3 - $\mathrm{O}_{2}$ consumption}

L. elliptica exposed to elevated temperature and reduced $\mathrm{pH}$ exhibited higher respiration rates and increased variability in $\mathrm{O}_{2}$ demand (Figs. 2.13, 2.14). The individual variation in respiration rate with thermal stress found here in L. elliptica was also found by Morley et al. (2009) and Peck et al. (2015). Comparatively, hypercapnic blue mussels (Mytilus edulis) maintained their $\mathrm{O}_{2}$ consumption rates at control temperatures, but had slightly greater increases in $\mathrm{O}_{2}$ demand with temperature rise than normocapnic mussels (Zittier et al., 2015). The fact that L. elliptica in two of the $+0.5^{\circ} \mathrm{C}$ treatments had $\mathrm{O}_{2}$ consumption rates similar to control animals may be a result of all individuals with higher $\mathrm{O}_{2}$ requirements dying off earlier in the experiment. The remaining individuals may also have been stressed and moribund. Alternatively, decreases in $\mathrm{pH}$ may have a narcotic effect, and this may have reduced respiration rate in some individuals (Christensen et al., 2011), although this was not noted for L. elliptica in this study, or when exposed to pH 7.78 in Cummings et al. (2011). However, marine invertebrates, including L. elliptica, may also repress metabolic demand in the face of environmental insult (Morley et al., 2009; Christensen et al., 2011; Navarro et al., 2013; Zittier et al., 2015); this may have occurred here with the two individuals in the $+0.5^{\circ} \mathrm{C}$ treatments.

$\mathrm{O}_{2}$ consumption rates can be used as a proxy for energy use and therefore metabolic demand (as in Brockington [2001]; Peck et al. [2002]; Heilmayer et al. [2004]; Morley et al. [2007, 2009]; Wood et al. [2008]; Zittier et al. [2015]). $\mathrm{O}_{2}$ consumption in L. elliptica 
varies by season, with a $\sim 3 \times$ seasonal variation in metabolic rate between the active summer period and the repressed winter period (Brockington, 2001; Morley et al., 2007). Animals in this study were acclimated to summer conditions, and similar respiration rates have been found in L. elliptica in summer (Peck et al., 2002; Brockington, 2001; Morley et al., 2007). Morley et al. (2007) found a 35\% increase in $L$. elliptica respiration rate with warming to $-0.4^{\circ} \mathrm{C}$, and Cummings et al. (2011) found a $150 \%$ increase with lowered $\mathrm{pH}(\mathrm{pH} 7.78)$; both are consistent in pattern to the 67$119 \%$ increase in mean respiration rate found here with elevated temperature and lowered pH. Interestingly, Ahn \& Shim (1998) found respiration rates higher $(159 \mu \mathrm{mol}$ $\mathrm{O}_{2} \mathrm{~g}^{-1} \mathrm{AFDW} \mathrm{h}^{-1}$ ) and Morley et al. (2009) found rates lower (i.e., $\leq 14 \mu \mathrm{mol} \mathrm{O} \mathrm{g}^{-1}$ AFDW $\left.\mathrm{h}^{-1}\right)$ than those observed here $\left(\sim 12-30 \mu \mathrm{mol} \mathrm{O}_{2} \mathrm{~g}^{-1}\right.$ AFDW $\left.\mathrm{h}^{-1}\right)$; these differences may be due to site-specificity in response in L. elliptica (Morley et al., 2012b).

High individual variation in $\mathrm{O}_{2}$ consumption rates (Figs. 2.13, 2.14) has ramifications for population-level survival (Peck et al., 2015). It is highly likely that amplified respiration leads to increased nutrient requirements, dramatic loss in condition, reduced growth, or even death (Doney et al., 2012; Alcaraz et al., 2014). In fact, L. elliptica adults experienced significant $(\sim 30 \%)$ loss in condition at -0.5 and $+0.5^{\circ} \mathrm{C}$ (Fig. 2.12). Oxygen consumption also increased with a decrease in body weight in L. elliptica (Ahn \& Shim, 1998), so the relationship found here between the loss of physiological condition and increased respiratory demand (Fig. 2.14) likely holds for L. elliptica populations in general. High $\mathrm{pH}$ buffered the effect of physiological condition loss on respiration demand. Almost all individuals at ambient $\mathrm{pH}$ (8.00) had low $\mathrm{O}_{2}$ demand even when their condition was comparatively low, while individuals in similar condition but exposed to lower $\mathrm{pH}$ and/or warmer temperatures, had highly variable and generally elevated respiration rates (Fig. 2.14). As discussed above, this result may be due to elevated activity in response to undersaturated conditions $\left(\Omega_{\mathrm{Ar}}<1\right.$; Table 2.3$)$.

The stress response of L. elliptica, particularly to thermal stress, seems to involve an increase in respiration and heartbeat rates until the stress is too much to withstand, at which point both activities rapidly fall to nearly zero and the animal dies (Peck et al., 2002). This response is very similar to the hierarchical stepwise behavioural response model, whereby processes such as movement and respiration are initially increased in 
response to a stressor, then decreased once they become unsustainable, followed by death (Gerhardt et al., 2006; Zhang et al., 2012). This stepwise stress response occurred in L. elliptica adults at $5-10^{\circ} \mathrm{C}$ (Peck et al., 2002; Peck, 2005a,b), and also seems to have occurred here, with respiration rates in experimental treatments either much higher than control rates, or much lower in treatments with high mortalities. Similarly, Pörtner (2010; 2012) proposed the oxygen- and capacity-limited thermal response behavioural model, whereby an organism has an optimal temperature range determined by its aerobic scope. An increase in temperature beyond optimum levels triggers the progressive repression of growth, reproduction, and other processes (Pörtner, 2010; 2012). This repression is similar to the deliberate metabolic repression and reduced siphon activity of L. elliptica in winter (Brockington, 2001; Morley et al., 2007). At the animal's critical temperature, there is a shift to anaerobic metabolism as aerobic metabolism becomes too energetically costly (Pörtner, 2010; 2012). This may have occurred here in adult L. elliptica with both warming and acidification. Given the consistent mortalities and loss in physiological condition with elevated temperature, it is most likely that the animals were unable to regulate their energetic expenditure, and died as a result of this imbalance.

\subsection{4 - Implications of sensitivity to warming in Laternula elliptica}

Loss of body mass and reduced survival of L. elliptica occurred at levels of warming predicted for 2050 and 2100. These changes, occurring with even relatively minor temperature increase, have negative implications for its survival in a warming environment. This carries negative consequences for the health of individuals and the persistence of L. elliptica populations with SO warming.

Survival in the face of environmental stress depends on animals surviving multiple breeding seasons; even if they cannot breed one year, they can breed the next (Peck, 2005b). This was not the case here. Adults spawned throughout the course of this study, but some also died rapidly in less than half the time it would take gonads to ripen. These results are from individuals in the laboratory supplied with non-Antarctic water and must be interpreted with caution. However, they do indicate that even with relatively 
minor temperature changes experienced over only a small proportion of its lifetime, $L$. elliptica may be unable to cope with associated metabolic costs, at least over the timescale of this investigation.

\subsection{5 - Concluding comments}

As a keystone species important to the Antarctic benthos, wide-scale depletions of $L$. elliptica would affect bentho-pelagic coupling and biodeposition throughout the coastal environments of Antarctica (Ahn, 1993; Guy et al., 2014). In this study, L. elliptica was severely affected by only $1-2^{\circ} \mathrm{C}$ warming above summer ambient conditions, with considerably reduced survival, significant loss of body tissue, and, in some individuals, highly elevated respiration rates. These responses occurred at smaller degrees of warming than are typically associated with temperature-related mortality in L. elliptica (i.e., +7.5-12.5 ${ }^{\circ}$; Peck, 2005a,b; Morley et al., 2009), confirming that thermal limits are narrower for successful long-term maintenance than for short-term tolerance (Pörtner, 2010; Alcaraz et al., 2014). L. elliptica adults were unable to acclimate to experimental conditions after 5 mo. Other Antarctic marine fauna take longer (2.5-5 mo and 6-9 mo) to acclimate to increases in temperature (Peck et al. [2014] and Suckling et al., [2015], respectively). However, some are unable to acclimate at all (Peck et al., 2014).

The waters of McMurdo Sound have very stable year-round temperatures, and a $\mathrm{pH}$ range that is stable in winter, increases considerably in summer, and shows some daily fluctuation, but is consistently higher than the experimental pHs tested here (GonzalezBernat et al., 2013; Kapsenberg et al., 2015). Therefore it is not surprising that $L$. elliptica specimens originating from Cape Evans were unable to withstand even minor warming for any extended period of time, but had some resistance to $\mathrm{pH}$ change. Warming is also found to be more important than decreased $\mathrm{pH}$ in other bivalves (Zittier et al., 2015). The temperature- and pH-specific seascape that L. elliptica, as an ectothermic marine invertebrate, is typically exposed to dictates its ability to cope with environmental conditions outside of these norms (Morley et al., 2009). The results of this Chapter have clearly shown that warming is more important than $\mathrm{OA}$ in terms of its effects on the function, condition, and continued survival of L. elliptica. 


\section{Chapter 3}

\section{HSP70 expression in Laternula elliptica in response to ocean acidification and warming: Preliminary results}

\section{1 - Introduction}

The distribution of a species is determined by its ability to tolerate a range of environmental conditions, termed its tolerance 'envelope' or 'window' (Pörtner, 2008). Environmental changes that push one or more of these variables beyond an organism's tolerance envelope can become stressful if they disturb homeostasis (Clark et al., 2008a; Fabbri et al., 2008). Environmental stresses can result in loss of performance, changes in species interactions, population declines, and range shifts or shrinkage (Pörtner, 2008, 2010; Pörtner et al., 2007). Understanding factors affecting species persistence is essential when predicting likely future species range shifts in the face of global anthropogenic climate change and ocean acidification (OA) (Tomanek, 2010; IPCC, 2013). Consequently, understanding the amount of variation in environmental variables that is tolerable to each species is vital, as it informs these predictions.

An organism's ability to survive disruptions to homeostasis by environmental change is greatly assisted by heat shock proteins (HSPs). Discovered in the context of temperature elevation, HSP induction may increase with stressors other than temperature, is related to cell signalling, and is part of the general physiological stress response of an organism (Feder \& Hofmann, 1999; Fabbri et al., 2008; Clark et al., 2009b). While HSP production is energetically costly, it protects the cell (Feder \& Hofmann, 1999; Clark \& Peck, 2009b; Tomanek, 2010). HSPs act as molecular chaperones, refolding and stabilising denatured proteins, preventing them from interacting with each other in an unwanted way, and preventing the formation of detrimental cytotoxic compounds (Feder \& Hofmann, 1999; Clark et al., 2008a; Clark \& Peck, 2009b). HSPs are classified by their weight in kilodaltons. The $70 \mathrm{kDa}$ HSP family is the most well-described and includes constitutively expressed genes (HSC70), 
glucose-regulated proteins, and most importantly, the inducible form (HSP70) (Clark et al., 2008a,b; Fabbri et al., 2008). HSP70 is a highly conserved protein that is present in all taxa, signifying the importance of HSPs to cell function (Feder \& Hofmann, 1999; Fabbri et al., 2008).

HSP70 is up-regulated by organisms in response to environmental stress, and is therefore of interest in heat shock response studies (Clark et al., 2008a). HSP70 induction indicates that an organism is not only able to make adjustments to cellular concentration of molecular chaperones to protect proteins from damage, but that conditions are stressful enough to warrant this expense (Feder \& Hoffman, 1991; Clark \& Peck, 2009; Tomanek, 2010). Therefore, an increase in HSP70 expression signals that an organism is experiencing environmental stress. HSP70 up-regulation in response to elevated temperatures, the classical heat shock response, has been observed in the majority of taxa that have been examined so far, except for a number of Antarctic species (Clark et al., 2008a,b).

Antarctic marine fauna are stenothermal and have evolved low metabolic rates, slow growth, longer lifespan, slow movement, and some gigantism, due to low temperatures and environmental stability over past millennia (Barnes \& Peck, 2007; Clark \& Peck, 2009b). These cold-water conditions may cause slow rates of protein synthesis and elevated rates of protein degradation (Barnes \& Peck, 2007), so that not only could proteins such as HSP be created slowly, but they may also be degraded quickly and have a limited lifespan within the cell. Having low metabolic rates reduces the amount of cellular energy consumed, and even small increases in temperature may therefore represent a comparatively large thermal stress to Antarctic marine invertebrates. It is of interest in an evolutionary context whether Antarctic species display a heat shock response, and whether they can sustain it for any period of time. An ability to upregulate HSP70 suggests a capacity to protect against protein denaturation and cell damage in the face of environmental change, while a down-regulation over time would signify an ability to acclimate to this change (Feder \& Hoffman, 1991; Clark \& Peck, 2009; Tomanek, 2010). The ability of Antarctic marine species to up-regulate levels of HSP70 expression considering their energy-limited, cold environment is relevant considering the long-term changes in ocean temperature and chemistry predicted for 
the next century and beyond as a result of anthropogenic climate change and OA (IPCC, 2013).

Understanding a species' heat shock response helps identify its tolerance limits to specific environmental variables. These variables, particularly temperature and $\mathrm{pH}$, set the boundaries for a species' range, and understanding a species' tolerance limits shows how this range may change with ocean warming and acidification (Pörtner et al., 2007; Clark \& Peck, 2009b). HSP70 and related genes have been sequenced in L. elliptica (Clark et al., 2008a; Park et al., 2007). L. elliptica displays a heat shock response under high temperatures $\left(+10^{\circ} \mathrm{C}\right.$; Clark et al., 2008a; Park et al., 2007) and up-regulates production of HSP70 with $\mathrm{pH}$ increase and decrease (to 8.32 and 7.78, respectively; Cummings et al. [2011]). However its response to smaller, more environmentally realistic temperature increases is unknown. Furthermore, HSP70 expression has not been measured in response to both elevated temperature and decreased $\mathrm{pH}$ in this species.

A keystone species with a circumpolar distribution, L. elliptica is a common coastal suspension-feeder with a significant role in bentho-pelagic coupling (Ahn, 1993; Clark et al., 2010). Understanding the response of L. elliptica to combined stressors, simulating predicted effects of $\mathrm{OA}$ and warming on the Southern Ocean (SO), is important given its ecological significance. As with other sessile bivalves, L. elliptica may rely heavily on HSP70 in combination with other mechanisms to adapt to environmental variation and stress, such as when colonising the productive coastal benthos after ice scour events (Pearse et al., 1991; Ahn, 1994; Ahn et al., 2001; Barnes \& Conlan, 2007; Fabbri et al., 2008). Ascertaining whether this species is likely to experience stress from ocean conditions predicted for the near future will inform predictions of population and ecosystem dynamics (as in Guy et al. [2014]). 


\section{2 - Methods}

See Chapter 2 Methods for details on L. elliptica collection, acclimation procedure, and experimental setup.

\subsection{1 - Tissue collection}

At $5 \mathrm{wk}$ and $5 \mathrm{mo}$, one individual per replicate tank was sacrificed. Mantle tissue was dissected out and used for analysis of HSP70 gene expression. Mantle tissue was dissected from $\sim 20 \mathrm{~mm}$ from the base of the siphon to $\sim 10 \mathrm{~mm}$ from the foot (Fig. 3.1). Tissue was weighed and snap-frozen in liquid nitrogen immediately after dissection, then stored at $-80^{\circ} \mathrm{C}$ until analysis.

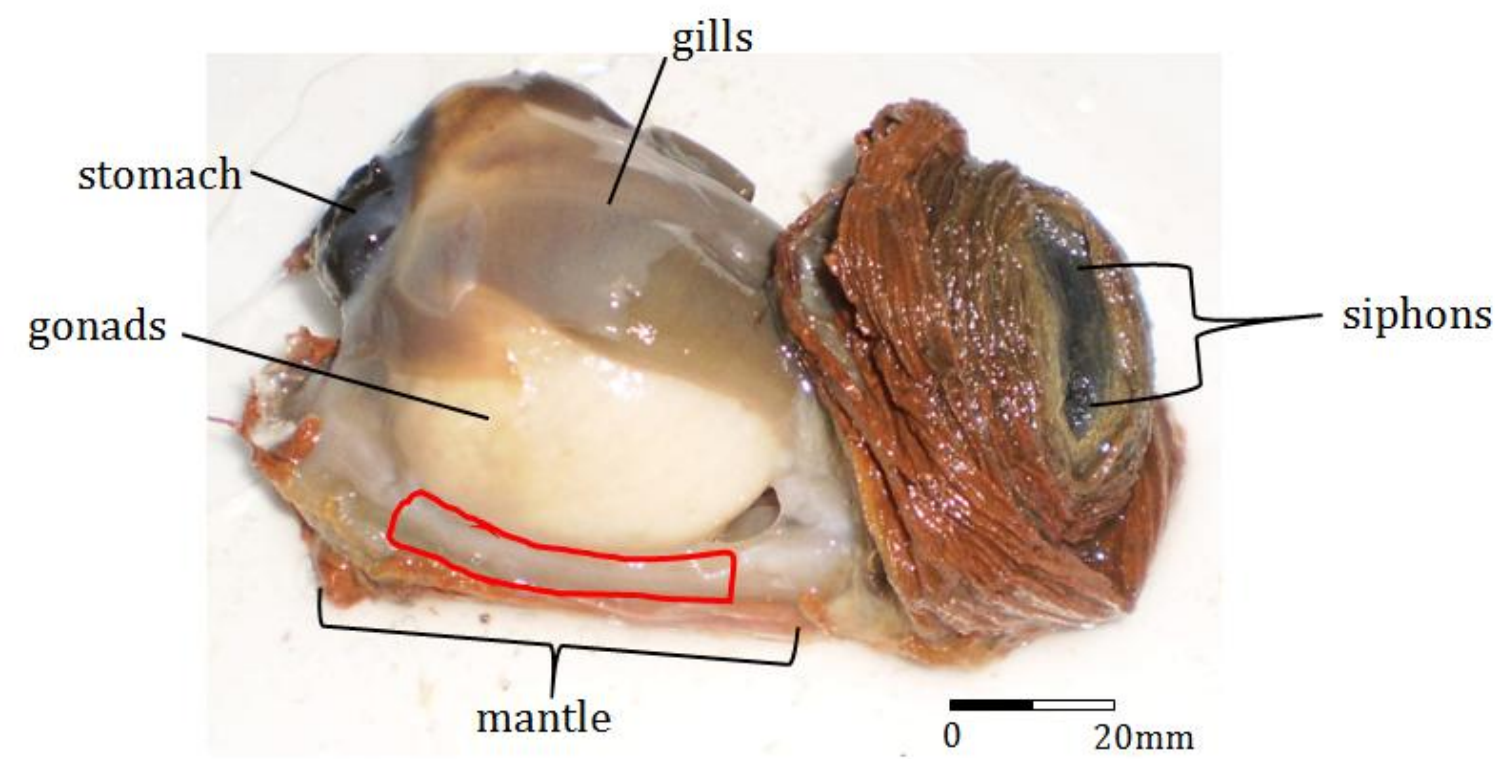

Figure 3.1 - Laternula elliptica mantle tissue dissection in progress. The region of mantle tissue to be dissected is outlined in red. 


\subsection{2 - Gene expression analysis}

As this was a preliminary study mainly focussing on method development, this analysis was performed on 1 replicate of each treatment at each time point. Thus in most cases statistical analyses were not appropriate, and only preliminary trends are presented. Due to the time-consuming nature of this analysis, and the duration of the experiment, it was not possible to process all samples within the timeframe required for the completion of this thesis.

The reverse transcription quantitative polymerase chain reaction (RT-qPCR) was used to compare relative expression levels of messenger RNA (mRNA) of the HSP70 gene to mRNA levels of $\beta$-actin, an internal reference gene. $\beta$-actin was used as a 'housekeeping' gene as it is expressed consistently in L. elliptica tissue and has been successfully used before as a reference gene in L. elliptica and in qPCR work (Park et al., 2007; Clark et al., 2008a; Cummings et al., 2011). Mantle tissue was selected for analysis as it is the site of highest HSP gene expression and constituent expression of HSP70 in L. elliptica (Clark et al., 2008a), and to allow comparison with the work of Cummings et al. (2011).

Total RNA was extracted from a subsample of mantle (mean wet mass $26.0 \mathrm{~g}$, range 9.1-84.4 g) using Trizol reagent (Invitrogen, Life Technologies, Auckland, New Zealand). The RNA was purified by binding it to a silicate column, then washed with binding buffers and eluted into nuclease-free water (GeneJET RNA Cleanup and Concentration Micro Kit, Thermo Scientific, Auckland, New Zealand). This combined technique of Trizol extraction and silicate column purification has been used before on bivalve tissue and gives high-quality RNA yields (see Mcleod et al. [2009] for a similar protocol). Tissue samples were homogenised in $900 \mu \mathrm{L}$ of Trizol, ensuring Trizol was supersaturated to guarantee full RNA extraction. The aqueous phase containing RNA was isolated by the addition of $0.2 \mu \mathrm{L}$ of chloroform per $1 \mu \mathrm{L}$ Trizol, followed by chilled centrifugation $\left(13,000 \times \mathrm{g}, 4^{\circ} \mathrm{C}, 10 \mathrm{~min}\right)$. The clear aqueous phase was isolated, $0.5 \mu \mathrm{L}$ of $100 \%$ ethanol per $1 \mu \mathrm{L}$ of isolate was added, and the solution was transferred to a RNA Cleanup and Concentration Micro Kit column (GeneJET, Thermo Scientific, Auckland, New Zealand). The RNA was bound to the column and washed as per the manufacturer's instructions, then suspended in $12 \mu \mathrm{L}$ of nuclease-free water. The concentration and 
quality of extracted RNA was spectrophotometrically assessed, with total RNA concentration measured at $260 \mathrm{~nm}$ and RNA purity assessed with the $A 260 / A 280$ ratio. The extracted RNA was then frozen at $-20^{\circ} \mathrm{C}$ until cDNA synthesis.

Immediately prior to cDNA synthesis, RNA was cleaned of genomic DNA contamination with Deoxyribonuclease I as per the manufacturer's instructions (Thermo Scientific, Auckland, New Zealand). cDNA was synthesised from $1 \mu \mathrm{g}$ RNA in a final volume of 20 $\mu \mathrm{L}$ using random hexamers and oligo $(\mathrm{dT})_{18}$ as in the Maxima First Strand cDNA Synthesis Kit for RT-qPCR (Thermo Scientific, Auckland, New Zealand). Samples were incubated at $25^{\circ} \mathrm{C}$ for $10 \mathrm{~min}$, then at $50^{\circ} \mathrm{C}$ for $15 \mathrm{~min}$, and terminated by heating to $85^{\circ} \mathrm{C}$ for $5 \mathrm{~min}$. cDNA was stored at $-20^{\circ} \mathrm{C}$ until the PCR step.

PCR reactions for each target gene (HSP70 and $\beta$-actin) consisted of $1 \mu \mathrm{L}$ cDNA, $2 \mu \mathrm{L}$ $0.25 \mu \mathrm{M}$ gene-specific primers, $9.5 \mu \mathrm{L}$ nuclease-free water, and $12.5 \mu \mathrm{L}$ SensiMix SYBR \& Fluorescein Kit (BioLine, Total Lab Systems, Auckland, New Zealand) to make a final volume of $25 \mu \mathrm{L}$, and analysed in duplicate. The primers used (Park et al., 2007) are given in Table 3.1. Amplifications were performed and monitored in a Bio Rad CFX 96 Real-Time PCR Machine with the following conditions: initial denaturation and enzyme activation at $95^{\circ} \mathrm{C}$ for $10 \mathrm{~min}$; 40 amplification cycles of $95^{\circ} \mathrm{C}$ for $10 \mathrm{sec}, 53^{\circ} \mathrm{C}$ for $15 \mathrm{sec}$ and $72^{\circ} \mathrm{C}$ for $15 \mathrm{sec}$; followed by a melt curve analysis. Temperatures and primer concentrations were determined from earlier testing, based on those conditions that yielded the lowest cycle threshold $\left(C_{t}\right)$ values and highest efficiencies. Fluorescence levels were recorded (SensiMix contains Sybr Green) as $C_{t}$ values, and relative expression of the HSP70 gene was compared to that of $\beta$-actin for each individual. Results are expressed as the relative $\mathrm{x}$-fold increase of the HSP70 gene relative to $\beta$-actin. 
Table 3.1 - Oligonucleotide primers used for qPCR of genes of interest in Laternula elliptica. Primers developed by Park et al. (2007).

\begin{tabular}{|c|c|c|c|}
\hline Gene & Direction & Primer nucleotide sequence (5'-3') & Amplicon size (bp) \\
\hline \multirow{2}{*}{ HSP70 } & Forward (+) & AGATGAGGCTGTTGCATACG & \multirow{2}{*}{97} \\
\cline { 2 - 3 } & Reverse (-) & GGTGACGTCAAGAAGAAGCA & \multirow{2}{*}{135} \\
\hline \multirow{2}{*}{$\boldsymbol{\beta}$-actin } & Forward (+) & GGTCGTACCACAGGTATTGT & \multirow{2}{*}{} \\
\cline { 2 - 4 } & Reverse $(-)$ & CATCAGGTAGTCGGTCAAAT & \\
\hline
\end{tabular}

HSP70 Genbank accession number: EF198332, $\beta$-actin Genbank accession number: EF198331

\subsection{3 - Statistical analyses}

As $n=1$, only trends in the data and correlations with some of the measures made in Chapter 2 could be examined, and only preliminary trends are presented. The relationships between HSP70 gene expression at both $5 \mathrm{wk}$ and 5 mo and a) physiological condition ( $\mathrm{CI}_{\mathrm{FW}: \mathrm{SL}}$ ) and b) $\mathrm{O}_{2}$ consumption determined in Chapter 2 at the same time points, were investigated with Spearman's correlation coefficient. The data did not meet assumptions of homoscedasticity, rendering parametric tests inappropriate. These analyses were conducted with SPSS Version 22, and $\alpha=0.05$ in all cases. 


\section{3 - Results and Discussion}

\subsection{1 - HSP70 expression in Laternula elliptica}

HSP70 was consistently expressed more than $\beta$-actin in all treatments, confirming its importance and deliberate expression in L. elliptica (Fig. 3.2). Preliminary (5 wk) levels of HSP70 gene expression were similar between ambient and mid-range $\mathrm{pH}(\mathrm{pH} 8.00$ and 7.85, respectively) at both ambient and mid-range temperatures $\left(-1.4\right.$ and $\left.-0.5^{\circ} \mathrm{C}\right)$. However pH 7.65 produced a $\sim 10$-fold increase at both $-1.4^{\circ} \mathrm{C}$ and $-0.5^{\circ} \mathrm{C}$ relative to ambient pH (15-16x the internal reference gene; Fig. 3.2a). An effect of pH on HSP70 gene expression was still present at $+0.5^{\circ} \mathrm{C}$, but at this temperature, $\mathrm{pH} 7.85$ stimulated the greatest expression, with pH 8.00 and 7.65 having lower levels. Similar levels of HSP70 gene expression relative to $\beta$-actin were found after $48 \mathrm{~h}$ at $+10^{\circ} \mathrm{C}$ in L. elliptica (i.e., between 1.9 and 3.6-fold; Park et al. [2007]) as were found here with increased temperature $\left(-0.5\right.$ and $\left.+0.5^{\circ} \mathrm{C}\right)$ and at $\mathrm{pH} 8.00$ and 7.85 , but the magnitude of upregulation at $\mathrm{pH} 7.65$ and $+0.5^{\circ} \mathrm{C} / \mathrm{pH} 7.85$ in this study was considerably greater.

At $5 \mathrm{mo}$, the magnitude of the up-regulation of HSP70 gene expression levels in the lowest $\mathrm{pH}$ treatment had decreased (Fig. 3.2b), especially at elevated temperatures (-0.5 and $+0.5^{\circ} \mathrm{C}$; Fig. $3.2 \mathrm{~b}, \mathrm{c}$ ). This may have occurred to save energy and resources at the cellular level. Over time, HSP70 gene expression appeared to reduce in most treatments (except for the control $\left[-1.4^{\circ} \mathrm{C} / \mathrm{pH} 8.00\right],-1.4^{\circ} \mathrm{C} / \mathrm{pH} 7.85$, and $-0.5^{\circ} \mathrm{C} / \mathrm{pH} 7.85$; Fig. $3.3 \mathrm{~b}, \mathrm{c})$. Consequently these results suggest that after several months at one or two degrees above summer ambient conditions, L. elliptica adults may have a reduced heat shock response. Similarly, reduced pH (pH 7.65) initially stimulated increased HSP70 gene expression levels, but this appears to have been downgraded over time. 


\section{a) $5 \mathrm{wk}$}

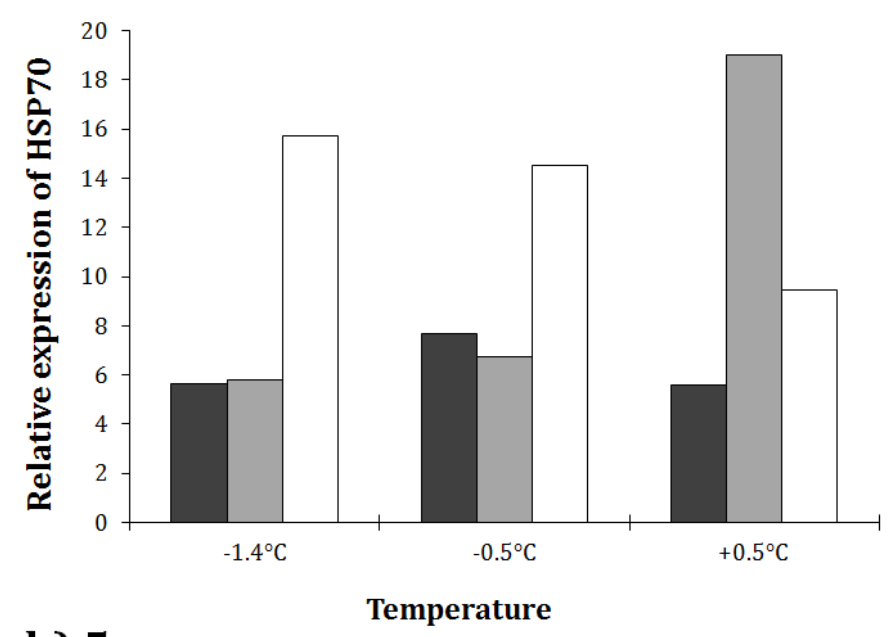

\section{b) 5 mo}

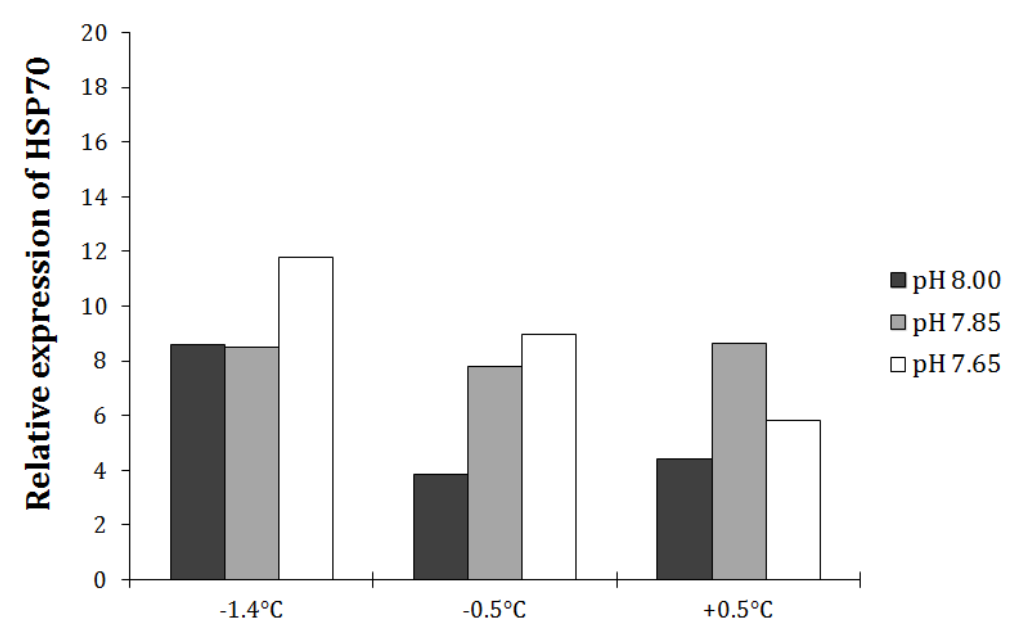

\section{c) Change between $5 \mathrm{wk}$ and $5 \mathrm{mo}$}

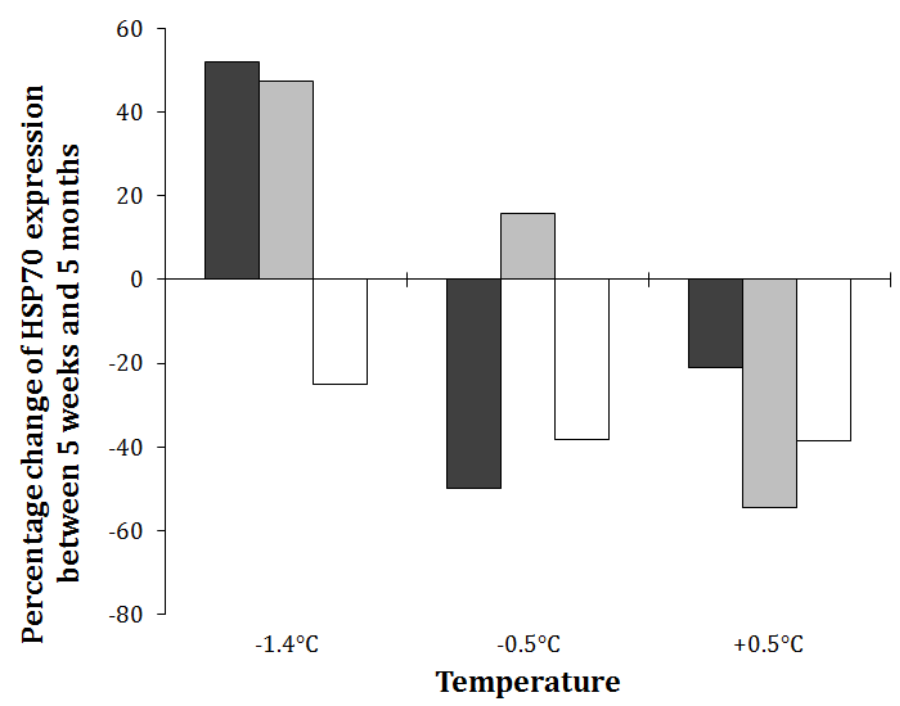

Figure 3.2 - HSP70 expression in Laternula elliptica. HSP70 gene expression levels are expressed as X fold induction relative to $\beta$-actin: a) after $5 \mathrm{wk}$ at experimental conditions; b) after $5 \mathrm{mo}$ at experimental conditions; and c) percentage change at 5 mo relative to $5 \mathrm{wk} ; \mathrm{n}=1$. 
Cummings et al. (2011) found an increase in HSP70 gene expression in L. elliptica with both an increase and decrease in $\mathrm{pH}$ (pH 7.78 and 8.30, relative to ambient $\mathrm{pH}$ of 7.99) at ambient temperatures after $3 \mathrm{wk}$. While smaller in magnitude ( 0.6-1.6-fold) than the up-regulation in HSP70 gene expression levels found in this study after 5 wk (5.619.0-fold; Fig. 3.2a), both of these studies suggest that HSP70 gene expression levels are up-regulated in adult L. elliptica in response to a change in $\mathrm{pH}$. This thesis work extends this understanding to longer timescales, and indicates that although this initial $\mathrm{pH}$ related heat shock response persists over longer time periods, it may be subsequently downgraded (i.e., between $5 \mathrm{wk}$ and $5 \mathrm{mo}$ ). Whether this is beneficial or not remains to be seen, considering HSPs can be either beneficial or detrimental to overall fitness (Feder \& Hofmann, 1999).

There was very little effect of temperature elevation on HSP70 gene expression at ambient $\mathrm{pH}$ (8.00); expression patterns with $1^{\circ} \mathrm{C}$ warming were the same as at ambient temperature, and at $2^{\circ} \mathrm{C}$ warming there was still little difference at 5 wk (Fig. 3.2a,b). It is interesting in this case to note the seeming lack of a classical heat shock response (i.e., up-regulation of HSP70 gene expression as a result of temperature increase). Stenothermal Antarctic bivalves live close to their thermal limits, and despite the fact that their low-energy lifestyle and temperature limitation might be expected to contribute to a lack of heat shock response, adult L. elliptica have previously induced HSP70 production under higher magnitude thermal stress (i.e., increases to $+10^{\circ} \mathrm{C}$; Clark et al., 2008a,b; Tomanek, 2010). A lack of heat shock response at ecologically realistic temperatures is suggested by the results of this study. However, a larger sample size is needed to confirm whether this is the case.

At $5 \mathrm{mo}$, control animals up-regulated HSP70 gene expression levels relative to levels at $5 \mathrm{wk}$ by $48-52 \%$ at ambient and $7.85 \mathrm{pH}$, and up-regulation was also noted in the $-1.4^{\circ} \mathrm{C} / \mathrm{pH} 7.85$ treatment (by $47 \%$ ), and in the $-0.5^{\circ} \mathrm{C} / \mathrm{pH} 7.85$ treatment (by $16 \%$; Fig. 3.2c). However in all other treatments, HSP70 gene expression levels were 21-55\% lower than at $5 \mathrm{wk}$ (Fig. 3.2c). Previous studies have demonstrated that HSP70 gene expression is rapidly up-regulated, but also swiftly down-regulated, both over week- 
long timescales and even in a matter of hours. This has been observed in response to $+10^{\circ} \mathrm{C}$ thermal shock in L. elliptica (Park et al., 2007) and $+3^{\circ} \mathrm{C}$ warming at both ambient and reduced pH (8.10 and 7.70, respectively) in the oyster Pinctada fucata (Liu et al., 2012). At $+10^{\circ} \mathrm{C}$, a similar response was also observed for gene expression levels of HSP90, a longer form of HSP, in L. elliptica (Kim et al., 2009).

It is likely advantageous for animals to down-regulate the heat shock response when conditions are not stressful, and a compromise of intermediate HSP gene expression is usually evolutionarily favourable (Feder \& Hofmann, 1999; Tomanek, 2010). As individuals were experiencing the same conditions (and stresses) at 5 mo as those that had stimulated up-regulation of HSP70 after $5 \mathrm{wk}$ in the same treatments, the lesser response observed here after 5 mo may instead be a result of phenological plasticity and successful acclimation to conditions. Comparatively, sea urchin (Psammechinus miliaris and Sterechinus neumayeri) adults acclimated to reduced $\mathrm{pH}(\mathrm{pH}$ 7.70) conditions after > $6 \mathrm{wk}$ (Suckling et al., 2014, 2015). Alternatively, it may be an acquiescence to the energetic costs of maintaining increased HSP70 induction. Individuals still experiencing reduced $\mathrm{pH}$ and elevated temperature may have downregulated HSP70 gene expression, sacrificing cellular protection, to maintain their basal energetic output. This may have occurred to save energy and resources at the cellular level. The energy may have been diverted to other aspects of the heat shock response that were not measured here; for a discussion of other genes activated by heat shock in L. elliptica, see Truebano et al. (2010).

Considering that their function is to stabilise and refold proteins that are degraded by stressors such as heat, and that they must be able to withstand heat stress to do this, HSP70 proteins are likely very stable and persist in the cell for some time after their synthesis. Similarly, small (20-30 kDa) HSPs in Toxoplasma gondii are thermally stable up to high temperatures (between 45 and $73^{\circ} \mathrm{C}$ ) (de Miguel et al., 2009). In prokaryotes and eukaryotes, pre-exposure to an oxidative stress conveys resistance to subsequent exposure to lethal levels of that stress (or another kind of stress, such as heat) (Crawford \& Davies, 1994). This process, 'adaptive response', indicates that the persistence of protective proteins, that accumulated in response to an initial stress, provides the ability to survive a second instance of stress (Crawford \& Davies, 1994). A 
similar concept, 'adaptive thermotolerance', has been observed in mammalian cells, involving the induction of a $72 \mathrm{kDa}$ HSP after pre-exposure to thermal stress (Mizzen \& Welch, 1988). Once formed, the persistence of HSPs in a cell would be consistent with an adaptive thermotolerance response, and convey protection over time.

Consequently, once a cell has induced HSP70 production long enough for suitable amounts of these proteins to accumulate within the cell, it would be beneficial to switch off HSP70 gene expression to avoid wasting cellular resources. A stenothermal Antarctic ciliate with naturally high levels of HSP70 in its macronucleus did not strongly upregulate HSP70 production with heat shock to $+20^{\circ} \mathrm{C}$, indicating the level of HSP70 already present was sufficient cellular protection against temperature elevation (La Terza et al., 2001). HSP regulation is tightly controlled and its induction can swiftly change after heat stress (Mizzen \& Welch, 1988), including in L. elliptica (Park et al., 2007). Therefore, the down-regulation in HSP70 gene expression levels found here in L. elliptica in some treatments at 5 mo may be a result of the reduced requirement for new HSP70, as cellular protein levels may have remained sufficiently high from the initial up-regulation at $5 \mathrm{wk}$ to combat subsequent cellular stress.

The lowered $\mathrm{pH}$ treatments yielded the greatest up-regulation in HSP70 induction at 5 wk (Fig. 3.2a), and all had relatively reduced HSP70 gene expression levels by 5 mo (Fig. 3.2b). Animals from the $\mathrm{pH} 7.65$ treatments were generally unable to acclimate to reduced $\mathrm{pH}$; their survival dropped particularly rapidly in the weeks before HSP70 was quantified at 5 mo (see Chapter 2). These animals may have suffered from a reduced expression of HSP70 and reduced molecular chaperoning, which would have resulted in proteins denaturing. Alternatively, individuals who continued to maintain high HSP70 gene expression may have been unable to maintain this metabolic demand, and may have died as a result of unsustainable energetic expenditure, leaving only those individuals with comparatively lower HSP70 gene expression. It is therefore useful to examine this hypothesis by evaluating the relationship between HSP70 gene expression levels and both physiological condition and $\mathrm{O}_{2}$ consumption rates presented in Chapter 2. 


\subsection{2 - HSP70 expression, physiological condition, and $\mathrm{O}_{2}$ consumption in}

\section{Laternula elliptica}

The overall relationship between HSP70 gene expression levels and physiological condition was non-significant (Spearman's rho $=0.038, \mathrm{p}=0.880, \mathrm{n}=18$ ), though trends were suggested with pH and physiological condition (i.e., $\mathrm{CI}_{\mathrm{FW}}$ :SL; Fig. 3.3). HSP70 gene expression levels stayed relatively stable and low under ambient $\mathrm{pH}$ conditions, while low pH induced a greater up-regulation of HSP70. Note that $\mathrm{pH} 8.00$ (ambient, circled green in Fig. 3.3) conditions produced lower induction of HSP70 for each animal's $\mathrm{CI}_{\mathrm{FW}: \mathrm{SL}}$ value than reduced $\mathrm{pH}$ and higher temperature treatments (Fig. 3.3, circled orange and dashed-red). This suggests that hypercapnia exacerbates the magnitude and variability of the heat shock response compared to normocapnic animals in the same physiological condition. A positive relationship between levels of HSP70 gene expression and physiological condition is indicated at $-0.5^{\circ} \mathrm{C}$ (triangles), but not at $-1.4^{\circ} \mathrm{C}$ (crosses) and $+0.5^{\circ} \mathrm{C}$ (open circles) (Fig. 3.3). Factor analysis would likely elucidate trends suggested here and confirm whether $\mathrm{pH}$ groupings are significant. Since only one replicate individual per treatment could be analysed, the collection of further HSP70 data from remaining samples, as is currently planned, will clarify these patterns. 


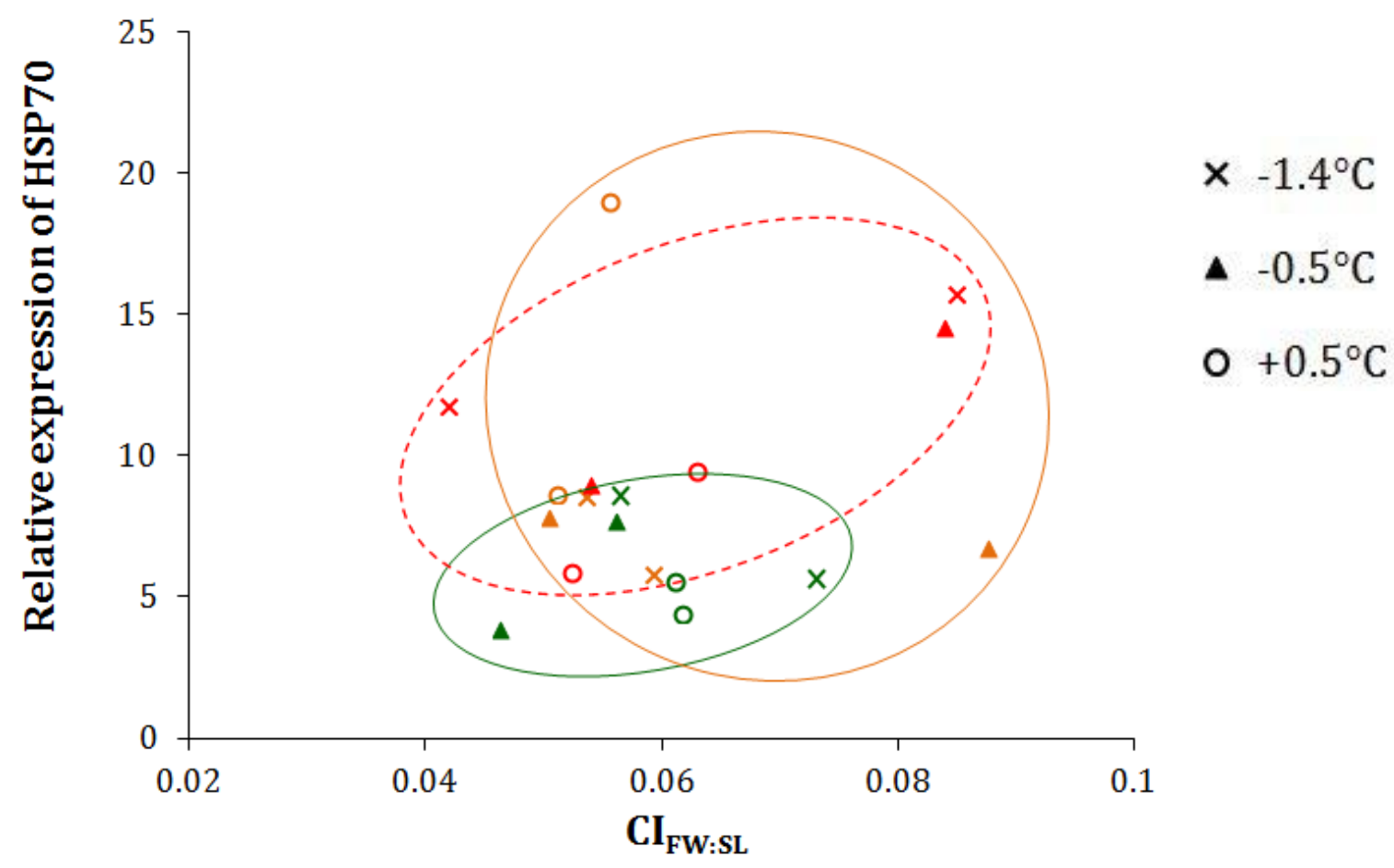

Figure 3.3 - HSP70 expression compared to physiological condition ( $\left.\mathrm{CI}_{\mathrm{FW}: \mathrm{SL}}\right)$ in Laternula elliptica. Data for both time points ( $5 \mathrm{wk}$ and $5 \mathrm{mo}$ ) are presented. Results are grouped by pH: pH 8.00 (green symbols and circle); pH 7.85 (orange symbols and circle), and pH 7.65 (red symbols and dashed red circle). Note the clustered, low HSP70 expression of individuals from ambient pH treatments, and the high, variable range of individuals from the reduced $\mathrm{pH}$ treatments.

Expression of HSP70 was positively correlated with $\mathrm{O}_{2}$ consumption (Spearman's rho = $0.886, \mathrm{p}=0.019, \mathrm{n}=6$; Fig. 3.4). This was largely due to high $\mathrm{O}_{2}$ consumption in one individual exposed to $+0.5^{\circ} \mathrm{C} / \mathrm{pH} 7.85$ (Fig. 3.4). The high individual variability observed in $\mathrm{O}_{2}$ demand with increased temperatures and reduced $\mathrm{pH}$ (see Chapter 2) also influenced the relationship with HSP70 gene expression levels here. The positive relationship between HSP70 gene expression and $\mathrm{O}_{2}$ consumption shows that both processes are increased at the same time by L. elliptica. Consequently, both are regulated by the organism in response to continued exposure to environmental conditions at the outer range of what they usually experience, that are potentially stressful. This indicates that both respiration rate and HSP70 gene expression levels are valuable markers of physiological change in this species. This result also suggests that higher expression of the HSP70 gene increased the energetic costs at the cellular level, with higher respiration rates reflecting increased metabolic cost of exposure to these 
conditions at the whole-organism level. Despite the small sample size, the correlation between $\mathrm{HSP70}$ expression and $\mathrm{O}_{2}$ consumption was significant, and additional work could potentially confirm this relationship.

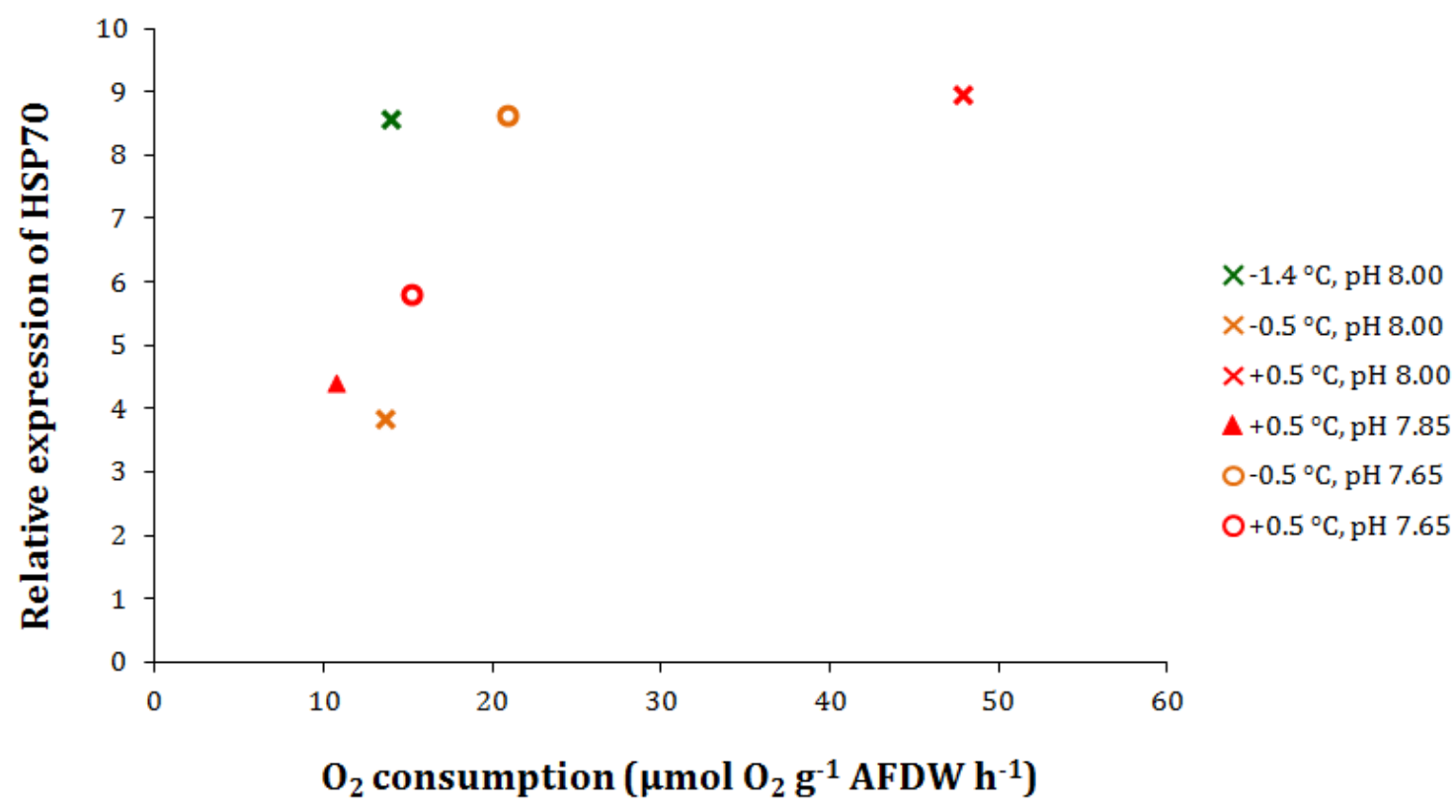

Figure 3.4 - HSP70 expression compared to $\mathrm{O}_{2}$ consumption in Laternula elliptica. Data for both time points (5 wk and $5 \mathrm{mo}$ ) are presented. HSP70 production is expressed as x-fold induction relative to $\beta$-actin, and $\mathrm{O}_{2}$ consumption is expressed as $\mu \mathrm{mol} \mathrm{O}_{2} \mathrm{~g}^{-1} \mathrm{AFDW} \mathrm{h}^{-1}$.

\subsection{3 - Preliminary conclusions}

Preliminary trends indicate that, after a short-term (5 wk) exposure to experimental treatments, adult L. elliptica increases HSP70 gene expression levels in response to lowered $\mathrm{pH}$ ( $\mathrm{pH}$ 7.65, -0.35 units below ambient). This up-regulation, while still apparent, was less obvious at 5 mo. In contrast, levels were similar across temperatures at ambient pH after both $5 \mathrm{wk}$ and 5 mo. These results suggest that L. elliptica does not exhibit a heat shock response at temperature increases $\left(1\right.$ and $2{ }^{\circ} \mathrm{C}$ above ambient) predicted for the near future. 
After 5 mo, HSP70 gene expression levels had increased further in the control treatment (by $48-52 \%$ relative to $5 \mathrm{wk}$; Fig. 3.2c), but had declined in the elevated temperature treatments (by 21-55\% relative to $5 \mathrm{wk}$; Fig. 3.2c), particularly at the highest temperature $\left(+0.5^{\circ} \mathrm{C}\right)$. In contrast to the lack of HSP70 response with warming, reduced $\mathrm{pH}$ (7.65) produced an up-regulation of HSP70 gene expression at $5 \mathrm{wk}$ that was less apparent at $5 \mathrm{mo}$, suggesting down-regulation over time with $\mathrm{pH}$. This longer-term response to both elevated temperature and decreased $\mathrm{pH}$ could be a result of acclimation, repression of induction in order to maintain the energy budget, or a result of all higher-expressing individuals dying before sampling. Alternatively, downregulation may occur once sufficient levels of HSP70 have been expressed within the cell. There was a significant positive relationship between $\mathrm{O}_{2}$ demand and levels of HSP70 gene expression, indicating that both are increased by the organism, and that the response at the cellular level may have influenced energetic demand, consequently resulting in the higher respiration rates with higher levels of HSP70 gene expression.

There is insufficient evidence at this time to conclude which of these processes (acclimation, active repression, or die-off) is occurring. Additional work is needed to fully explore the effect of the combination of reduced $\mathrm{pH}$ and elevated temperature on the heat shock response of this stenothermal species. Analysis of the remaining available samples is planned, to enable quantification of the variability and the consistency of the response observed here. HSP70 concentration in these tissues could also be measured directly, to determine whether adaptive thermotolerance is occurring in adult L. elliptica. Both mantle and adductor tissue samples are available for future work on HSP expression in L. elliptica exposed to elevated temperatures and reduced $\mathrm{pH}$. 


\section{Chapter 4}

\section{General overview and conclusions}

\section{1 - Synthesis of findings}

Anthropogenic ocean warming and acidification are currently changing the temperature and chemistry of the oceans at an unprecedented pace, particularly the Southern Ocean. To address the effect that these processes will have on a vulnerable, common Antarctic bivalve in the near future, the response of the infaunal bivalve Laternula elliptica was investigated under elevated temperature and reduced $\mathrm{pH}$. In Chapter 2, the survival and function of adult L. elliptica was tested in response to both lowered $\mathrm{pH}$ and elevated temperature over 5 mo (21 wk). Patterns of survival over time, time to $50 \%$ survival ( $\left(D_{50}\right)$, and overall survival at 5 mo were examined. Physical and physiological condition indices were calculated at both $5 \mathrm{wk}$ and $5 \mathrm{mo}$, and $\mathrm{O}_{2}$ consumption was assessed at $20 \mathrm{wk}$. Chapter 3 concerned the development of gene expression protocols for extracting HSP70 mRNA in L. elliptica, and presented preliminary results of HSP70 gene expression levels over time in response to lowered $\mathrm{pH}$ and elevated temperature. The combined results of these chapters are presented in Fig. 4.1.

Temperature elevation significantly affected several aspects of L. elliptica function studied; in fact almost all significant effects were noted at the highest temperature $\left(+0.5^{\circ} \mathrm{C}\right)$ after 5 mo (Fig. 4.1). Increasing the temperature by $\sim 1^{\circ} \mathrm{C}$, to $-0.5^{\circ} \mathrm{C}$, caused a significant decrease in $\mathrm{CI}_{\mathrm{FW}} \mathrm{SL}$. Further warming to $+0.5^{\circ} \mathrm{C}$ resulted in a significant decline in both $\mathrm{CI}_{\mathrm{FW}: \mathrm{SL}}$ and $\mathrm{CI}_{\mathrm{FW}} \mathrm{SW}$. In addition, the odds of dying were significantly and severely affected at the high-temperature treatment, with an almost 8-fold increase in the odds of dying observed when the temperature was raised from ambient to $+0.5^{\circ} \mathrm{C}$. Mortalities were noted earlier, and while not significant, survival was lower at the conclusion of the experiment at $+0.5^{\circ} \mathrm{C}$ than at ambient $\left(-1.4^{\circ} \mathrm{C}\right)$. A similar pattern was evident at each $\mathrm{pH}$ when pooled by temperature, and was likely influenced by the effect of the $+0.5^{\circ} \mathrm{C}$ treatment on mortalities. Temperature increase did not appear to affect 
HSP70 production at either 5 wk or 5 mo. $\mathrm{CI}_{\mathrm{FW}} \mathrm{SL}$ was negatively correlated with $\mathrm{O}_{2}$ consumption. In contrast, reduction in $\mathrm{pH}$ had no significant effect on any of the variables measured, although there are indications of influences on HSP70 gene expression levels that require further analyses. HSP70 gene expression levels were highest at $\mathrm{pH} 7.65$ at both -1.4 and $-0.5^{\circ} \mathrm{C}$ at $5 \mathrm{wk}$, yet this up-regulation pattern was reduced by 5 mo. While decreases in $\mathrm{pH}$ appeared to increase overall survival and $\mathrm{LD}_{50}$, increase $\mathrm{O}_{2}$ consumption and variability, and exacerbate the degree by which $\mathrm{O}_{2}$ consumption increased with reduced physiological condition, statistical analyses were unable to identify any differences. Overall, there was ultimately no significant interaction between temperature and $\mathrm{pH}$ for any of the variables measured. 
Temperature $\left({ }^{\circ} \mathrm{C}\right)$

Increasing severity of stressor

\begin{tabular}{|c|c|c|c|c|c|c|}
\hline & \multicolumn{2}{|c|}{ Ambient (-1.4) } & \multicolumn{2}{|c|}{ Med $(-0.5)$} & \multicolumn{2}{|c|}{ High (+0.5) } \\
\hline & 5 wk & $5 \mathrm{mo}$ & $5 \mathrm{wk}$ & $5 \mathrm{mo}$ & $5 \mathrm{wk}$ & $5 \mathrm{mo}$ \\
\hline $\begin{array}{c}\text { Ambient } \\
(8.00)\end{array}$ & & $\downarrow$ survival & & $\begin{array}{c}\downarrow \text { survival } \\
\downarrow \downarrow \text { flesh weight } \\
\\
\uparrow \mathrm{O}_{2} \text { demand } \\
\uparrow \begin{array}{c}\text { variability of } \mathrm{O}_{2} \\
\text { demand }\end{array} \\
\end{array}$ & $\downarrow \downarrow$ survival & $\begin{array}{c}\downarrow \downarrow \downarrow \text { survival } \\
\downarrow \downarrow \text { flesh weight }{ }^{2} \\
\uparrow \uparrow \text { odds of dying }\end{array}$ \\
\hline $\begin{array}{c}\text { Med } \\
(7.85)\end{array}$ & & $\uparrow$ survival & & $\begin{array}{c}\uparrow \text { survival } \\
\downarrow \downarrow \text { flesh weight }{ }^{1}\end{array}$ & & $\begin{array}{c}\uparrow \text { survival } \\
\downarrow \downarrow \text { flesh weight }^{2} \\
\uparrow \mathrm{O}_{2} \text { demand } \\
\uparrow \text { variability of } \mathrm{O}_{2} \\
\uparrow \uparrow \text { odds of dying }\end{array}$ \\
\hline $\begin{array}{c}\text { Low } \\
(7.65)\end{array}$ & $\downarrow$ survival & $\begin{array}{c}\downarrow \downarrow \text { survival } \\
\\
\uparrow \text { HSP70 } \\
\uparrow \mathrm{O}_{2} \text { demand } \\
\uparrow \text { variability of } \\
\mathrm{O}_{2} \text { demand }\end{array}$ & $\uparrow \uparrow$ HSP70 & $\begin{array}{c}\downarrow \text { survival } \\
\downarrow \downarrow \text { flesh weight }{ }^{1} \\
\uparrow \text { HSP70 } \\
\uparrow \mathrm{O}_{2} \text { demand } \\
\uparrow \text { variability of } \mathrm{O}_{2} \\
\text { demand }\end{array}$ & & $\begin{array}{c}\downarrow \downarrow \downarrow \text { survival } \\
\text { (sudden decline) } \\
\downarrow \downarrow \text { flesh weight }{ }^{2} \\
\uparrow \uparrow \text { odds of dying }\end{array}$ \\
\hline
\end{tabular}

Figure 4.1 - Synthesis of the main responses of Laternula elliptica exposed to elevated temperature and decreased pH at both 5 wk and 5 mo. Statistically significant results $(\mathrm{p}<0.05)$ are bolded. The number of arrows indicates the relative magnitude of the response: one = small; two = medium; three = large. "Flesh weight ${ }^{1 "}=$ ratio of flesh weight to shell length $\left(\mathrm{CI}_{\mathrm{FW}: \mathrm{SL}}\right)$. "Flesh weight ${ }^{2}$ " $=$ both $\mathrm{CI}_{\mathrm{FW}: \mathrm{SL}}$ and the ratio of flesh weight to shell weight $\left(\mathrm{CI}_{\mathrm{FW}} \mathrm{SW}\right)$. HSP70 = heat shock protein 70.

HSP70 expression patterns less clear after 5 mo. However, changes in physiological condition were apparent by $5 \mathrm{mo}$. At $+0.5^{\circ} \mathrm{C}$, L. elliptica adults exhibited a significant loss in physiological condition relative to individuals at ambient temperature, losing body mass relative to both shell length and shell weight at $5 \mathrm{mo}$. The loss of tissue mass is a strong indication that individuals were stressed, with adults likely utilising 
resources such as their own proteins to maintain increased metabolic demand (Ahn et al., 2003). This loss in condition affected $\mathrm{O}_{2}$ consumption, with individuals of lower condition exhibiting not only significantly increased respiration rates, but also an increase in the variability of these rates. High individual variability indicates that some individuals were coping with experimental conditions and had $\mathrm{O}_{2}$ consumption rates on par with control animals, while others were not, and were significantly elevating their $\mathrm{O}_{2}$ consumption. This increased respiratory demand may be in part to synthesise new tissue to replace lost body mass (Clarke, 1987). It may also be a result of an increased level of protein synthesis, as preliminary trends indicate that HSP70 gene expression levels increased in conjunction with increased respiration rates. The loss of body mass is a clear negative response to the stress of treatment conditions. This has negative implications for the long-term survival of L. elliptica adults, especially over winter, when resources are limited. An increase in metabolic demand could increase physiological condition loss over this period, contributing to reduced reproductive output and reduced population size (Guy et al., 2014).

$\mathrm{A} \sim 2^{\circ} \mathrm{C}$ rise in temperature was enough to seriously affect $L$. elliptica function, with potential consequences for survival of the population. In the SO, $\mathrm{pH}$ lowering and aragonite undersaturation are expected first over winter as early as 2035, and the strongest warming will also happen in winter (Feely et al., 2004; Orr et al., 2005; McNeill \& Matear, 2008; Mattsdotter Björk et al., 2014). Aragonite saturation states are already at their lowest in winter at Cape Evans (Kapsenberg et al., 2015). What does this mean for L. elliptica in the future living in a warming and acidifying ocean? L. elliptica is presumably at its most vulnerable in winter, when it must reduce periods of active respiration to reduce energy expenditure, down-regulate metabolic activity, and subsist on muscle proteins (Brockington, 2001; Ahn et al., 2003; Morley et al., 2007). Ahn et al. (2003) found that L. elliptica decreased body mass by $\sim 24 \%$ over winter. This is comparable in magnitude to the body mass decreases relative to shell length reported here over 4 mo (between $5 \mathrm{wk}$ and $5 \mathrm{mo}$ ) while well-fed under experimental conditions; though Brockington (2001) found no such loss. These results indicate that, under future conditions, L. elliptica will have to survive increased metabolic demand and loss of physiological condition in addition to other stresses. 
The exact physiological mechanisms underlying the loss of condition in L. elliptica found here are unknown. However, the loss in physiological condition and reduced survival exhibited here by L. elliptica in response to small amounts of warming are consistent with the observations of Beukema et al. (2009) of reduced body mass and survival in the tellinid bivalve Macoma balthica in warmer-than-average years in the Wadden Sea. As with L. elliptica, in order to survive months of harsh conditions with limited resources, $M$. balthica relies on growth during periods of food availability over spring and summer and metabolic suppression over winter. The significant loss in body mass observed here in L. elliptica at increased temperature is likely a result of its inability to depress energy usage, resulting in reduced body mass. This may convey a reduced ability to successfully over-winter, or to successfully reproduce come spring, as proposed by Beukema et al. (2009). This is further supported by the negative correlation between physiological condition and $\mathrm{O}_{2}$ consumption observed here in animals exposed to temperatures both +1 and $+2^{\circ} \mathrm{C}$ above ambient. The reduced survival of L. elliptica in treatments that also produced condition loss indicates that the loss of physiological condition is associated with an increase in mortalities. Consequently, it is very likely that in conditions of environmental stress (e.g., winter), L. elliptica would continue to lose body weight relative to shell length, continue to respire more intensely, and ultimately suffer the consequences of reduced physiological condition, such as an inability to ripen gonads for spawning in summer (Kang et al., 2009).

Although temperature stress is known to affect L. elliptica (Peck et al., 2002, 2004), the magnitude of the response (i.e., survival, $\mathrm{LD}_{50}$, respiratory demand, and the maintenance of body mass) to the relatively small temperature increase investigated here was considerable over 5 mo. This confirms the importance of conducting longerterm studies. These negative impacts occurred at lower levels of warming than are typically considered acutely stressful for L. elliptica (Peck et al., 2002; Peck, 2005a,b; Morley et al., 2009; Morley et al., 2012a), indicating that thermal limits for successful long-term maintenance are narrower than those of short-term tolerance in this species (Pörtner, 2010; Alcaraz et al., 2014), at least over a 5 mo period. Future predictions of population success (such as Guy et al. [2014]) should consider that L. elliptica may exhibit significant reductions in survival at lower temperatures than previously 
thought. These results are consistent with the prediction that $\mathrm{a}+1^{\circ} \mathrm{C}$ increase in sea temperature may cause significant loss of biological function in many Antarctic marine species, and $\mathrm{a}+2^{\circ} \mathrm{C}$ warming has the potential to cause many populations to reduce or vanish altogether (Peck et al., 2004). While L. elliptica adults appeared unable to maintain their energy demand over 5 mo timescales, urchin Sterechinus neumayeri adults successfully acclimated to the combined effects of elevated temperature and reduced pH over 6-9 mo timescales (Suckling et al., 2015). This may be expected considering the respective susceptibility of these taxa; survival and calcification are more negatively impacted by acidification in molluscs than in echinoderms (Kroeker et al., 2013).

L. elliptica maintained shell condition, with no change in shell weight relative to length of shells over the experiment. Considering that empty L. elliptica valves rapidly begin to dissolve under reduced pH (McClintock et al., 2009), and that chitin synthase, an enzyme crucial to bivalve biomineralisation, is up-regulated in response to $\mathrm{pH}$ decrease in live L. elliptica (Cummings et al., 2011), this indicates that L. elliptica adults were able to successfully calcify enough to keep shells at a stable weight in this experiment. While calcification is generally more difficult under acidified conditions (but see Roleda et al. [2012]), responses are species-specific (Ries et al., 2009; Hendriks et al., 2010; Kroeker et al., 2013). Decreased pH combined with elevated temperature can change the structure of calcified shells, with the mussel Mytilus edulis producing softer, less stiff aragonite under these conditions (Fitzer et al., 2014). As L. elliptica already has a thin, brittle shell, if a structural change of this kind were to occur with warming and acidification, it could increase its vulnerability to damage from iceberg scour or other disturbance. Other calcifying species have also exhibited stable $\mathrm{CaCO}_{3}$ structures with reduced $\mathrm{pH}$. Sea urchin $\mathrm{CaCO}_{3}$ structures were not affected by low pH while supersaturated $\left(\Omega_{\mathrm{Ar}}=1.60\right.$; Hazan et al. [2014]), and at pH $7.7\left(\Omega_{\mathrm{Ar}}\right.$ not given) there was no significant dissolution of the dead arms of the burrowing brittle star Amphiura filiformis (Wood et al., 2008); however, the latter experienced dissolution at pH 6.8. L. elliptica was also able to maintain its shell condition with reduced $\mathrm{pH}$, even at the low $\Omega_{\mathrm{Ar}}$ found in both reduced $\mathrm{pH}$ treatments, especially in the lowest-pH treatment. However, this may have come at the cost of tissue loss and an associated decline in physiological condition. 
L. elliptica was not significantly affected by reduced $\mathrm{pH}$ conditions predicted under future OA. Trends apparent with reduced $\mathrm{pH}$ are discussed here, but were ultimately non-significant. Reduced $\mathrm{pH}$ increased $\mathrm{O}_{2}$ consumption. In combination with warming, intermediate $\mathrm{pH}$ decrease slightly improved rates of survival, but increased average $\mathrm{O}_{2}$ demand and the variability of this demand (Figs. 2.13,4.1), as well as exacerbating the effect of physiological condition loss on $\mathrm{O}_{2}$ consumption (Fig. 2.14). Furthermore, reduced $\mathrm{pH}$ appeared to initially induce up-regulation in HSP70 expression at both -1.4 and $-0.5^{\circ} \mathrm{C}$ at $5 \mathrm{wk}$, followed later by an up-regulation of smaller magnitude in these treatments at 5 mo. Down-regulation in levels of HSP70 gene expression was observed in most elevated temperature treatments at 5 mo relative to $5 \mathrm{wk}$. The comparatively minor effect of reduced $\mathrm{pH}$ relative to elevated temperature must be interpreted in the context of the site-specific pH-seascape normally experienced by Cape Evans L. elliptica, which experience rapid increases in $\mathrm{pH}$ (but not decreases) over short time periods in association with spring phytoplankton blooms (Kapsenberg et al., 2015; Schram et al., 2015). Considering the lack of statistically significant functional responses seen here in L. elliptica in response to reduced $\mathrm{pH}$, adults may continue to withstand these seasonal $\mathrm{pH}$ fluctuations in the future.

When interpreted in light of these environmental conditions, the response of L. elliptica to $\mathrm{pH}$ decrease found here suggests a certain ability to cope with future acidification. This supports previous work showing change in basal metabolic function and protein expression with $\mathrm{pH}$ change in this species (Cummings et al., 2011). However, while less striking in magnitude than those associated with warming, the negative effects of $\mathrm{pH}$ decrease still represent a threat to L. elliptica function and survival. Low pH still poses a threat to the functioning of L. elliptica, and reflects a seascape not experienced by these bivalves over evolutionary timescales. As L. elliptica display some site-specificity in temperature acclimation and burial ability (Morley et al., 2012b), it would be beneficial to investigate the effect of ocean warming and acidification on animals from other sites.

Despite their infaunal mode of life, L. elliptica adults are exposed to overlying water conditions as they draw demersal water into their internal spaces through their siphons. Consequently, their internal tissues will still be exposed to any future warming 
or acidification of the water column. Animals in this experiment experienced artificial laboratory conditions, such as a lack of sediment in tanks. As a consequence, their entire outer surface was exposed to experimental conditions. This may have artificially changed the magnitude of the observed response, considering sediment $\mathrm{pH}$ is often considerably lower than that of the water column (Green et al., 2004; Widdicombe \& Spicer, 2008; Wood et al., 2008). Despite this, the impact of $\mathrm{pH}$ on the condition and functioning of L. elliptica was considerably smaller than that of temperature, with most effects of hypercapnia visible as trends that were biologically relevant, yet small in magnitude. L. elliptica's apparent higher tolerance to hypercapnia is possibly due to this reduced $\mathrm{pH}$ of the infaunal sediment environment relative to overlying water conditions (Green et al., 2004; Widdicombe \& Spicer, 2008; Wood et al., 2008), thus supporting the theory in Widdicombe \& Spicer (2008) of increased resistance by infaunal species. Future studies could bring animals from the field in a core of in situ sediment (Wood et al., 2008), however logistical constraints likely limit this.

The increase in respiration rate of L. elliptica represented increased metabolic demand. The highest respiration rate was expected to occur in the $+0.5^{\circ} \mathrm{C} / \mathrm{pH} 7.65$ treatment, combining the highest temperature and the lowest $\mathrm{pH}$, a pattern observed in the mussel M. galloprovincialis (Chinellato et al., 2010). This was not the case with L. elliptica in this study. While both increased temperature and lowered $\mathrm{pH}$ produced increased $\mathrm{O}_{2}$ consumption rates, combining stressors did not noticeably increase this rate (see next paragraph). The pattern of $\mathrm{O}_{2}$ demand found here fits with the stepwise stress model, where behavioural responses to a stressor are increased until they are unsustainable, at which point the behaviour is rapidly decreased or stopped and survival decreases (Gerhardt et al., 2006; Zhang et al., 2012). High $\mathrm{O}_{2}$ consumption in certain individuals at elevated temperature or reduced $\mathrm{pH}$ was likely a symptom of greatly increased energy requirements under these conditions. Had the experiment continued or the stressor increased in severity, energetic demand, already indicated by the loss of tissue mass, may have become unsustainable, and $\mathrm{O}_{2}$ demand may have crashed, with an associated decrease in survival (but see Suckling et al., 2015). This pattern would be consistent with the peak, then crash and subsequent deaths, seen in L. elliptica respiration and heartbeat rates with stepwise temperature increases beyond the species' tolerance limits (Peck et al., 2002; Peck, 2005a,b). 
L. elliptica in this study, especially those exposed to $+0.5^{\circ} \mathrm{C} / \mathrm{pH} 7.65$, were able to withstand these conditions for a short period of time, but following a $13 \mathrm{wk}$ threshold, they were rapidly and seriously affected, and could no longer maintain themselves under those conditions. Survival dropped precipitously over the following 5 weeks to just $12.5 \%$, the lowest in the study. Individuals with low $\mathrm{O}_{2}$ consumption, found with both elevated temperature and lowered $\mathrm{pH}$, and particularly when these stressors were combined, may have persisted because they were able to maintain a low total $\mathrm{O}_{2}$ consumption rate for their physiological condition, while individuals unable to cope may have all died. This may be an early indication of selection pressure. Interestingly, one individual from the $-1.4^{\circ} \mathrm{C} / \mathrm{pH} 7.65$ treatment assessed for $\mathrm{O}_{2}$ consumption indicated an extremely elevated $\mathrm{O}_{2}$ demand $(20 \times$ that of other animals, even allowing for a considerable margin of error). This individual died several days later and the unrealistic values were excluded from the analyses. This elevated rate, followed days later by the death of the individual, is consistent with the spike then crash in respiration followed by death found in L. elliptica (Peck et al., 2002; Peck, 2005a,b).

A similar pattern is evident in the preliminary results of HSP70 expression. As previously discussed here, $\mathrm{pH}$ decrease to 7.65 at ambient and intermediate temperatures stimulated an up-regulation in HSP70 gene expression. However, at high temperatures, HSP70 expression was similar (and low) at both pH 8.00 and 7.65. Only one individual from the $+0.5^{\circ} \mathrm{C} / \mathrm{pH} 7.65$ treatment survived to the end of the experiment. The $+0.5^{\circ} \mathrm{C} / \mathrm{pH} 8.00$ was also a high-mortality treatment, with only two animals surviving, and a low level of HSP70 gene expression was measured for these individuals. Therefore the low levels of HSP70 expression measured in the $+0.5^{\circ} \mathrm{C} / \mathrm{pH}$ 8.00 and $+0.5^{\circ} \mathrm{C} / \mathrm{pH} 7.65$ treatments relative to the $+0.5^{\circ} \mathrm{C} / \mathrm{pH} 7.85$ treatment may not be a genuine signal of reduced stress, but instead a sign of selection pressure where stressed individuals who continued to up-regulate their response died, and only those few individuals requiring a small increase in response survived. This artificially low signal may be masking the fact that for L. elliptica, an HSP70 expression rate outside of the norm at high temperatures is potentially lethal. 
As environmental stresses increase, organisms may: a) move to a new site (physical migration); b) modify internal processes to withstand change, either in the short-term or over weeks to months (physiological plasticity); or c) genetically adapt to the conditions (Peck, 2005a; Barnes \& Peck, 2008; Barnes et al., 2009; Peck et al., 2014). L. elliptica, as a sessile, deep-burrowing organism (Ahn, 1993), has little ability to physically migrate elsewhere in the SO. Additionally, the coastline of Antarctica offers a limited latitudinal range, so opportunities for migration to avoid predicted changes in ocean pH and temperature are few (Peck, 2005a; Barnes et al., 2009). L. elliptica is a long-lived species with long generation times; rebuilding gonads post-spawning takes at least $12 \mathrm{mo}$, and juveniles take 3 y to reach reproductive size (Kang et al., 2009; Ahn et al., 2001; Peck, 2005a,b; Guy et al., 2014). Therefore any genetic adaptation would take time to propagate through the population (Peck, 2005). L. elliptica has encapsulated lecithotrophic larvae that are dispersed on or near the benthos (Pearse et al., 1986; Berkman et al., 1991; Kang et al., 2009). Depending on local water currents, the dispersal of genetic material may be restricted to the vicinity of the parent population, further slowing allele transfer between populations. Successful genetic adaptation is also complicated by a lack of physiological plasticity, which affects the ability of adults to survive long enough to reproduce. L. elliptica adults could not acclimate to experimentally elevated temperatures here, as even a $+1^{\circ} \mathrm{C}$ temperature change resulted in a significant loss of body mass after 5 mo, along with increased respiratory demand and decreased survival. A similar physiological inflexibility with temperature increase has been noted in this species, and this is true for Antarctic marine invertebrates in general (Peck et al., 2002, 2014). As a cold-adapted species with a narrow thermal window and a long generation time, L. elliptica will likely be negatively affected by climate change and OA (Pörtner et al., 2007; Pörtner \& Farrell, 2008). 


\section{2 - Future directions}

This research concerned the effect of elevated temperature and lowered $\mathrm{pH}$, conditions that are predicted to occur in the Ross Sea in the near future, on the metabolism, survival, condition, and heat shock response of adult L. elliptica. In doing so it filled a key knowledge gap pertaining to infaunal benthic molluscs in the evolutionarily interesting SO ecosystem. Understanding the response of benthic species such as L. elliptica is important because the seafloor hosts many marine species, and any decrease in biodiversity could affect key ecosystem services such as nutrient cycling, especially in disproportionately productive shelf environments (Widdicombe \& Spicer, 2008). The response of L. elliptica in particular to $O A$ and warming, such as potential reductions of growth, respiration, metabolic rate and calcification, is of interest as this species plays an important role in bentho-pelagic coupling in shallow Antarctic coastal environments (Widdicombe \& Spicer, 2008; Ahn, 1993; Clark et al,, 2010). Over the course of this research, further questions arose that may provide direction for future research into SO OA and warming.

In L. elliptica, adults are particularly vulnerable to ocean warming, less so to low $\mathrm{pH}$ (Peck et al., 2002, 2004; Peck, 2005a,b; this study). Understanding the response of juveniles forms an important complement to that of larvae and adults, informing understanding of the effect of ocean warming and acidification on the entire life cycle. Larvae are expected to be the most vulnerable bivalve life stage under OA, especially when forming shells (Kroeker et al., 2013; Parker et al., 2013). In some cases juveniles are more resistant to warming than adults (Beukema et al., 2009), including in $L$. elliptica (Peck et al., 2013). The response of juvenile L. elliptica to ocean warming and acidification is at present poorly understood. This needs to be explored further, as early and mid-life stages are vital for the persistence of populations in L. elliptica (Guy et al., 2014). Environmental stressors that severely affect juveniles affect the proportion surviving to reproductive size, and the time to reproduction, with consequences for the biomass and size of L. elliptica populations in the future (Guy et al., 2014). Stresses that particularly threaten pre-reproductive-age L. elliptica could create a bottle-neck, further reducing numbers of viable adults (Wicks \& Roberts, 2012). 
The L. elliptica used in this study were large and in good condition at the beginning of the experiment. They demonstrated a significant and considerable loss of physiological condition, with a $\sim 30 \%$ decrease in tissue weight relative to both shell weight and shell length. Might younger or smaller individuals, or those in poorer condition, fare even worse in a future ocean? In fact, larger L. elliptica utilise comparatively greater amounts of protein to fuel metabolism than smaller individuals (Brockington, 2001), so smaller animals may lose a lower proportion of tissue under thermal stress, and actually do better than larger individuals. Larger animals are also more affected by thermal extremes, and larger L. elliptica are less able to re-bury themselves following temperature stress (Peck, 2005a; Pörtner, 2008). Smaller animals provide comparatively greater biodeposition rates than larger individuals (Ahn, 1993), indicating the ecological value of their persistence. Smaller individuals may be selected for under future OA and warming, provided they have wider thermal windows (Pörtner, 2008), but this should be examined further in stenothermal L. elliptica. Increased basal metabolic demands may necessitate the sacrifice of energy usually used for growth, potentially resulting in slower growth, smaller overall sizes, and a delay in the onset of reproduction, which occurs at $\sim 40 \mathrm{~mm}$ SL in L. elliptica (Ahn et al., 2001). Juveniles are considered to be more vulnerable to environmental stressors than adults (Parker et al., 2013). Juveniles' smaller size could be disadvantageous, creating comparatively higher energetic demand, especially when considering their faster growth rate. Juveniles reach $60 \mathrm{~mm}$ SL in 4-5 y, while it takes another $\sim 15-20$ y for adults to reach $\sim 100 \mathrm{~mm}$ SL (Ahn et al., 2001; Guy et al., 2014). Husmann et al. (2012, 2014) classified young and old L. elliptica by SL ( $<50 \mathrm{~mm}$ and $>70 \mathrm{~mm}$, respectively), while Peck et al. (2013) used juveniles of SL $<20 \mathrm{~mm}$. Similar differentiations between juvenile and mature animals could apply to future work.

The improved resistance to increased temperature in smaller individuals, if present, may come at the cost of growth rates and future productivity. There is considerable ecological value in including studying the response of L. elliptica to ocean acidification and warming both before and after gamete production; i.e., pre-reproductive vs. mature reproductive individuals. Gamete production is a large drain on bivalve resources; survival in acidified conditions decreased noticeably post-spawning in juveniles of the 
clam Ruditapes decussatus, associated with the increased energy demanded by this process (Range et al., 2011). Almost all animals in the present study had very large gonads, taking up a large part of their body (Fig. 3.1), and animals spawned throughout the experiment. Keeping these large organs functional is a drain on resources, particularly for high-latitude organisms (Clarke, 1987). However, pre-reproductive age juveniles that have not yet formed gonads may have more energy available to divert to metabolic functions, and resist the negative influence of $\mathrm{OA}$ and warming that way. The energy used for reproduction, usually a consistent proportion of total energy budget, could fully be diverted to growth (Clarke, 1987; Wicks \& Roberts, 2012). However, the stresses of ocean warming and acidification could still affect these juveniles.

The animals in this study were well-fed and upon dissection had consistently large, full stomachs, indicating that they were receiving sufficient food. What happens when food supply is limited? Incorporating food availability into future OA and climate change research would be an interesting addition. After initial feeding was stopped in sea urchin larvae, metabolic rates increased in response to acidification (Pan et al., 2015). The ability of molluscs to withstand and adapt to the physiological stresses of future ocean changes is likely dependent on food availability; when food is low, they must use internal energy reserves to compensate, or else repress metabolism to prolong survival (Parker et al., 2013). Low food concentrations and reduced $\mathrm{pH}$ conditions lowered physical condition in several bivalve species, with shells reaching shorter lengths and losing internal mass in individuals with low physiological condition (Gazeau et al., 2013). Physiological condition clearly affects the ability of bivalves to maintain their condition in the face of $\mathrm{OA}$, with starved organisms unable to compensate (Gazeau et al., 2013). Feeding bivalve larvae are able to compensate for increased energetic costs of calcification when there is sufficient food available, indicating that reduced calcification is mainly due to reduced scope for growth (Thomsen et al., 2015), and this likely applies to adults as well.

Food availability already strongly constrains the growth and distribution of Antarctic marine species (Chiantore et al., 2002; Thrush et al., 2006); food limitation is also likely to limit their ability to overcome increases in aerobic output with ocean warming and acidification. Daily fluctuations in pH observed under sea-ice at sites like Cape Evans are 
linked to biological processes such as spring phytoplankton blooms (Matson et al., 2014; Kapsenberg et al., 2015; Schram et al., 2015). In the future, pH change and phytoplankton communities will continue to interact, modifying plankton community structure and accentuating or diminishing $\mathrm{pH}$ variability over short timescales. As temperature increases in the ocean, smaller picophytoplanktonic species may become more abundant (Doney et al., 2012). If $\mathrm{C} / \mathrm{N}$ ratios in these organisms increase, there may be a reduction in food quality, with a subsequent reduction in energy available to higher trophic levels (Doney et al., 2009, 2012). Similarly, reductions in sea ice extent due to warming could result in a shift in composition away from diatoms and largecelled species towards smaller phytoplankton (Montes-Hugo et al., 2009). Considering L. elliptica feeds on large diatom species and is most common where diatoms are abundant (Ahn, 1994; Ahn et al., 2001), the likelihood of populations becoming foodlimited in the future is largely dependent on which of these scenarios occur.

Diatom species compositions have changed in response to past climate change (Barnes \& Peck, 2008), so a switch in dominant diatom species in response to future climate change is possible, and may seriously affect L. elliptica unless it can switch prey species to match this change. Effects of food shortages take time to propagate through benthic communities, but would significantly reduce population sizes, with associated demographic changes (Thrush \& Cummings, 2011). Larger L. elliptica would be expected to lose body weight first under energy-limited conditions due to comparatively greater utilisation of protein reserves, and would therefore be expected to suffer negative consequences sooner than smaller animals (Brockington, 2001). Future experiments should consider incorporating food-limited treatments to determine the effect of food stress on the response of L. elliptica to ocean change.

Samples already gathered as part of this research could be analysed in additional ways to enhance current understanding. Firstly, regarding gene expression work, increasing the sample size of the HSP70 gene expression analyses presented here would clarify patterns observed in this preliminary work. Measuring HSP70 concentration levels within the cell would complement gene expression levels and clarify whether HSP70 accumulates and remains in the cell after it is expressed, as discussed in Chapter 3. Further work on HSP70 gene expression in L. elliptica adductor tissue could show 
whether HSP70 expression varies between the two types of tissue. HSP90 expression levels could also be analysed, as the HSP90 gene has been sequenced for L. elliptica (Kim et al., 2009). This would serve as a complement to HSP70 gene expression patterns and assist further exploration of the heat shock response of L. elliptica. Total RNA could also be measured (as described in Cummings et al. [2011]) to indicate whether general protein synthesis is up-regulated within cells in response to reduced $\mathrm{pH}$ and/or elevated temperature. In addition, the shell structure of L. elliptica valves from this study could be examined using scanning electron microscopy, and the calcium content could be analysed. This would identify changes in the shell structure, and provide a more exact measure of net calcification or dissolution. Finally, antioxidant production and calcium signalling in L. elliptica could further indicate functional response to elevated ocean temperatures, as they appear to signify physiological stress under increased temperature (Truebano et al., 2010). While beyond the scope of this thesis, empty valves from animals in this study have been collected, and additional mantle and adductor samples gathered during the course of this experiment are currently stored at $-80^{\circ} \mathrm{C}$ and available for future analyses of this nature.

Future work should incorporate more respiration measurements at several time points throughout in the experiment. This will enable greater temporal resolution in respiration 'snapshots', and may reveal relationships between longer-term $\mathrm{O}_{2}$ demand and survival. Following individuals more closely with repeated monthly assessments of $\mathrm{O}_{2}$ consumption would show any change in $\mathrm{O}_{2}$ demand over time, and would allow individual responses to be linked to that individual's ability to survive the experiment. High inter-individual variability in $\mathrm{O}_{2}$ consumption reduced the clarity and hindered the interpretation of the trends found in this study, and it would be valuable to ascertain whether certain individuals are able to maintain consistently high (or low) $\mathrm{O}_{2}$ consumption rates over time. It would be interesting to explore whether the moribundity of individuals can be predicted from their respiration rate, and how this responds over time to a treatment. Any individuals with consistently high $\mathrm{O}_{2}$ consumption rate are likely using a lot of energy to maintain their metabolic condition, which is likely to be a considerable drain on their resources. Will these individuals lose more condition than an individual with lower $\mathrm{O}_{2}$ demand? Will they then die as a result of this? Conversely, if an individual has a spike in $\mathrm{O}_{2}$ demand over time and then dies, 
that would show how respiration rate is affected by experimental conditions, and how effective an indicator it is of serious organism stress, as in Peck et al. (2002) and Peck (2005a,b). Alternatively, are L. elliptica with reduced $\mathrm{O}_{2}$ demand able to maintain this decreased rate consistently, and is there an energetic and condition loss associated with this metabolic depression? Addressing these questions would inform the understanding of the metabolic demands of L. elliptica with environmental change, and whether maintaining this increased metabolic demand is feasible over longer timeframes.

Ocean warming appears to be a more significant stressor than acidification for L. elliptica. Future studies should reflect this and feature a range of temperatures extending to $+3^{\circ} \mathrm{C}$ or even $+4^{\circ} \mathrm{C}$ warming, to enable more detailed study of the response of L. elliptica to temperature stress. It would also be beneficial to test the response of smaller temperature increases, such as the $+1-2^{\circ} \mathrm{C}$ warming tested here, over longer timescales than $5 \mathrm{mo}$, which has been understudied compared to more acute temperature stress in L. elliptica. The choice of temperatures used should be tailored to the site of origin of L. elliptica. High-latitude Antarctic sites such as Cape Evans are cold and stable year-round, and experimental increases of a few degrees in temperature represent a considerable temperature stress for these animals. Accordingly, for Cape Evans animals, $+2-2.6^{\circ} \mathrm{C}$ increases are suitable as an experimental treatment (Kapsenberg \& Hofmann, 2014; this study). Conversely, animals from the Western Antarctic Peninsula are experiencing the fastest warming in Antarctica and among the most rapid rates warming on the planet (Meredith \& King, 2005; Montes-Hugo et al., 2009), and consequently $\geq 3^{\circ} \mathrm{C}$ experimental warming is appropriate for these animals (Morley et al., 2012a). Environmentally realistic warming should be the dominant focus of future studies on the response of L. elliptica to future environmental change. 


\section{3 - Concluding comments}

Upon exposure to elevated temperature and lowered $\mathrm{pH}$ for $5 \mathrm{mo}$, the dominant Antarctic filter-feeding infaunal bivalve L. elliptica experienced an increase in respiration rate, increased variability of respiration rate, decreased physiological condition, and strong trends of decreased survival at temperatures both +1 and $+2^{\circ} \mathrm{C}$ above ambient temperatures. These results support the prediction of that a $+2^{\circ} \mathrm{C}$ warming of the SO could cause the disappearance of populations and even entire species (Peck et al., 2004).

Adults were able to maintain shell (physical) condition, indicating that mechanisms were in place to compensate for dissolution in undersaturated conditions. The considerable tissue loss relative to shell length and weight (physiological condition) suggests that $L$. elliptica were unable to reduce their energetic expenditure, possibly as a result of maintaining physical condition or up-regulating HSP70 gene expression levels. The increased $\mathrm{O}_{2}$ consumption observed with elevated temperature or lowered $\mathrm{pH}$ was consistent with this hypothesis. This decrease in physiological condition would likely be particularly detrimental over winter, exacerbating previously observed physiological condition loss due to food limitation (Ahn et al., 2003), and would presumably be difficult for L. elliptica to sustain for extended periods of time.

Lowered $\mathrm{pH}$ conditions exacerbated the rate and variability of $\mathrm{O}_{2}$ consumption with loss of physiological condition. Hypercapnia also appeared to decrease survival, stimulate a short-term increase in HSP70 expression, and reduce HSP70 expression in lowercondition animals. These $\mathrm{pH}$ trends were biologically relevant, but small in effect compared to the impact of warming on metabolic demand, function, and survival. Warming has a greater influence than acidification on the survival and functioning of L. elliptica, at least over the medium-term 5 mo timescale studied here. 


\section{References}

Abele, D., Tesch, C., Wencke, P. \& Pörtner, H. O. 2001. How does oxidative stress relate to thermal tolerance in the Antarctic bivalve Yoldia eightsi? Antarctic Science, 13 (2): 11-118.

Ahn, I.-Y. 1993. Enhanced particle flux through the biodeposition by the Antarctic suspension-feeding bivalve Laternula elliptica in Marian Cove, King George Island. Journal of Experimental Marine Biology and Ecology, 171: 75-90.

Ahn, I.-Y. 1994. Ecology of the Antarctic bivalve Laternula elliptica (King and Broderip) in Collins Harbour, King George Island: Benthic environment and an adaptive strategy. Memoirs of National Institute of Polar Research, Special Issue, 50: 1-10.

Ahn, I.-Y. \& Shim, J. H. 1998. Summer metabolism of the Antarctic clam, Laternula elliptica (King and Broderip) in Maxwell Bay, King George Island and its implications. Journal of Experimental Marine Biology and Ecology, 224: 253-264.

Ahn, I.-Y., Chung, H. \& Choi, K.-S. 2001. Some ecological and physiological features of the Antarctic clam, Laternula elliptica (King and Broderip) in a nearshore habitat on King George Island. Ocean and Polar Research, 23 (4): 419-424.

Ahn, I.-Y., Surh, J., Park, Y.-G., Kwon, H., Choi, K.-S., Kang, S.-H., Choi, H. J., Kim, K.-W. \& Chung, H. 2003. Growth and seasonal energetics of the Antarctic bivalve Laternula elliptica from King George Island, Antarctica. Marine Ecology Progress Series, 257: 99-110.

Alcaraz, M., Felipe, J., Grote, U., Arashkevich, E., Nikishina, A. 2014. Life in a warming ocean: Thermal thresholds and metabolic balance of arctic zooplankton. Journal of Plankton Research, 36 (1): 3-10. 
Aronson, R. B., Thatje, S., Clarke, A., Peck, L. S., Blake, D. B., Wilga, C. D. \& Siebel, B. A. 2007. Climate change and invasibility of the Antarctic benthos. Annual Review of Ecology, Evolution, and Systematics, 38: 129-154.

Aronson, R. B., Moody, R. M., Ivany, L. C., Blake, D. B., Werner, J. E. \& Glass, A. 2009. Climate change and trophic response of the Antarctic bottom fauna. PLoS ONE, 4 (2): e4385

Barnes, D. K. A. \& Conlan, K. E. 2007. Disturbance, colonisation and development of Antarctic benthic communities. Philosophical Transactions of the Royal Society B, 362: 11-38.

Barnes, D. K. A., Peck, L. S. 2008. Vulnerability of Antarctic shelf biodiversity to predicted regional warming. Climate Research, 37: 149-163.

Barnes, D. K. A., Griffiths, H. J. \& Kaiser, S. 2009. Geographic range shift responses to climate change by Antarctic benthos: where we should look. Marine Ecology Progress Series, 393: 13-26.

Bednaršek, N., Tarling, G. A., Bakker, D. C. E., Fielding, S. \& Feely, R. A. 2014. Dissolution dominating calcification process in polar pteropods close to the point of aragonite undersaturation. PLOS ONE, 9 (10): e109183.

Berkman, P. A., Waller, T. R. \& Alexander, S. P. 1991. Unprotected larval development in the Antarctic scallop Adamussium colbecki (Mollusca: Bivalvia: Pectinidae). Antarctic Science, 3 (2): 151-157.

Beukema, J. J., Dekker, R. \& Jansen, J. M. 2009. Some like it cold: Populations of the tellinid bivalve Macoma balthica (L.) suffer in various ways from a warming climate. Marine Ecology Progress Series, 384: 135-145.

Brey, T. \& Mackensen, A. 1997. Stable isotopes prove shell growth bands in the 
Antarctic bivalve Laternula elliptica to be formed annually. Polar Biology, 17: 465-468.

Brockington, S. 2001. The seasonal energetics of the Antarctic bivalve Laternula elliptica (King and Broderip) at Rothera Point, Adelaide Island. Polar Biology, 24: 523-530.

Byrne, M., Smith, A. M., West, S., Collard, M., Dubois, P., Graba-landry, A. \& Dworjanyn, S. A. 2014. Warming influences $\mathrm{Mg}^{2+}$ content, while warming and acidification influence calcification and test strength of a sea urchin. Environmental Science \& Technology, 48 (21): 12620-12627.

Camus, L., Gulliksen, B., Depledge, M. H. \& Jones, M. B. 2005. Polar bivalves are characterised by high antioxidant defences. Polar Research, 24 (1-2): 111-118.

Caldeira, K. \& Wickett, M. E. 2003. Anthropogenic carbon and ocean pH. Nature, 425: 365.

Chiantore, M., Cattaneo-Vietti, R., Elia, L., Guidetti, M. \& Antonini, M. 2002.

Reproduction and condition of the scallop Adamussium colbecki (Smith 1902), the sea-urchin Sterechinus neumayeri (Meissner 1900) and the sea-star Odonaster validus (Koehler 1911) at Terra Nova Bay (Ross Sea): different strategies related to inter-annual variations in food availability. Polar Biology, 25: 251-255.

Chinellato, A., Munari, M., Matozzo, V., Bressan, M. \& Marin, M. G. 2010. First attempts in evaluating acidification effects on physiological responses in Mytilus galloprovincialis. Comparative Biochemistry and Physiology, Part A, 157: S19.

Christensen, A. B., Nguyen, H. D. \& Byrne, M. 2011. Thermotolerance and the effects of hypercapnia on the metabolic rate of the ophiuroid Ophionereis schayeri: Inferences for survivorship in a changing ocean. Journal of Experimental Marine Biology and Ecology, 403: 31-38. 
Clark, D., Lamare, M. \& Barker, M. 2009. Response of sea urchin pluteus larvae (Echinodermata: Echinoidea) to reduced seawater $\mathrm{pH}$ : a comparison among a tropical, temperate, and a polar species. Marine Biology, 156: 1125-1137.

Clark, M. S. \& Peck, L. S. 2009a. HSP70 heat shock proteins and environmental stress in Antarctic marine organisms: A mini-review. Marine Genomics, 2: 11-18.

Clark, M. S. \& Peck, L. S. 2009b. Triggers of the HSP70 stress response: environmental responses and laboratory manipulation in an Antarctic marine invertebrate (Nacella concinna). Cell Stress and Chaperones, 14: 649-660.

Clark, M. S., Fraser, K. P. P. \& Peck, L. S. 2008a. Antarctic marine molluscs do have an HSP70 heat shock response. Cell Stress and Chaperones, 13: 39-49.

Clark, M. S., Fraser, K. P. P. \& Peck, L. S. 2008b. Lack of an HSP70 heat shock response in two Antartic marine invertebrates. Polar Biology, 31: 1059-1065.

Clark, M. S., Thorne, M. A. S., Vieira, F. A., Cardoso, J. C. R., Power, D. M. \& Peck, L. S. 2010. Insights into shell deposition in the Antarctic bivalve Laternula elliptica: Gene discovery in the mantle transcriptome using 454 pyrosequencing. $B M C$ Genomics, 11: 362-375.

Clarke, A. 1987. Temperature, latitude and reproductive effort. Marine Ecology Progress Series, 38: 89-99.

Clarke, A. 1991. What is cold adaptation and how should we measure it? American Zoologist, 31 (1): 81-92.

Coleman, D. W., Byrne, M. \& Davis, A. R. 2014. Molluscs on acid: Gastropod shell repair and strength in acidifying oceans. Marine Ecology Progress Series, 509: 203-211. 
Convey, P., Bindschadler, R., Di Prisco, G., Fahrbach, E., Gutt, J., Hodgson, D.A., Mayewski, P.A., Summerhayes, C.P., Turner, J. \& The ACCE Consortium, 2009. Antarctic climate change and the environment. Antarctic Science, 21 (6): 541563.

Crawford, D. R. \& Davies, K. J. A. 1994. Adaptive response and oxidative stress. Environmental Health Perspectives, 102 (Supplement 10): 25-28.

Crim, R. N., Sunday, J. M. \& Harley, C. D. G. 2011. Elevated seawater $\mathrm{CO}_{2}$ concentrations impair larval development and reduce larval survival in endangered northern abalone (Haliotis kamtschatkana). Journal of Experimental Marine Biology and Ecology, 400: 272-277.

Crosby, M. P. \& Gale, L. D. 1990. A review and evaluation of bivalve condition index methodologies with a suggested standard method. Journal of Shellfish Research, 9 (1): 223-237.

Cummings, V., Hewitt, J., Van Rooyen, A., Currie, K., Beard, S., Thrush, S., Norkko, J., Barr, N., Heath, P., Halliday, N. J., Sedcole, R., Gomez, A., McGraw, C. \& Metcalf, V. 2011. Ocean acidification at higher latitudes: Potential effects on functioning of the Antarctic bivalve Laternula elliptica. PLoS ONE, 6(1): e16069.

Cunningham, S. C., Smith, A. M. \& Lamare, M. D. 2015. The effects of elevated $p \mathrm{CO}_{2}$ on growth, shell production and metabolism of cultured juvenile abalone, Haliotis iris. Aquaculture Research, 2015: 1-18.

de Miguel, N., Braun, N., Bepperling, A., Kriehuber, T., Kastenmüller, A., Buchner, J., Angel, S. O. \& Haslbeck, M. 2009. Structural and functional diversity in the family of small heat shock proteins from the parasite Toxoplasma gondii. Biochimia et Biophysica Acta, 1793: 1738-1748. 
Doney, S. C., Fabry, V. J., Feely, R. A. \& Kleypas, J.A. 2009. Ocean acidification: The other $\mathrm{CO}_{2}$ problem. Annual Review of Marine Science, 1: 169-192.

Doney, S. C., Ruckelshaus, M., Duffy, J. E., Barry, J. P., Chan, F., English, C. A., Galindo, H. M., Grebmeier, J. M., Hollowed, A. B., Knowlton, N., Polovina, J., Rabalais, N. N., Sydeman, W. J. \& Talley, D. 2012. Climate change impacts on marine ecosystems. Annual Review of Marine Science, 4: 11-37.

Fabbri, E., Valbonesi, P. \& Franzellitti, S. 2008. HSP expression in bivalves. Invertebrate Survival Journal, 5: 135-161.

Fabry, V. J., McClintock, J. B., Mathis, J. T. \& Grebmeier, J. M. 2009. Ocean acidification at high latitudes: The bellwether. Oceanography, 22 (4): 160-171.

Feder, M. E. \& Hofmann, G. E. 1999. Heat-shock proteins, molecular chaperones, and the stress response: Evolutionary and ecological physiology. Annual Review of Physiology, 61: 243-282.

Feely, R. A., Sabine, C. L., Lee, K., Berelson, W., Kleypas, J., Fabry, V. J. \& Millero, F. J. 2004. Impact of anthropogenic $\mathrm{CO}_{2}$ on the $\mathrm{CaCO}_{3}$ system in the oceans. Science, 305: 362-366.

Fitzer, S. C., Wenzhong, Z., Tanner, K. E., Phoenix, V. R., Kamenos, N. A. \& Cusack, M. 2014. Ocean acidification alters the material properties of Mytilus edulis shells. Journal of the Royal Society Interface, 12: 1227.

Gazeau, F., Parker, L. M., Comeau, S., Gattuso, J.-P., O’Connor, W. A., Martin, S., Pörtner, H.-O. \& Ross, P. 2013. Impacts of ocean acidification on marine shelled molluscs. Marine Biology, 160 (8): 2207-2245.

Gerhardt, A., Janssens de Bisthoven, L. \& Soares, A. M. V. 2006. Evidence for the 
Stepwise Stress Model: Gambusia holbrooki and Daphnia magna under acid mine drainage and acidified reference water stress. Environmental Science and Technology, 39: 4150-4158.

Gonzalez-Bernat, M. J., Lamare, M. \& Barker, M. 2013. Effects of reduced seawater pH on fertilisation, embryongenesis and larval development in the Antarctic seastar Odonaster validus. Polar Biology, 36: 235-247.

Green, M. A., Jones, M. E., Boudreau, C. L., Moore, R. L. \& Westman, B. A. 2004. Dissolution mortality of juvenile bivalves in coastal marine deposits. Limnology and Oceanography, 49 (3): 727-734.

Griffiths, H. J. 2010. Antarctic marine biodiversity - What do we know about the distribution of life in the Southern Ocean? PLOS ONE, 5(8): e11683.

Guinotte, J. M. \& Fabry, V. J. 2008. Ocean acidification and its potential effects on marine ecosystems. Annals of the New York Academy of Science, Volume 1134, The Year in Ecology and Conservation Biology 2008: 320-342.

Guy, C. I., Cummings, V. J., Lohrer, A. M., Gamito, S. \& Thrush, S. F. 2014. Population trajectories for the Antarctic bivalve Laternula elliptica: Identifying demographic bottlenecks in differing environmental futures. Polar Biology, 37: 541-553.

Hauck, J., Arrigo, K. R., Hoppema, M., van Dijken, G. L., Völker, C. \& Wolf-Gladrow, D. A. 2013. Insignificant buffering capacity of Antarctic shelf carbonates. Global Biogeochemical Cycles, 27: 11-20.

Hazan, Y., Wangensteen, O. S. \& Fine, M. 2014. Tough as a rock-boring urchin: Adult Echinometra sp. EE from the Red Sea show high resistance to ocean acidification over long-term exposures. Marine Biology, 161: 2531-2545.

Heilmayer, O., Brey, T., Chiantore, M., Cattaneo-Vietti, R. \& Arntz, W. E. 2003. Age and 
productivity of the Antarctic scallop, Adamussium colbecki, in Terra Nova Bay (Ross Sea, Antarctica). Journal of Experimental Marine Biology and Ecology, 288: 239-256.

Heilmayer, O., Brey, T. \& Pörtner, H. 0. 2004. Growth efficiency and temperature in scallops: a comparative analysis of species adapted to different temperatures. Functional Ecology, 18: 641-647.

Hendriks, I. E., Duarte, C. M. \& Álvarez, M. 2010. Vulnerability of marine biodiversity to ocean acidification: A meta-analysis. Estuarine, Coastal and Shelf Science, 86: 157-164.

Huber, C. \& Krause, C. 2004. Instruction Manual Fibox-3 LCD. PreSens Precision Sensing GmbH, Regensburg, Germany. 101 pp.

Hunt, B. M., Hoefling, K. \& Chi-Hing, C. C. 2003. Annual warming episodes in seawater temperatures in McMurdo Sound in relationship to endogenous ice to notothenioid fish. Antarctic Science, 15 (3): 333-338.

Husmann, G., Abele, D., Monien, D., Monien, P., Kriews, M. \& Philipp, E.E.R. 2012. The influence of sedimentation on metal accumulation and cellular oxidative stress markers in the Antarctic bivalve Laternula elliptica. Estuarine, Coastal and Shelf Science, 111: 48-59.

Husmann, G., Abele, D., Rosenstiel, P., Clark, M. S., Kraemer, L. \& Philipp, E. R. R. 2014. Age-dependent expression of stress and antimicrobial genes in the hemocytes and siphon tissue of the Antarctic bivalve, Laternula elliptica, exposed to injury and starvation. Cell Stress and Chaperones, 19: 15-32.

Ingels, J., Vanreusel, A., Brandt, A., Catarino, A. I., David, B., De Ridder, C., Dubois, P., Gooday, A. J., Martin, P., Pasotti, F. \& Robert, H. 2012. Possible effects of global environmental changes on Antarctic benthos: a synthesis across five major taxa. Ecology and Evolution, 2 (2): 453-485. 
Intergovernmental Panel on Climate Change (IPCC), 2013. Climate Change 2013: The Physical Science Basis. Contribution of Working Group I to the Fifth Assessment Report of the Intergovernmental Panel on Climate Change [Stocker, T. F., Qin,, Plattner, G.-K., Tignor, M., Allen, S. K., Boschung, J., Nauels, A., Xia, Y., Bex, V. \& Midgley, P.M. (eds.)]. Cambridge University Press, Cambridge, United Kingdom and New York, NY, USA, 1535 pp.

Jakubowska, M. \& Normant, M. 2015. Metabolic rate and activity of blue mussel Mytilus edulis trossolus under short-term exposure to carbon dioxide-induced water acidification and oxygen deficiency. Marine and Freshwater Behaviour and Physiology, 48 (1): 25-39.

Kang, D.-H., Ahn, I.-Y. \& Choi, K.-S. 2009. The annual reproductive pattern of the Antarctic clam, Laternula elliptica from Marian Cove, King George Island. Polar Biology, 32: 517-528.

Kapsenberg, L. \& Hofmann, G. E. 2014. Signals of resilience to ocean change: High thermal tolerance of early stage Antarctic sea urchins (Sterechinus neumayeri) reared under present-day and future $p \mathrm{CO}_{2}$ and temperature. Polar Biology, 37: 967-980.

Kapsenberg, L., Kelley, A. L., Shaw, E. C., Martz, T. R. \& Hofmann, G. E. 2015. Nearshore Antarctic variability has implications for the design of ocean acidification experiments. Scientific Reports, 5: 9638.

Kim, M., Ahn, I.-Y., Kim, H., Cheon, J. \& Park, H. 2009. Molecular characterization and induction of heat shock protein 90 in the Antarctic bivalve Laternula elliptica. Cell Stress and Chaperones, 14: 363-370.

Kroeker, K. J., Kordas, R. L., Crim, R. N. \& Singh, G. G. 2010. Meta-analysis reveals negative yet variable effects of ocean acidification on marine organisms. Ecology Letters, 13: 1419-1434. 
Kroeker, K. J., Kordas, R. L., Crim, R., Hendriks, I. E., Ramajo, L., Singh, G. S., Duarte, C. M. \& Gattuso, J.-P. 2013. Impacts of ocean acidification on marine organisms: Quantifying sensitivities and interaction with warming. Global Change Biology, 19: 1884-1896.

La Terza, A., Papa, G., Miceli, C. \& Luporini, P. 2001. Divergence between two Antarctic species of the ciliate Euplotes, E. focardii and E. nobilii, in the expression of heatshock protein 70 genes. Molecular Ecology, 10: 1061-1067.

Langer, G., Nehrke, G., Baggini, C., Rodolfo-Metalpa, R., Hall-Specncer, J. M. \& Bijina, J. 2014. Limpets counteract ocean acidification induced shell corrosion by thickening of aragonitic shell layers. Biogeosciences, 11: 7363-7368.

Lenton, A., Codron, F., Bopp, L., Metzl, N., Cadule, P., Tagliabue, A. \& Le Sommer, J. 2009. Stratospheric ozone depletion reduces ocean carbon uptake and enhances ocean acidification. Geophysical Research Letters, 36: L12606, doi:10.1029/2009GL038227.

Linse, K., Griffiths, H. J., Barnes, D. K. A. \& Clarke, A. 2006. Biodiversity and biogeography of Antarctic and sub-Antarctic mollusc. Deep-Sea Research II, 53: 985-1008.

Llabres, M., Agusti, S., Fernández, M., Canepa, A., Maurin, F., Vidal, F. \& Duarte, C. M. 2013. Impact of elevated UVB radiation on marine biota: A meta-analysis. Global Ecology and Biogeography, 22: 131-144.

Matoo, O. B., Ivanina, A. V., Ullstad, C., Beniash, E. \& Sokolova, I. M. 2013. Interactive effects of elevated temperature and $\mathrm{CO}_{2}$ levels on metabolism and oxidative stress in two common marine bivalves (Crassostrea virginica and Mercenaria mercenaria). Comparative Biochemistry and Physiology, Part A, 164: 545-553.

Matson, P. G., Washburn, L., Matrz, T. R. \& Hofmann, G. E. 2014. Abiotic versus biotic 
drivers of ocean $\mathrm{pH}$ variation under fast sea ice in McMurdo Sound, Antarctica. PLoS ONE, 9 (9): e107239.

Mattsdotter Björk, M., Fransson, A., Torstensson, A. \& Chierici, M. 2014. Ocean acidification state in western Antarctic surface waters: Controls and interannual variability. Biogeosciences, 11: 57-73.

McClintock, J. B., Angus, R. A., McDonald, M. R., Amsler, C. D., Catledge, S. A. \& Vohra, Y. K. 2009. Rapid dissolution of shells of weakly calcified Antarctic benthic macroorganisms indicates high vulnerability to ocean acidification. Antarctic Science, 21 (5): 449-456.

Mcleod, C., Hay, B., Grant, C., Greening, G. \& Day, D. 2009. Inactivation and elimination of human enteric viruses by Pacific oysters. Journal of Applied Microbiology, 107: 1809-1818.

Meredith, M. P. \& King, J. C. 2005. Rapid climate change in the ocean west of the Antarctic Peninsula during the second half of the 20th century. Geophysical Research Letters, 32: L19604.

McNeill, B. I. \& Matear, R. J. 2008. Southern Ocean acidification: A tipping point of 450-ppm atmospheric $\mathrm{CO}_{2}$. Proceedings of the National Academy of Sciences of the United States of America, 105 (48): 18860-18864.

Miller, A. W., Reynolds, A. C., Sobrino, C. \& Riedel, G. F. 2009. Shellfish face uncertain future in high $\mathrm{CO}_{2}$ world: Influence of acidification on oyster larvae calcification and growth in estuaries. PLoS ONE, 4 (5): e5661.

Mizzen, L. A. \& Welch, W. J. 1988. Characterisation of the thermotolerant cell. I. Effects of on protein synthesis activity and the regulation of heat-shock protein 70 expression. The Journal of Cell Biology, 106: 1105-1116. 
Montes-Hugo, M., Doney, S. C., Ducklow, H. W., Fraser, W., Martinson, D., Stammerjohn, S. E. \& Schofield, O. 2009. Recent changes in phytoplankton communities associated with rapid regional climate change along the Western Antarctic Peninsula. Science, 323: 1470-1473.

Morley, S. A., Peck, L. S., Miller, A. J. \& Pörtner, H.-O. 2007. Hypoxia tolerance associated with activity reduction is a key adaptation for Laternula elliptica seasonal energetics. Oecologia, 153: 29-36.

Morley, S. A., Hirse, T., Pörtner, H.-O. \& Peck, L. S. 2009. Geographical variation in thermal tolerance within Southern Ocean marine ectotherms. Comparative Biochemistry and Physiology, Part A, 153: 154-161.

Morley, S. A., Hirse, T., Thorne, M. A. S., Pörtner, H. O., Peck, L. S. 2012a. Physiological plasticity, long term resistance or acclimation to temperature, in the Antarctic bivalve, Laternula elliptica. Comparative Biochemistry and Physiology, Part A, 162: $16-21$.

Morley, S. A., Martin, S. M., Bates, A. E., Clark, M. S., Ericson, J., Lamare, M. \& Peck, L. S. 2012b. Spatial and temporal variation in the heat tolerance limits of two abundant Southern Ocean invertebrates. Marine Ecology Progress Series, 450: 8192.

Navarro, J. M., Torres, R., Acuña, K., Duarte, C., Manriquez, P. H., Lardies, M., Lagos, N. A., Vargas, C. \& Aguilera, V. 2013. Impact of medium-term exposure to elevated $p \mathrm{CO}_{2}$ levels on the physiological energetics of the mussel Mytilus chilensis. Chemosphere, 90: 1242-1248.

Orr, J. C., Fabry, V. J., Aumont, O., Bopp, L., Doney, S. C., Feely, R. A., Gnanadesikan, A., Gruber, N., Ishida, A., Joos, F., Key, R. M., Lindsay, K., Maier-Reimer, E., Matear, R., Monfray, P., Mouchet, A., Najjar, R. G., Plattner, G.-K., Rodgers, K. B., Sabine, C. L., Sarmiento, J. L., Schlitzer, R., Slater, R. D., Totterdell, I. J., Weirig, M.-F., Yamanaka, 
Y. \& Yool, A. 2005. Anthropogenic ocean acidification over the twenty-first century and its impact on calcifying organisms. Nature, 437: 681-686.

Pan, T.-C. F., Applebaum, S. L. \& Manahan, D. T. 2015. Experimental ocean acidification alters the allocation of metabolic energy. Proceedings of the National Academy of Sciences of the United States of America, 112 (15): 46964701.

Park, H., Ahn, I.-Y. \& Lee, H. E. 2007. Expression of heat shock protein 70 in the thermally stressed Antarctic clam Laternula elliptica. Cell Stress and Chaperones, 12 (3): 275-282.

Parker, L. M., Ross, P. M., O'Connor, W, A., Borysko, L., Raftos, D. A. \& Pörtner, H.-O. 2011. Adult exposure influences offspring response to ocean acidification in oysters. Global Change Biology, 18: 82-92.

Parker, L. M., Ross, P. M., O’Connor, W. A., Pörtner, H.-O., Scanes, E. \& Wright, J. M. 2013. Predicting the response of molluscs to the impact of ocean acidification. Biology, 2: 651-692.

Pearse, J. S., Bosch, I. \& McClintock, J. B. 1985. Contrasting modes of reproduction by common shallow-water Antarctic invertebrates. Antarctic Journal of the United States, 30: 138-139.

Pearse, J. S., McClintock, J. B. \& Bosch, I. 1991. Reproduction of Antarctic benthic marine invertebrates: Tempos, modes, and timing. American Zoologist, 31 (1): 65-80.

Peck, L. S. 2005a. Prospects for surviving climate change in Antarctic aquatic species. Frontiers in Zoology, 2 (9): doi: 10.0086/1742-9994-2-9.

Peck, L. S. 2005b. Prospects for survival in the Southern Ocean: vulnerability of benthic species to temperature change. Antarctic Science, 17 (4): 497-507. 
Peck. L. S., Pörtner, H.-O. \& Hardewig, I. 2002. Metabolic demand, oxygen supply, and critical temperatures in the Antarctic bivalve Laternula elliptica. Physiological and Biochemical Zoology, 75 (2): 123-133.

Peck, L. S., Webb, K. E. \& Bailey, D. M. 2004. Extreme sensitivity of biological function to temperature in Antarctic marine species. Functional Ecology, 18: 625-630.

Peck, L. S., Souster, T. \& Clark, M. S. 2013. Juveniles are more resistant to warming than adults in 4 species of Antarctic marine invertebrates. PLOS ONE, 8 (6): e66033.

Peck, L. S., Morley, S. A., Richard, J. \& Clark, M. S. 2014. Acclimation and thermal tolerance in Antarctic marine ectotherms. Journal of Experimental Biology, 217: 16-22.

Peck, L. S., Thorne, M. A. S., Hoffman, J. I., Morley, S. A. \& Clark, M. S. 2015. Variability among individuals is generated at the gene expression level. Ecology, 96 (7): 2004-2014.

Pörtner, H.-0. 2002. Climate variations and the physiological basis of temperature dependent biogeography: Systemic to molecular hierarchy of thermal tolerance in animals. Comparative Biochemistry and Physiology Part A, 132: 739-761.

Pörtner, H.-O. 2008. Ecosystem effects of ocean acidification in times of ocean warming: A physiologist's view. Marine Ecology Progress Series, 373: 203-217.

Pörtner, H.-0. 2010. Oxygen- and capacity-limitation of thermal tolerance: A matrix for integrating climate-related stressor effects in marine ecosystems. Journal of Experimental Biology, 213: 881-893.

Pörtner, H.-O. 2012. Integrating climate-related stressor effects on marine organisms: 
Unifying principles linking molecule to ecosystem-level changes. Marine Ecology Progress Series, 470: 273-290.

Pörtner, H.-0. \& Farrell, A. P. 2008. Physiology and climate change. Science, 322: 690692.

Pörtner, H.-O., Reipschläger, A. \& Heisler, N. 1998. Acid-base regulation, metabolism and energetics in Sipunculus nudus as a function of ambient carbon dioxide level. The Journal of Experimental Biology, 201: 43-55.

Pörtner, H.-O., Langenbuch, M. \& Reipschläger, A. 2004. Biological impact of elevated ocean $\mathrm{CO}_{2}$ concentrations: Lessons from animal physiology and Earth history. Journal of Oceanography, 60: 705-718.

Pörtner, H.-O., Peck, L. S. \& Somero, G. 2007. Thermal limits and adaptation in marine Antarctic ectotherms: An integrative view. Philosophical Transactions of the Royal Society $B, 362:$ 2233-2258.

Range, P., Chícharo, M. A., Ben-Hamadou, R., Piló, D., Matias, D., Joaquim, S., Oliveira, A. P. \& Chícharo, L. 2011. Calcification, growth and mortality of juvenile clams Ruditapes decussatus under increased $p \mathrm{CO}_{2}$ and reduced $\mathrm{pH}$ : Variable responses to ocean acidification at local scales? Journal of Experimental Marine Biology and Ecology, 396: 177-184.

Richards, S. A. 2005. Testing ecological theory using the information-theoretic approach: Examples and cautionary results. Ecology, 86 (10): 2805-2814.

Ries, J. B., Cohen, A. L. \& McCorkle, D. C. 2009. Marine calcifiers exhibit mixed responses to $\mathrm{CO}_{2}$-induced ocean acidification. Geology, 37 (2): 1131-1134.

Roleda, M. Y., Boyd, P. W. \& Hurd, C. L. 2012. Before ocean acidification: Calcifier chemistry lessons. Journal of Phycology, 48: 840-843. 
Roper, D. S., Pridmore, R. D., Cummings, V. J. \& Hewitt, J. E. 1991. Pollution related differences in the condition cycles of Pacific oysters Crassostrea gigas from Manukau Harbour, New Zealand. Marine Environmental Research, 31: 197-214.

The Royal Society, 2005. Ocean acidification due to increasing atmospheric carbon dioxide. Policy document 12/05, June 2005, London. 68pp.

Sabine, C. L., Feely, R. A., Gruber, N., Key, R. M., Lee, K., Bullister, J. L., Wannikhof, R., Wong, C. S., Wallace, D. W. R., Tilbrooke, B., Millero, F. J., Peng, T.-H., Kozyr, A., Ono, T. \& Rios, A. F. 2004. The oceanic sink for anthropogenic $\mathrm{CO}_{2}$. Science, 305 (5682): 367-371.

Sato-Okoshi, W., Okoshi, K., Sasaki, H. \& Akiha, F. 2010. Shell structure characteristics of pelagic and benthic molluscs from Antarctic waters. Polar Science, 4: 257-261.

Schram, J. B., Schoenrock, K. M., McClintock, J. B., Amsler, C. D. \& Angus, R. A. 2015. Multi-frequency observations of seawater carbonate chemistry on the central coast of the western Antarctic Peninsula. Polar Research, 34: 25582.

Sleight, V. A., Thorne, M. A. S., Peck, L. S. \& Clark, M.S. 2015. Transcriptomic response to shell damage in the Antarctic clam, Laternula elliptica: Time scales and spatial location. Marine Genomics, 20: 45-55.

Smith Jr, W. O. 2007. Marine ecosystems: The Ross Sea. Philosophical Transactions of the Royal Society of London, Series A, 362: 95.

Smith Jr, W. O., Ainley, D. G., Arrigo, K. R. \& Dinniman, M. S. 2014. The oceanography and ecology of the Ross Sea. Annual Review of Marine Science, 6: 469-487.

Suckling, C. S., Clark, M. S., Beveridge, C., Brunner, L., Hughes, A. D., Harper, E. M., Cook, E. J., Davies, A. J. \& Peck, L. S. 2014. Experimental influence of pH on the early life-stages of sea urchins II: Increasing parental exposure times gives rise 
to different responses. Invertebrate Reproduction \& Development, 58 (3): 161175.

Suckling, C. C., Clark, M. S., Richard, J., Morley, S. A., Thorne, M. A. S., Harper, E. M. \& Peck, L. S. 2015. Adult acclimation to combined temperature and pH stressors significantly enhances reproductive outcomes compared to short-term exposures. Journal of Animal Ecology, 84 (3): 773-784.

Thomsen, J., Haynert, K., Wegner, K. M. \& Melzner, F. 2015. Impact of seawater carbonate chemistry on the calcification of marine bivalves. Biogeosciences, 12: 4209-4220.

Thrush, S. F. \& Cummings, V. J. 2011. Massive icebergs, alteration in primary food resources and change in benthic communities at Cape Evans, Antarctica. Marine Ecology, 2011: 1-11.

Thrush, S., Dayton, P., Cattaneo-Vietti, R., Chiantore, M., Cumings, V., Andrew, N., Hawes, I., Kim, S., Kvitek, R. \& Schwarz, A-M. 2006. Broad-scale factors influencing the biodiversity of coastal benthic communities of the Ross Sea. Deep-Sea Research II, 53: 959-971.

Tomanek, L. 2010. Variation in the heat shock response and its implications for predicting the effect of global climate change on species' biogeographical distribution ranges and metabolic costs. The Journal of Experimental Biology, 213: 971-979.

Truebano, M., Burns, G., Thorne, M. A. S., Hillyard, G., Peck, L. S., Skibinski, D. O. F. \& Clark, M. S. 2010. Transcriptional response to heat stress in the Antarctic bivalve Laternula elliptica. Journal of Experimental Marine Biology and Ecology, 391: 6572.

Urban, H.-J. \& Mercuri, G. 1998. Population dynamics of the bivalve Laternula elliptica 
from Potter Cove, King George Island, South Shetland Islands. Antarctic Science, 10 (2): 153-160.

Wicks, L. C. \& Roberts, J. M. 2012. Benthic invertebrates in a high- $\mathrm{CO}_{2}$ world. Oceanography and Marine Biology: An Annual Review, 50: 127-188.

Widdicombe, S. \& Spicer, J. I. 2008. Predicting the impact of ocean acidification on benthic biodiversity: What can animal physiology tell us? Journal of Experimental Marine Biology and Ecology, 366 (1,2): 187-197.

Wood, H. L., Spicer, J. I. \& Widdicombe, S. 2008. Ocean acidification may increase calcification rates, but at a cost. Proceedings of the Royal Society B, 275: 17671773.

Zhang, G., Chen, L., Chen, J., Ren, Z., Wang, Z. \& Chon, T.-S. 2012. Evidence for the stepwise behavioural response model (SBRM): The effects of carbamate pesticides on medaka (Oryzias latipes) in an online monitoring system. Chemosphere, 87: 734-741.

Zittier, Z. M. C., Bock, C., Lannig, G. \& Pörtner, H. O. 2015. Impact of ocean acidification on thermal tolerance and acid-base regulation of Mytilus edulis (L.) from the North Sea. Journal of Experimental Marine Biology and Ecology, 473: 16-25. 


\section{Appendices}

\section{Appendix A - Adductor muscle dissection}

Adductor muscle samples were dissected from the two attachment points to the valves: at the base of the siphon near the hinge, and at the posterior end near the foot (Sup. Fig. 1). Tissue was weighed and snap-frozen in liquid nitrogen immediately after dissection, then stored at $-80^{\circ} \mathrm{C}$.
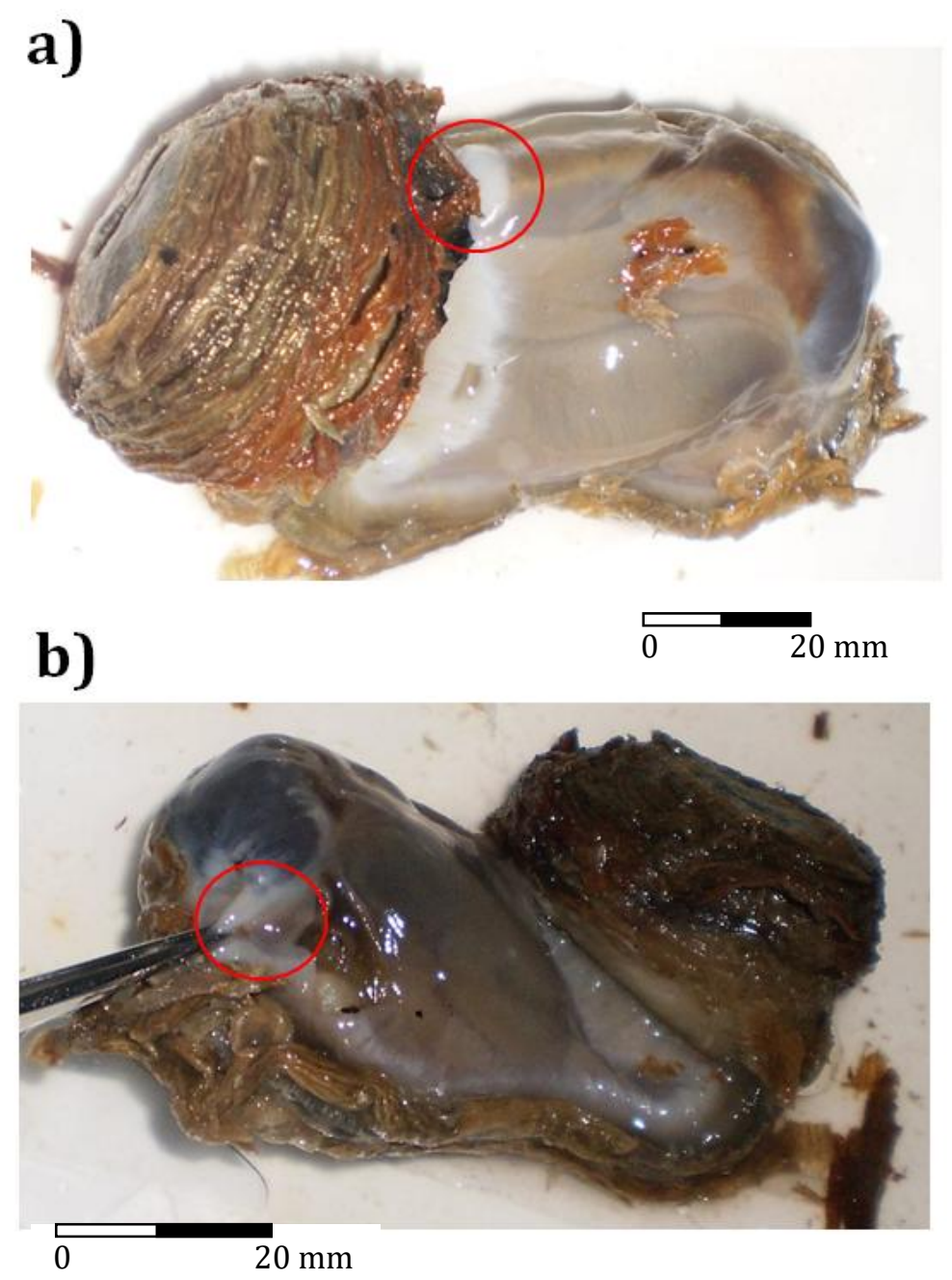

Supplementary Figure 1 - Laternula elliptica adductor muscle dissection. The location of the adductor muscles are shown: a) anterior adductor muscle; b) posterior adductor muscle. Muscles were detached from the valves during valve removal. 


\section{Appendix B - Supplementary data}

\section{Chapter 3}

Supplementary Table 1 - Annealing temperature results of Laternula elliptica HSP70 and $\beta$-actin qPCR gene amplification. Data presented are the number of cycles at which annealing occurred, means \pm SE.

\begin{tabular}{|c|c|c|c|}
\hline Temperature $\left.\mathbf{~}^{\circ} \mathbf{C}\right)$ & HSP70 & $\boldsymbol{\beta}$-actin & Negative control \\
\hline 58.0 & $17.29 \pm 0.11$ & $18.81 \pm 0.66$ & N/A \\
\hline 56.3 & $17.41 \pm 0.34$ & $18.69 \pm 0.66$ & N/A \\
\hline 51.9 & $17.69 \pm 0.19$ & $18.87 \pm 0.69$ & N/A \\
\hline 50.0 & $18.28 \pm 0.15$ & $19.68 \pm 0.61$ & N/A \\
\hline 48.0 & $18.39 \pm 0.21$ & $20.03 \pm 0.69$ & N/A \\
\hline
\end{tabular}

Supplementary Table 2 - Melt curve profile data of HSP70 and $\beta$-actin qPCR gene amplification products. Data are presented as number of cycles, and peak height in reading frame units (mean $\pm \mathrm{SE}$ ).

\begin{tabular}{|c|c|c|c|}
\hline L. elliptica gene & Cycles & Temperature $\left({ }^{\circ} \mathbf{C}\right.$ ) & $\begin{array}{c}\text { Peak height } \\
\text { (Reading frame units) }\end{array}$ \\
\hline HSP70 & $21.02 \pm 0.24$ & 80.00 & $323.93 \pm 6.10$ \\
\hline$\beta$-actin & $24.19 \pm 0.35$ & 82.00 & $216.21 \pm 4.62$ \\
\hline
\end{tabular}

